\title{
Morphology of lymphatic cells and of their derived tumours
}

\author{
FRANCO RILKE 1 , SILVANA PILOTTI ${ }^{1}$, ANTONINO CARBONE ${ }^{1}$, AND \\ LUCIANO LOMBARDI ${ }^{2}$ \\ From the ${ }^{1}$ Division of Anatomical Pathology and Cytology and ${ }^{2}$ Division of Experimental Oncology A, \\ Istituto Nazionale per lo Studio e la Cura dei Tumori, Via Venezian 1, 20133 Milan, Italy
}

The morphological description of diseases of the lymphatic and reticulum cells, and the classification of neoplasms derived from these cells, are in a state of some confusion, which arises, in part at least, from the different approaches and terminology used by histopathologists and by cytologically orientated haematologists. The addition of electron microscopy, of enzyme histochemistry, and of immunological methods for cell typing has not entirely resolved the differences. The subject is still in a state of rapid development but an analysis of current knowledge is needed to promote mutual understanding among histopathologists, haematologists, immunologists, and many others who may be concerned. Whereas attempts to classify neoplastic disorders of the haemopoietic system have largely succeeded because the derivation of the tumour cells from the normal cells could be inferred from morphological study of marrow and blood cells, we have had to wait much longer for a comparable classification of lymphoreticular neoplasms-with the possible exception of Hodgkin's disease.

In non-Hodgkin's malignant lymphoma (ML) a major advance was made by Rappaport (1966; Rappaport et al., 1956), who moved from a popular terminology (lymphosarcoma, reticular cell sarcoma, and giant follicular lymphoma) to one based on lymph node structure, but the first step in the direction of a cytological analysis of the variety of ML was the use of haematological staining techniques applied to tissue sections in order to bridge the gap between histological findings and haematocytological data. For this purpose the use of the Giemsa stain was proposed by Lennert $(1957,1961)$. The major indications were, on the one hand, the morphological specificity of germinal centre cells and the comparability with them of the cells of follicular lymphomas and, on the other hand, the fact that

Received for publication 20 July 1978 follicular neoplasms made up of large and small cells were not tumours of different cell lines but of cells of the same line in different stages of modulation. Details of nuclear structure, nucleolar configuration, and the staining properties of the cytoplasm were also helpful in distinguishing ML with apparently similar morphology when stained with haematoxylin and eosin only. Further distinctions were derived from enzyme histochemistry applied to haematological and histological material (reviewed by Leder and Stutte, 1975; Harigaya, 1977), the significance of which was increased by the combination with electron microscopy (reviewed by Müller-Hermelink and Kaiserling, 1975; Kaiserling, 1977a).

However, the major recent contribution to the identification of the linkages between the cells of the normal lymphoreticular system and their malignant counterparts comes from immunological typing (reviewed by Preud'homme et al., 1975). The discovery of markers that are morphologically undetectable has permitted the characterisation and, to a great extent, also the function of both normal and malignant cells.

Since B and T lymphocytes (for reviews see Roitt et al., 1969; Henry and Goldman, 1975; Lennert and Müller-Hermelink, 1975) can be characterised by a variety of surface markers, the same techniques have been applied extensively to neoplasms of the lymphoreticular system (review, Stein, 1975). However, as has been stressed repeatedly (Brown et al., 1974; Seligmann et al., 1977a), great caution is advised both in the technical evaluation of the results and in the transfer of the data obtained from normal cells to pathological conditions. The remarkable progress in the immunological characterisation of ML is unfortunately occasionally hindered, particularly when detailed immunological analyses of valuable case material have been correlated with inadequate morphological investigations and inappropriate histological diagnoses.

The process of revision of the classification of $\mathrm{ML}$ 
has brought into focus in recent years the fact that these disorders are, in fact, neoplasms of the immune system and that the great majority of them are derived from lymphoid cells at various stages of functional and morphological modulation. More specifically, while some classification schemes stressed predominantly nondistinctive morphological features (Bennett et al., 1974; Dorfman, 1974), others linked morphological appearances to functional phenotype (Lukes and Collins, 1974). A cytogenealogical approach expressed, however, in purely morphological terms was preferred for the Kiel classification (Gerard-Marchant et al., 1974), which also incorporates a distinction between low- and high-grade ML. The existence of a group of ML with intermediate biological behaviour was demonstrated later on the basis of cell kinetic studies (Silvestrini et al., 1977). Finally, the classification supported by the World Health Organisation (Mathé et al., 1976) tried to express recent subdivisions while still respecting the conventional nomenclature.

Although a number of areas of uncertainty still remain, it seems more meaningful to support the natural trend towards the separation of nosographic entities. For this purpose, in the following review the strict adoption of any one classification is avoided, and within the limits of the data at present available the known entities are grouped according to the cell type of possible origin. The class of lymphocytic ML is heterogeneous, since the only common denominator is the small lymphocyte-like size of the cell, but this shortcoming is partly compensated by the existence of well-defined clinicopathological entities. For example, malignant lymphomas of immunoglobulinsecreting cells and of germinal centre cells represent excellent examples of the correlation that is possible between the normal cells and their malignant counterparts. Immunoblastic ML could, to a certain extent, be considered together with ML of immunoglobulin-secreting cells; however, insufficient knowledge of T-type immunoblastic $\mathrm{ML}$ and the high percentage of large cell ML which are purely morphologically immunoblastic but 'receptor-silent', suggest a separate categorisation. The last group in which lymphoblastic ML and acute lymphoblastic leukaemia (ALL) have been combined depends much less on morphological and functional analysis than on immunological and biochemical properties. The comparatively exiguous group of neoplasms of histiocytic origin should not be classified among ML, since it would be preferable to reserve this term for malignancies of strictly lymphatic origin, except for Hodgkin's disease, which in turn deserves a fully autonomous position. The different cytogenealogy of reticulum cells in general, and of histiocytes in particular, makes this distinction necessary in spite of the close functional and anatomical relationship between the respective cell lines of origin.

This classificatory rearrangement (Stein, 1975) is based mainly on the work presented in recent years by Professor Lennert's group at the University of Kiel (Lennert et al., 1975b, 1975c) and has been terminologically revised (Gerard-Marchant et al., 1974). However, reference is made, whenever necessary, to other systems and especially to the Rappaport classification (Rappaport et al., 1956; Rappaport, 1966) because it has been widely accepted in many countries for many years by pathologists and clinicians.

The illustrations are from our own material, observed during the last four years, including over 500 cases of ML, 150 of which were also investigated ultrastructurally.

\section{Malignant lymphoma, lymphocytic}

CHRONIC LYMPHOCYTIC LEUKAEMIA

This disease, first described by Virchow (1864-65), is characterised by an excessive number of small lymphocytes in the blood and bone marrow, and in most patients also in lymph nodes, spleen, liver, and other organs (Wintrobe et al., 1974). Although its malignant nature is out of the question, its peculiar clinicopathological behaviour has been noted (Galton, 1966; Dameshek, 1967; Wintrobe et al., 1974), and clinical classification and staging systems take this into consideration (Levin et al., 1973; Rai et al., 1975; Binet et al., 1977a). In the majority of cases of chronic lymphocytic leukaemia (CLL) the proliferating cell is of B-cell origin (B-CLL), while in a small percentage it is of T-cell origin (T-CLL).

In sections of lymph nodes, B-CLL consists of a diffuse monomorphic proliferation of lymphocytes, most of which are morphologically not atypical and are almost indistinguishable from normal. The size of the latter is quite variable (Wintrobe et al., 1974; Kaung and Ott, 1975), but lymphocytes of CLL often give the impression of being slightly larger. Their nucleus is round with a regular contour and measures 7 to $9 \mu$ in diameter; the chromatin is made up of coarse, mosaic-shaped chromocentres, and the nucleoli are either inconspicuous or hardly visible. Mitotic figures are rare. The cytoplasm is scanty, lightly basophilic, and PAS-negative, whereas in smears it occasionally reveals tiny granules and droplets of glycogen, which show a positive diastasesensitive periodic acid-Schiff (PAS) reaction. The glycogen content is higher than in normal lymphocytes (Astaldi and Verga, 1957; Leder, 1971). The acid phosphatase reaction is weak to moderate in a minority of cells and less evident than in normal lymphocytes (Douglas et al., 1973; Catovsky et al., 
1974a). Beta-glucuronidase is also scarce (Zittoun et al., 1973), whereas a strong membrane-bound ATPase reaction can be visualised (Kaiserling, 1977a). Both intracytoplasmic crystalline inclusions associated with IgM (Hurez et al., 1972; Clark et al., 1973), IgMk (Mennemeyer et al., 1974), and IgA (Cawley et al., 1973) and non-crystalline PASpositive intracytoplasmic inclusions related to an excess of IgM in the neoplastic tissue (Stein et al., 1973) have been reported. It is questionable, however, whether these cases are true CLL or whether they should be considered lymphoplasmacytoid immunocytomas with a CLL-like clinical course.

While irregularly shaped lymphocytes of germinal centre origin (centrocytes) are essentially absent, in the tissue there is usually an admixture with a variable number of so-called prolymphocytes and lymphoblasts. The latter are up to twice the size of the small lymphocytes, and their nuclei contain sparse, finely granular chromatin, which is in part adherent to the nuclear membrane and in part arranged in threads that are extended between the nucleolus and the nuclear membrane. The large amphophilic nucleolus is central, and the cytoplasm shows a moderate degree of basophilia and contains no granules. These cells are also called paraimmunoblasts, because of their nuclear resemblance to immunoblasts, by those who reserve the conventional term 'lymphoblasts' for the immature lymphoid cell of ALL (Lennert, 1976). Prolymphocytes reveal morphological features that are intermediate between lymphocytes and lymphoblasts, and in sections both cell types are either irregularly scattered or more often grouped in pseudofollicular, clear 'proliferation centres' (Lennert, 1976) of variable size, which are not surrounded by condensed reticulin fibres as are the neoplastic follicles of follicular (nodular) ML. In these areas mitotic activity is increased. B-CLL lymphocytes replace the involved lymph nodes completely, and usually no remnants of normal structures are left; the capsule and the subcapsular sinus are often still recognisable. Other cell types, such as plasma cells, lymphoplasmacytic cells, and follicular centre cells, are rarely found.

In the blood of the majority of patients with B-CLL, there are usually more than $10 \times 10^{9} / 1$ and less than $100 \times 10^{9} / 1$ lymphocytes at the time of diagnosis, with considerable fluctuations during the course of the disease. Another haematological definition of B-CLL is a persistent lymphocytosis of at least $5 \times 10^{9} / 1$ associated with a lymphocyte count of $25 \%$ or more in the bone marrow films (Galton, 1966). In blood smears the neoplastic, small lymphocytes dominate the picture, and there is no morphological abnormality to distinguish them from normal lymphocytes. The nuclei contain dense chromatin which is subdivided into coarse blocks, nucleoli are therefore unidentifiable. Nuclear abnormalities are uncommon in B-CLL, but the cells are fragile, as is apparent from the large number of damaged cells in the smears (Galton, 1966). The narrow cytoplasmic rims are pale blue and usually devoid of granules and vacuoles. In a number of otherwise typical cases of CLL, large (up to $20 \mu$ in diameter) lymphocytes may predominate,and their prognostic significance is a matter of debate (Gray et al., 1974; Peterson et al., 1975; Binet et al., 1977b).

Immature cells (lymphoblasts) are more commonly detected in lymph node aspirates and sections than they are in blood or marrow films or marrow sections prepared at the same time (Galton, 1966). Marrow invasion is always an early event (Galton, 1966), as revealed by aspirate smears; however, marrow biopsies show variable pictures of focal, nodular, diffuse, or massive invasion (Duhamel, 1974), which correlate to a certain extent with the indolent or active clinical behaviour of the disease (Gray et al., 1974; Carbone et al., 1978).

A minority (1-3\%) of patients with CLL may develop an acute leukaemia after a variable, but usually long (more than 5 years), interval (Zarrabi et al., 1977). Either truly undifferentiatied cells or large lymphoblasts with vacuolated cytoplasm containing rare granules are found to circulate in the blood and to replace to a great extent the marrow. The finding of surface immunoglobulin on the blasts of two cases, and in one of them of the same monoclonal IgM with an anti-IgG antibody activity on both the leukaemic lymphocytes and the blast cells, is against the possibility of a second malignancy and is suggestive of a derivation of the blasts from the same clone as the small lymphocytes (Brouet et al., 1973b).

In lymph node sections the numerical increase of lymphoblasts among the monomorphic B-CLL lymphocytic population is usually considered by histopathologists to be suggestive of neoplastic progression. The development of an anaplastic lymphoid malignancy ('reticular cell sarcoma') during the terminal phases of CLL was described by Richter in 1928. It has distinct clinicopathological features (Long and Aisenberg, 1975) and is usually diagnosed at necropsy. Rather than a metachronous association of two malignant lymphomas, it should be considered an immunoblastic sarcomatous evolution of CLL with predominant tissue manifestation. The possible role of long-term chemotherapy in the switch-on of the blastic phase is at present a matter of debate. By contrast, the development of acute megaloblastic or myelomonocytic leukaemia is an exceedingly rare event (cf. myeloma).

Ultrastructurally, the great majority of the 
lymphocytes (Figs 1 and 2) have round nuclei with coarsely clumped chromatin (Mori and Lennert, 1969; Cawley and Hayhoe, 1973). There are no indentations of the nuclear membrane; however, occasional nuclear pockets are found. The inconspicuous nucleoli frequently have a characteristic ring-shaped pattern. Conversely, the lymphoblasts (Fig. 3) have diffuse nuclear chromatin and welldeveloped nucleoli with a prominent nucleolonema. The prolymphocytes (Fig. 2) have a roughly oval nucleus and a well-developed nucleolus as in the homonymous cells of Galton's prolymphocytic leukaemia (PL) (Galton et al., 1974), but they have a more abundant cytoplasm and a less clumped nuclear chromatin. Prolymphocytes of both B-CLL and PL are distinguishable from centrocytes, which have deeply indented irregular nuclei, inconspicuous nucleoli, and scanty cytoplasm with scarce organelles.

The cytoplasm of B-CLL cells is rather scanty in lymphocytes and is somewhat more conspicuous in lymphoblasts and prolymphocytes. It contains a small or moderate number of mitochondria, numerous free ribosomes, a small Golgi apparatus, and a few rough endoplasmic reticulum cisternae. Abundant cytoplasmic microfilaments are present in some cells. The previously mentioned inclusions with a regular crystalline-like structure lie within the rough endoplasmic reticulum cisternae. A morphological marker that indicates a plasymcytoid transformation of rare CLL lymphocytes is represented by some cisternae of long, flat, and rough, endoplasmic reticulum placed around the nucleus (Fig. 4). Scanning electron microscopy (SEM) does not permit the identification of the lymphocytes of B-CLL as neoplastic (Braylan et al., 1976).

Extensive studies of cell surface immunological markers, such as surface-bound immunoglobulin (Pernis et al., 1970), membrane receptors for the activated third component of complement (Bianco et al., 1970; Ross et al., 1973), and aggregated IgG (Dickler et al., 1973) on CLL lymphocytes (Johansson and Klein, 1970; Grey et al., 1971; Wilson and Nossal, 1971; Aisenberg and Bloch, 1972; Frøland et al., 1972; Preud'homme and Seligmann, 1972; Piessens et al., 1973; Ross et al., 1973) proved that this B-lymphocyte proliferation is made up of cells in most of which no immunoglobulin secretion takes place but which do bear synthesised membrane-bound immunoglobulin. This is of one type only and is usually restricted to one type of heavy chain $(\mu, \gamma$, or $\alpha)$ and one light chain ( $\kappa$ or $\lambda)$, thus indicating the monoclonality of the cell proliferation (Aisenberg and Bloch, 1972), even though biclonal processes have rarely been detected (Preud'homme and Seligmann, 1972). In a number of cases $\delta$ chains are associated with $\mu$ chains, as may be observed in normal lymphocytes (Fu et al., 1974). Routine immunofluorescent staining procedures for the demonstration of immunoglobulin on the cell surface of leukaemic lymphocytes reveal positivity that is weak (Braylan et al., 1976), particularly when compared with that of the cells of lymphosarcoma-cell leukaemia (Aisenberg and Bloch, 1972; Aisenberg et al., 1973a), that is, the leukaemic conterpart of a lymphoma of germinal centre cell origin. In general, the cells of B-CLL also have weakly represented complement receptor sites (Shevach et al., 1972) and membrane receptors for aggregated IgG (Braylan et al., 1976). However, the expression of binding sites varies considerably from case to case. The absence of surface immunoglobulin (Piessens et al., 1973; Wilson and Hurdle, 1973) has been related to the proliferation of a pre-Ig-synthesising lymphocytic population (Preud'homme and Seligmann, 1972). B-CLL cells either fail to respond or respond poorly to mitogens in short-term cultures (Quaglino and Cowling, 1964). It has also been shown that a high percentage of them form rosettes with mouse erythrocytes (Catovsky et al., 1976; Koziner et al., 1977) in contrast to the cells of lymphosarcoma-cell leukaemia.

It has been suggested that B-CLL most likely represents the proliferative disease of a 'virgin' $\left(\mathbf{B}_{1}\right)$ B-lymphocyte clone, which is still untouched by the antigen, is blocked in its modulation process, and is therefore unable to secrete immunoglobulin; but its derivation from 'memory' $\left(B_{2}\right)$ B-lymphocytes in some cases cannot be ruled out (Salmon and Seligmann, 1974). It has also been suggested that $B_{1}$ cell proliferations are those whose cells bear surface immunoglobulin and have complement receptors, whereas $\mathbf{B}_{2}$-cell proliferations also bear surface immunoglobulin but are devoid of complement receptors (Stein, 1975).

When the tissue manifestation of B-CLL is not accompanied by an excess of cells in the blood and/or marrow, the disease has been referred to as well-differentiated, lymphocytic, diffuse ML (Pangalis et al., 1977); a leukaemic manifestation may appear later (Galton, 1966) or never (Goldberg and Emanuel, 1964). However, the morphology and the surface characteristics of the cells are the same as they are in B-CLL (Huber et al., 1974; Peter et al., 1974; Aisenberg and Long, 1975; Brouet et al., 1975b; Braylan et al., 1976). One major difference between B-CLL and well-differentiated lymphocytic diffuse ML was reported to consist of a less evident degree of hypogammaglobulinaemia in the latter (Pangalis et al., 1977). In spite of clinical and haematological differences, leukaemic and non-leukaemic B-lymphocytic neoplastic proliferations are so 

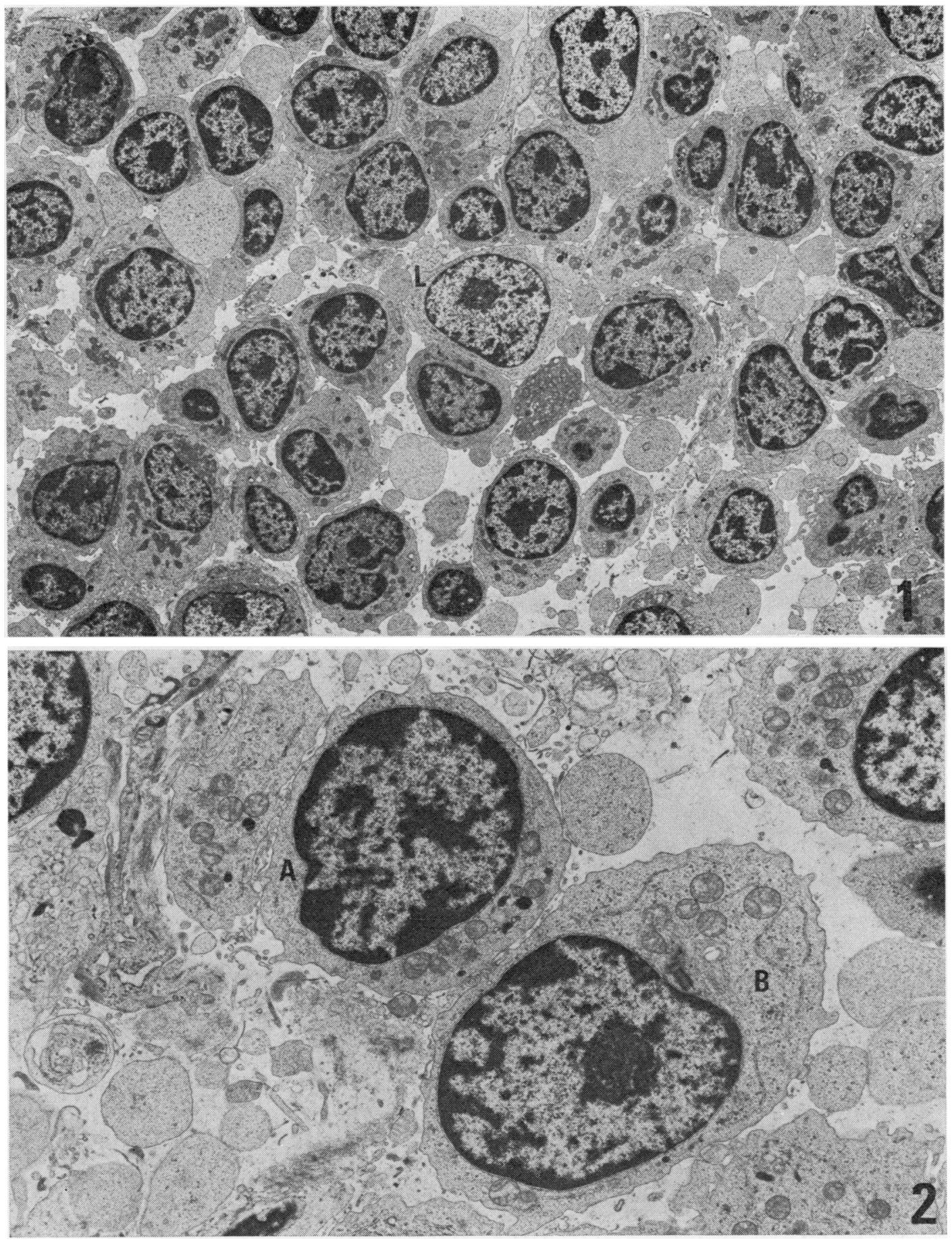

Fig. 1 Chronic lymphocytic leukaemia. Small lymphocytes and a lymphoblast $(L) .(\times 4000)$

Fig. 2 Chronic lymphocytic leukaemia. A small lymphocyte $(A)$ with coarsely clumped nuclear chromatin, numerous monoribosomes, scarce rough endoplasmic reticulum, and lysosome-like dense granules. $A$ prolymphocyte $(B)$ with a well-developed nucleolus and a larger cytoplasm. $(\times 10000)$ 

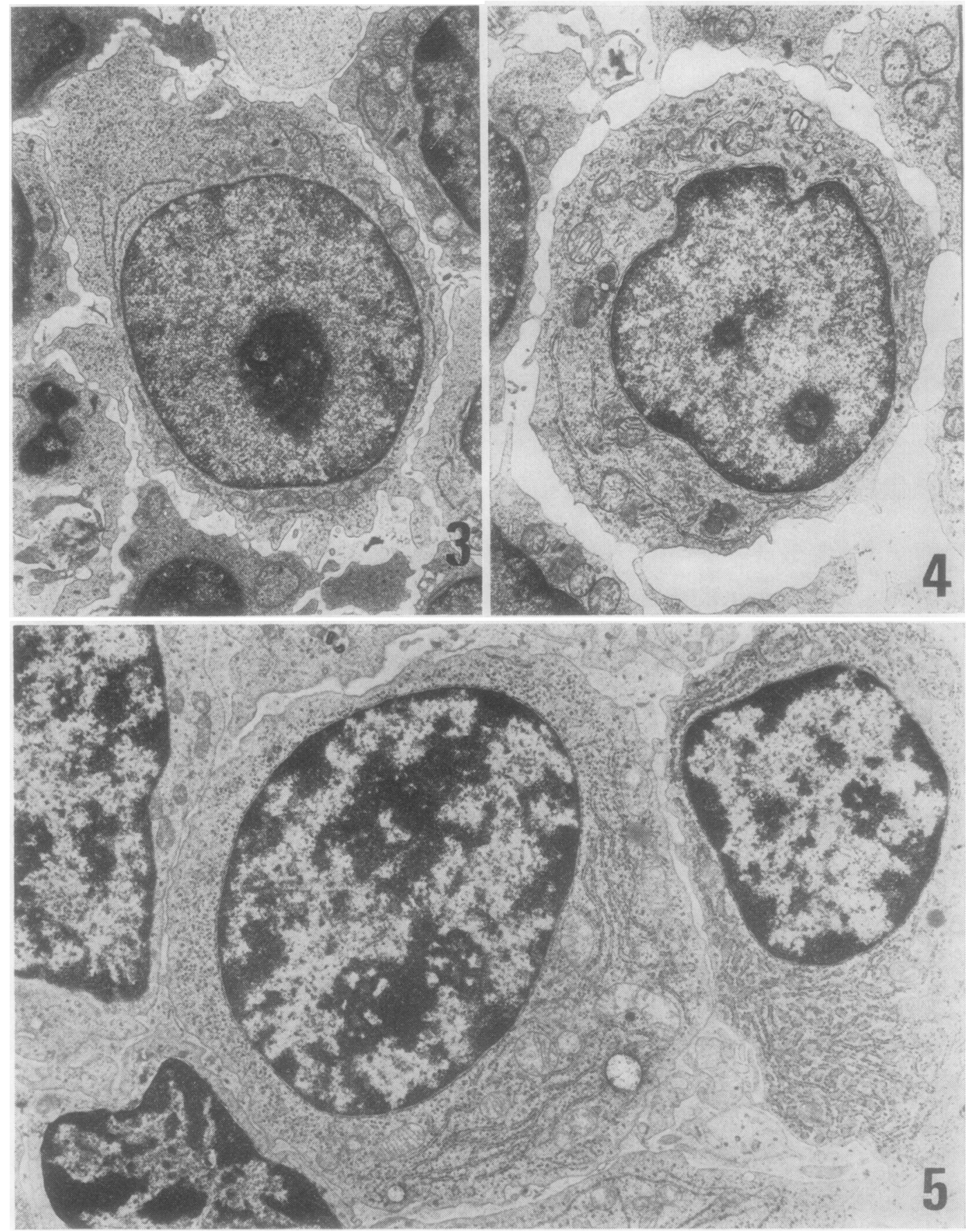

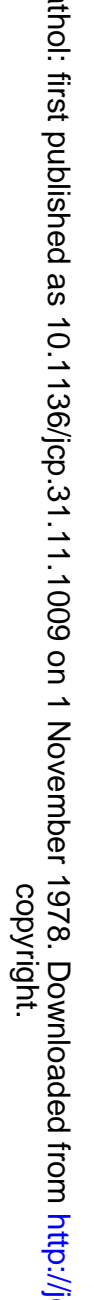

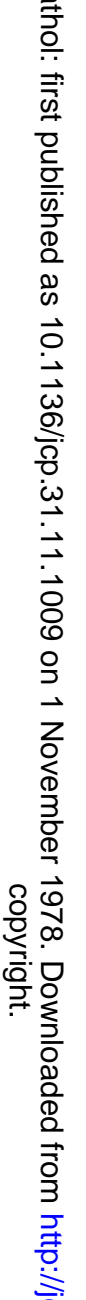

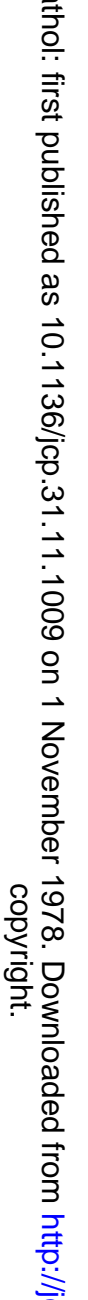

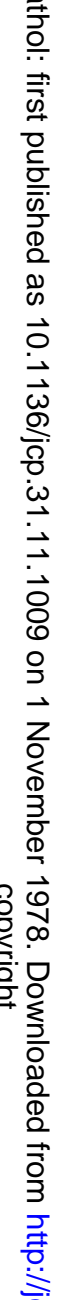

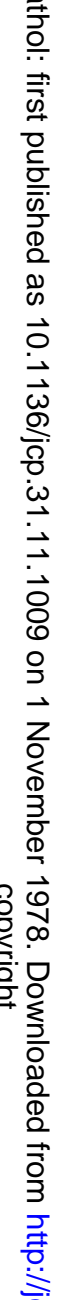

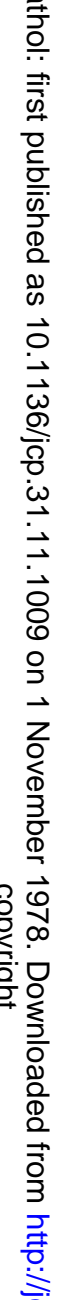

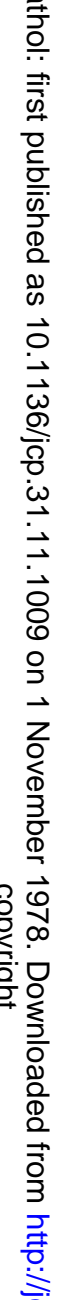

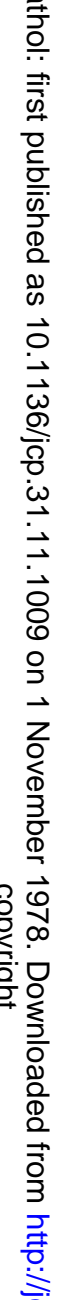

홍

$\frac{0}{3}$

ᄋ̊

은

근

$\stackrel{\text { N }}{\varrho}$

N

กิ

ర్

○

Fig. 3 Chronic lymphocytic leukaemia. A lymphoblast with diffuse nuclear chromatin and a prominent nucleolus. Some long rough endoplasmic reticulum cisternae and mitochondria are present. $(\times 9000)$ Fig. 4 Chronic lymphocytic leukaemia. A small lymphocyte with a well-developed rough endoplasmic reticulum. $(\times 11000)$

Fig. 5 Malignant lymphoma, T-zone type. A T-associated plasma cell with a prominent nucleolus and a well-developed rough endoplasmic reticulum. $(\times 28000)$ 
closely related that they are probably just different haematopathological expressions of the same disease.

In large series of cases of CLL, occasional patients may be encountered in whom morphological and/or immunological deviations from the classic picture are noticed. Morphological deviations are represented by cases in which circulating cells have either cleft nuclei similar to Rieder cells and to small follicular centre cells (centrocytes) of lymphoplasmacytic features (Rudders, 1976) and contain cytoplasmic inclusions. In general, lymphocytes of abnormal appearance have been related to a more rapid course of the disease. Along these lines, immunological variations are exemplified either by cases whose cells demonstrate a surface marker phenotype, which is comparable to that usually displayed by follicular centre cells (Braylan et al., 1976) or by so-called 'atypical CLL' cases whose cells contain intracytoplasmic IgG (Rudders, 1976). On the basis of these descriptions one might suspect that these atypical cases of CLL are, in fact, leukaemic maifestations of ML, respectively of follicular centre cell origin or of lymphoplasmacytoid type. In rare instances, both B- and T-cell surface markers have been found on leukaemic cells (Chin et al., 1973); however, their true $B+T$ nature has been questioned (Brouet et al., 1975c; Siegal et al., 1976). Shifts of markers have also been noticed during the course of the disease (Kay et al., 1974).

T-CLL (Bentwich and Kunkel, 1973; Dickler et al., 1973; Lille et al., 1973; Wilson and Hurdle, 1973 ) is a rare entity (less than $2 \%$ of all CLL), with onset in adulthood, frequent massive splenomegaly, skin lesions, and variable lymphocyte count, which is characterised cytologically by somewhat larger lymphocytes than those of B-CLL (Brouet et al., 1975a). The cells have fairly large, occasionally deeply basophilic, PAS-negative cytoplasm which contains large azurophilic granules and shows a positive beta-glucuronidase and acid-phosphatase reaction (Catovsky, 1975). The nuclei contain coarse chromatin granules and a small nucleolus. Prolymphocytes and lymphoblasts are absent.

On electron microscopy the nuclei are irregular and there is a high content of lysosomal enzymes. Transmission and SEM cannot detect any morphological difference either between normal $\mathbf{B}$ and $\mathbf{T}$ lymphocytes (Alexander et al., 1976; Newell et al., 1976; Polliack, 1977) or between CLL with T or B surface immunological markers. Immunologically, the presence of receptors for sheep erythrocytes (Lay et al., 1971; Jondal et al., 1972) and the reactivity with heterologous anti-T-cell antiserum (Aisenberg et al., 1973b) indicate the T-derived nature of the cells.
Additional cases of this or of a closely related disease with a poor prognosis have been reported in Japan. The circulating lymphocytes, however, showed a higher degree of nuclear pleomorphism and fewer cytoplasmic granules (Uchiyama et al., 1977) as compared with the T-CLL described in western countries. As far as we are aware, detailed histological descriptions of lymph nodes involved by T-CLL are lacking.

\section{T-ZONE MALIGNANT LYMPHOMA}

Whether T-CLL bears any relationship to the Tzone lymphocytic ML has not yet been established (Lennert et al., 1975b). It seems, however, that this recently described entity (Lennert et al., 1975b; Lennert, 1976) is a well-defined one and that it represents neoplastic malignant proliferation of the lymphocytes of the nodal paracortical area. In fact, in cases that are not too far advanced, uninvolved secondary follicles which are widely dissociated by the neoplastic growth remain recognisable. The neoplastic cell population is somewhat pleomorphic and is made up of irregularly shaped lymphocytes, the nuclei of which are on average less hyperchromatic than are those of B-CLL. The chromocentres are smaller and not clumped, and a small prominent nucleolus is usually visible. The mitotic index is low. The cells display a strong acid phosphatase activity (Kaiserling, 1977b). The histological picture is also characterised by the presence of the normal components of the T-dependent paracortical area (Kaiserling, 1977b), that is, postcapillary venules lined by hob-nailed endothelial cells and surrounded by small lymphocytes, a network of reticulin fibres, and interdigitating reticulum cells, the clear, highly irregular nuclei of which may be recognised even on light microscopy (Veldman, 1970). These cells are considered to be the characteristic reticulum cells of the paracortical area of the lymph nodes. They do not usually display phagocytic activity. In addition, so-called T-associated plasma cells are part of the picture (Lennert et al., 1975a).

The intermingled rare large blast cells are similar to Hodgkin's mononuclear cells and may possibly be interpreted as $\mathrm{T}$ immunoblasts. Multinucleate cells of the same type simulate Reed-Sternberg cells. Six cases of a very similar entity, defined as ML of peripheral T-lymphocyte origin, were recently reported by Waldron et al. (1977) in elderly patients. The majority of the malignant cells of these cases were identified immunologically as $\mathbf{T}$ lymphocytes.

On electron microscopy the cellular population of the T-zone ML diffusely infiltrates the lymph nodes and consists of pleomorphic lymphoid cells, a smaller number of non-neoplastic macrophages, rare plasma cells, and granulocytes (Waldron et al., 
1977). T-associated plasma cells may be numerous (Fig. 5). The size and the nuclear morphology of the lymphoid cells vary considerably. The small lymphoid cells are similar to small circulating lymphocytes, whereas large cells (Fig. 6) look like transformed lymphocytes with pale oval nuclei, scanty heterochromatin, and prominent nucleoli. The abundant cytoplasm contains many polyribosomes, scarce rough endoplasmic reticulum cisternae, a variable number of mitochondria, and occasional lysosome-like dense granules located in the Golgi area. A few abnormal cells (Fig. 7) may show either a huge central nucleolus with a very prominent nucleolonema or an irregularly indented nucleus (Fig. 8) with dispersed chromatin; these cells recall the descriptions of mononuclear Hodgkin's cells (Dorfman et al., 1973; Glick et al., 1976). The identification within the tumour tissue of interdigitating reticulum cells can be considered a diagnostic marker of the T-zone lymphoma and other T-derived lymphomas (Kaiserling, 1977b). Interdigitating reticulum cells have a clear nucleus with scarce heterochromatin placed along the nuclear membrane and with a regular shape or, occasionally, with deep indentations. A small nucleolus is observed. The abundant cytoplasm is extended into interdigitating processes. No junctional differentiation is evident among the plasma membranes of two contiguous reticulum cells. In the cytoplasm a complex of vesicles and sacs, markedly contrasted by silver-methenamine staining, is found. This electron microscope cytochemical method is considered specific for glycoproteins (Veldman, 1970). The Golgi apparatus also shows a positive silver-methenamine reaction, which supports a functional correlation between the two structures. A few rough endoplasmic reticulum cisternae, some mitochondria, bundles of filaments, and a small number of mono- and polyribosomes are also found. No digestive vacuoles are seen.

PROLYMPHOCYTIC LEUKAEMIA (PL)

This disease (Galton et al., 1974) is a rare variant of CLL with distinctive features; lymphadenopathy is inconspicuous, whereas the spleen and liver are markedly enlarged. There is usually a high WBC count, and the proliferating cell has been designated 'prolymphocyte', with a different meaning, however, from that used in the WHO classification of neoplastic lymphoid diseases. The leukaemic cells are larger than the lymphocytes of B-CLL, have a fairly large basophilic cytoplasm, a nucleus with condensed chromatin, and a single vesicular and prominent nucleolus. A variable number of lymphocytes as well as larger blast-like cells are also present. The latter are different from the lymphoblasts of
CLL because of the larger size and the greater amount of chromatin. Abnormal looking cells are often found. Most of the reported cases have been of B-cell origin, but a few have been of T-cell origin. The former reveal a stronger expression of surface membrane-bound immunoglobulin and of complement receptors than the lymphocytes of B-CLL (Catovsky et al., 1973), while the T-cell prolymphocytes lack those markers but yield a high spontaneous E-rosette count. In smears, a high percentage of the cells of B-type PL contain glycogen (Stathopoulos et al., 1974) in the form of granules which are coarser than those found in B-CLL lymphocytes. Acid phosphatase content is weak but occasionally tartrate-resistant (Catovsky et al., 1974a). On the other hand, T-cell type PL cells reveal a higher content of acid phosphatase and are PAS negative.

Essential differences between the ultrastructural features of prolymphocytes and those of B-CLL lymphocytes consist of the larger size and the more prominent nucleolus, with the well-developed nucleolonema of the former. Ring-shaped nucleoli are seldom seen. In the cytoplasm a variable number of mitochondria and some rough endoplasmic reticulum cisternae are found. The blasts of PL have large nucleoli and dispersed chromatin. In comparison to prolymphocytes of B-CLL, prolymphocytes of PL are characterised by a clumped chromatin pattern and may therefore be placed morphologically in an intermediate position between small lymphocytes and the intermediate cells of CLL. No morphological differences have been reported between T- and B-type PL.

\section{MYCOSIS FUNGOIDES AND SÉZARY} SYNDROME

Mycosis fungoides is an uncommon (less than $1 \%$ of all ML) but distinctive histopathological and clinical entity which involves primarily the skin (Edelsonet al., 1974; Cline, 1975) and later, in over two-thirds of cases, the lymph nodes and other organs (Long and Mihm, 1974; Rappaport and Thomas, 1974). The cellular composition of the infiltrates of mycosis fungoides is lymphocytic in nature (Crossen et al., 1971); the cells are unique and different from those of other ML, and are considered to originate from $\mathrm{T}$ dependent lymphocytes.

Histological diagnosis is usually made on skin biopsies of the second (indurated neoplastic cutaneous plaque) and of the third (mycotic or neoplastic) stage of the disease. The neoplastic cellular population is identical in the cutaneous and extracutaneous sites. In the skin there is an infiltration by mononuclear atypical cells, which invade the papillary dermis and the basal layers of the 

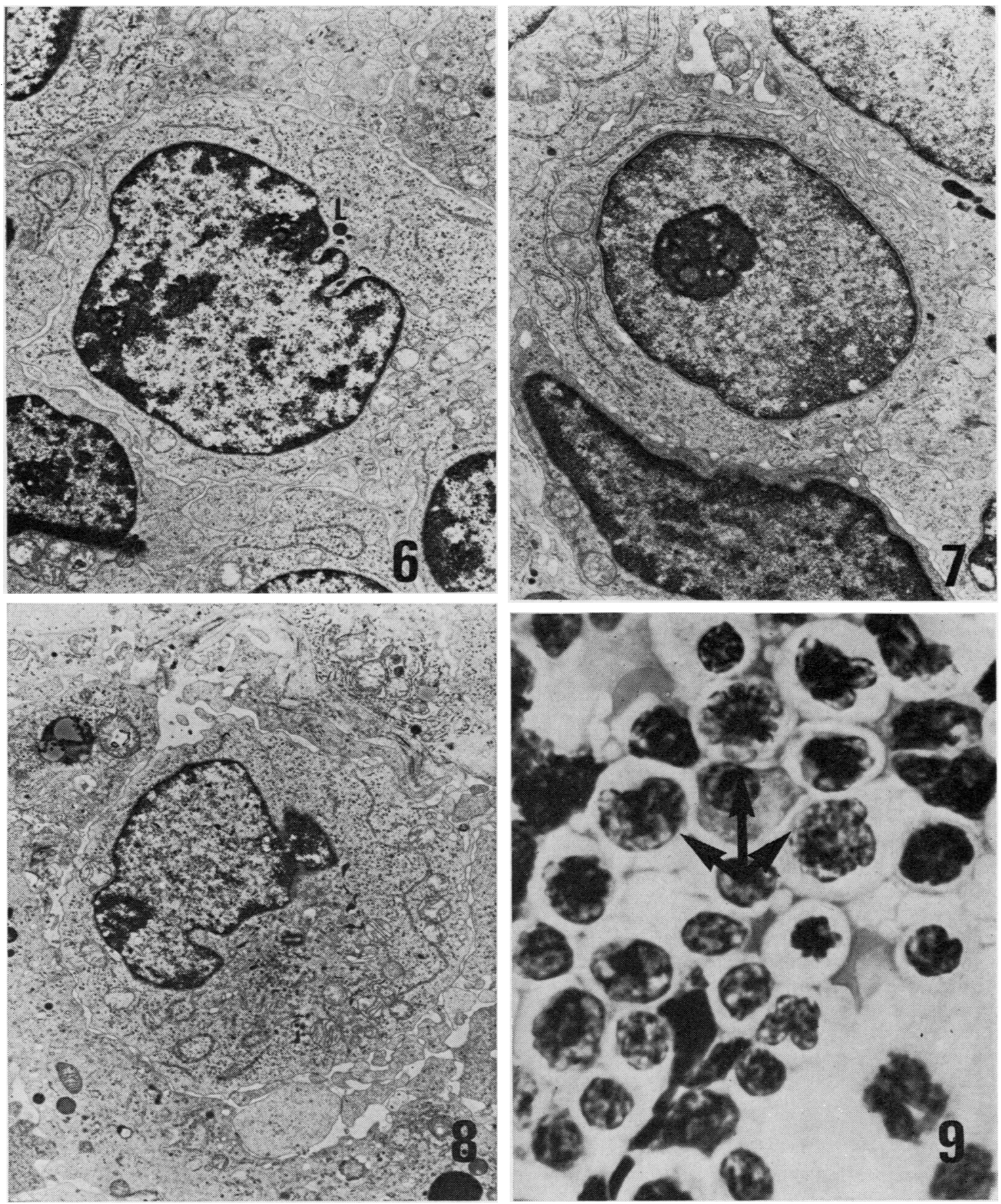

Fig. 6 Malignant lymphoma, T-zone type. Large lymphoid cell with two prominent nucleoli, many polyribosomes, scarce rough endoplasmic reticulum, a small lipid droplet $(L)$, and a few lysosome-like dense bodies. $(\times 8000)$

Fig. 7 Malignant lymphoma, T-zone type. A tumour cell with a roughly oval, pale nucleus and a very large central nucleolus. $(\times 14000)$

Fig. 8 Malignant lymphoma, T-zone type. A neoplastic cell with an irregular, indented nucleus, abundant polyribosomes, and small lysosome-like dense bodies. $(\times 8000)$

Fig. 9 Mycosis fungoides: imprint of skin lesion. Medium-sized neoplastic cells with highly irregular and cerebriform nuclei (arrow). The nucleolus is hardly visible and the cytoplasm is clear. (Papanicolaou $\times 1000$ ) 
epidermis, in which the so-called Darier-Pautrier's abscesses are often formed within epidermolytic spaces. The neoplastic infiltrate consists of cells with a wide range of sizes. The most common cells, however, are medium-sized and measure 10 to $20 \mu$ in diameter; they have a scanty, faintly stained cytoplasm, which shows a focal acid phosphatase activity (Schwarze, 1975) and contains perinuclear diastase-resistant, PAS-positive granules. Their nuclei are pleomorphic, with dense chromocentric chromatin and a small nucleolus.

The atypical cells may show a certain variation in size and shape with marked atypicalities. The larger the cells the more evident are the irregularities of the nuclear membrane, particularly in imprints (Fig. 9), with hyperconvolution and cerebriform patterns. In the very small cells nuclear details are barely visible. The so-called mycosis cells are a rare finding; they are the largest of the whole neoplastic cell population and show marked hyperconvolution and hyperchromasia of the nucleus and amphophilic cytoplasm. In addition, a large number of abnormal looking histiocytes may be present (Robinowitz et al., 1976).

In lymph nodes, the neoplastic proliferation of mycosis fungoides seems to involve initially the 'thymic-dependent' paracortical area and later, to a variable extent, the remaining node (Thomas and Rappaport, 1975). All cell types present in the cutaneous infiltrate can be encountered in extracutaneous sites of invasion. In the spleen, either scattered foci in both the red and the white pulp or a diffuse infiltration may be seen (Variakojis et al., 1974). The selective involvement of the thymicdependent periarteriolar lymphatic sheath has been stressed (Thomas and Rappaport, 1975).

Sézary's syndrome (Sézary and Bouvrain, 1938), a chronic leukaemia associated with erythroderma, is considered the leukaemic variant of mycosis fungoides (Lutzner et al., 1975; Robinowitz et al., 1976). In fact, the cutaneous infiltrate in Sézary syndrome is very similar to that of mycosis fungoides, and, on the other hand, in a high percentage of cases of mycosis fungoides circulating Sézary cells were found (Moran et al., 1977). In addition, in Sézary syndrome the earliest infiltration in lymph nodes was reported to be found histologically in tertiary follicles (Lennert, 1974). It was therefore proposed that mycosis fungoides and Sézary syndrome should be grouped together under the term 'cutaneous T-cell lymphoma' (Schein et al., 1976).

The circulating cells, which represent the diagnostic marker of the disease- - even though not an absolute one (Lutzner et al., 1975) - are variable in number (between 10 and $50 \%$ of the nucleated cells in blood smears) and reveal nuclear and cytoplasmic features that are closely related to those described for mycosis cells. In marrow smears Sézary cells are rarer than expected in a leukaemic disease. The cells usually measure between 15 and $20 \mu$ in diameter and have a high nuclear:cytoplasmic ratio. The scanty cytoplasm is well defined, appears light blue with the Giemsa stain, and does not contain granules, while empty vacuoles may be present. In thin blood smears the nuclei disclose their highly characteristic structure: the nuclear membrane shows various furrows, indentations, folds, and convolutions. Nucleoli are barely visible. The same finding is revealed by imprints of skin lesions as well as of lymph nodes that are involved by mycosis fungoides and by Sézary syndrome. Sézary syndrome also has a more markedly leukaemic small cell variant that is made up of lymphocytes measuring about $8 \mu$ in diameter which are morphologically more closely similar to small lymphocytes even though nuclear indentations are present (Lutzner et al., 1973). The large cells have near-tetraploid DNA values and near-tetraploid chromosome counts, whereas the small cells have diploid DNA values and pseudodiploid or hyperdiploid chromosome counts.

Sézary cells reveal a granular acid phosphatase content, are moderately positive for $\beta$-glucuronidase and $\alpha$-naphthyl acetate esterase, and are negative for peroxidase, naphthol-AS-D-chloroacetate esterase, alkaline phosphatase, adenosine-triphosphatase, OilRed O, and Sudan black-B (Löffler, 1972). PAS stains cytoplasmic granules of neutral mucopolysaccharides in a variable number without diffuse background staining (Crossen et al., 1971). Large and small Sézary cells have T-cell markers; they form spontaneous $E$ rosettes, react with antihuman T-cell antisera, respond to phytohaemagglutinin (Brouet et al., 1973a; Lutzner et al., 1973), and lack B-cell markers; they do not bear complement receptor sites and are devoid of surface-bound immunoglobulin (Broome et al., 1973). In addition, evidence was given that Sézary cells represent a neoplastic proliferation of T-helper cells (Broder $e t$ al., 1976). A few cases of Sézary syndrome in which the neoplastic cells failed to form E rosettes have also been reported (Goldstone et al., 1976).

Ultrastructurally, tissue-bound mycosis fungoides cells (Lutzner et al., 1971) are also very similar to circulating Sézary cells (Lutzner and Jordan, 1968; Zucker-Franklin et al., 1974). The nuclear:cytoplasmic ratio is high, and the nucleus is characteristically irregular, serpentine, indented, and lobed. However, this degree of irregularity varies largely from cell to cell and from case to case (RosasUribe et al., 1974). Heterochromatin is abundant and concentrated along the nuclear membrane. One or two nucleoli with nucleolonema or ring-shaped 
nucleoli and occasional nuclear inclusions are observed. The cytoplasm contains glycogen and a prominent network of microfilaments (ZuckerFranklin et al., 1974). The number of mitochondria, multivesicular bodies, rough endoplasmic reticulum cisternae, and free mono- and polyribosomes varies from case to case. Cytoplasmic pseudopods and lysosomes are found, whereas phagocytosis is never seen.

At SEM most of the Sézary cells show a moderate to markedly villous surface and do not display ruffled membranes (Polliack et al., 1977). Since Sézary-like cells are found in patients with a variety of nonlymphomatous dermatoses, it is of diagnostic importance that atypical cells should be demonstrated in clusters or sheets in the affected tissues.

\section{HAIRY CELL LEUKAEMIA}

This uncommon form of a chronic leukaemic lymphoproliferative disorder is characterised clinically in most cases by splenomegaly, hepatomegaly, and pancytopenia. Lymphadenopathy is a rare and late symptom. In sections of spleens there is a diffuse proliferation of monomorphic cells which measure between 12 and $20 \mu$ in diameter. The nucleus is roundish or oval, occasionally kidneyshaped, often indented and wrinkled, and eccentric. It occupies about half of the cell area. Mitotic figures are rarely seen. The chromatin is delicate and loose, and nucleoli (if discernible) are small and pale. The cytoplasm is quite large, ill-defined, irregular, and lightly basophilic (grey-blue in Wright-Giemsa smears) and does not contain granules. Large blast-like cells are never found. In ordinary blood smears in which the cell morphology is best observed, the hairy finger-like projections of the cytoplasm may be recognised. However, they appear to be better preserved and defined in phasecontrast microscopy. In thin, well-stained smears and splenic imprints, small, cigar-shaped or roundish pyroninophilic cytoplasmic inclusions may be detected that correspond to the ribosome-lamellar complexes (Katayama et al., 1973).

The cytological marker is the presence of a prominent focal acid-phosphatase activity, which is resistant to degradation by tartaric acid (isoenzyme 5) (Yam et al., 1972). Even though hairy cells may occasionally be tartaric-acid sensitive, this isozyme should always be sought, preferably in blood smears (Katayama and Schneider, 1977); it is absent in normal lymphocytes but may be found in some CLL and PL lymphocytes, and its appearance in hairy cells should be considered as a newly acquired property that is related to the malignant status of the cells. Hairy cells are negative for Sudan black-B, peroxidase, and PAS, even though in some cells a PAS- positive granulation has occasionally been seen (Haak et al., 1974). A moderate granular sodium fluoride-resistant naphthol AS-D-acetate esterase activity, allegedly stronger than that of lymphocytes and weaker than that of histiocytes, has been reported (Flandrin et al., 1973). Recent extensive enzymohistochemical investigations revealed that hairy cells show only occasionally $a$-naphthylacetate esterase activity, while they are negative for alkaline phosphatase, $\alpha$-naphthyl-butyrate esterase, sodium fluoride-resistant naphthol AS-D-acetate esterase, 5'-nucleotidase, and $\mathrm{N}$-acetyl- $\beta$-glucosaminidase (Nanba et al., 1977b).

The earliest and most striking proliferation of cells takes place in the spleen, which usually becomes markedly enlarged. Grossly, the spleen is dark red in colour, firmer than normal, and does not reveal discrete tumour masses. In the early stages, however, hairy cells appear first in the cords of the red pulp, and subsequently the sinusoidal structure and the Malpighian corpuscles of the white pulp tend to disappear because of compression and atrophy. In addition, an increase of actively phagocytosing histiocytes has been described around the arteries of the red pulp (Nanba et al., 1977b). Plasma cells, both normal and of atypical appearance, are found among the hairy cells. Their purely reactive nature has been questioned. Distended spaces filled with erythrocytes and lined by hairy cells and not by endothelial cells, which show a strong fluoridesensitive naphthol-AS-D-acetate esterase activity, were recently described as pseudosinuses (Nanba et al., 1977c).

Marrow invasion may be either massive or focal. The marked and diffuse increase in reticulin fibres (Burke et al., 1974) explains the 'dry tap' that is most often found; however, imprints of marrow biopsies yield adequate diagnostic cytological material (Krause et al., 1977). In the liver, the invasion usually follows the sinusoidal structure, and pseudoangiomatous lesions similar to those of the spleen and lined by hairy cells have also been described. In the lymph nodes, the neoplastic proliferation appears late in the course of the disease and begins in the Bcell region of the outer cortex with early infiltration of the marginal sinus. The spread to the paracortical and medullary areas develops later (Lennert, 1974). Lymph node invasion is often only partial, with residual follicles and foci of lymphoid cells.

The large number of synonyms used so far for the definition of this disease, which is still also called leukaemic reticuloendotheliosis (Ewald, 1923; Bouroncle et al., 1958), indicates the uncertainties about the proliferating cell type, the normal counterpart of which has not yet been identified. It has been questioned whether hairy cell leukaemia is really a 
completely homogeneous disease rather than a group of subentities (Golde et al., 1977b), and its origin from histiocytic, endothelial, or lymphoid cells was and still is a matter of controversy.

The moderate nonspecific esterase activity, the occasional and inconsistent ability of phagocytic activity in vitro (latex particles and complementcoated zymogen particles) (Boldt et al., 1977) and in vivo (Catovsky et al., 1975a; Nanba et al., 1977b; Utsinger et al., 1977), and adhesion of the cells to glass and nylon (Flandrin et al., 1973; Boldt et al., 1977) are weak arguments, indicating that hairy cells may be monocytic in nature; and the severe monocytopenia associated with the disease has been interpreted in the same way (Seshadri et al., 1976). However, none of these is a compelling reason and furthermore, hairy cells do not produce muramidase (Catovsky et al., 1975a). An origin from endothelial cells also seems unlikely because of the tartaric acid-resistant acid phosphatase activity and the absence of naphthol AS-D-acetate esterase reaction.

On the other hand, arguments identfying the hairy cell as a neoplastic B-modified lymphocyte, in addition to the morphological findings are: frequent surface-bound ATPase activity (as in CLL) and $\beta$ glucuronidase activity (as in malignant plasma cells) (Nanba et al., 1977b); the finding of surface immunoglobulin (Catovsky et al., 1974c; Stein and Kaiserling, 1974; Leech et al., 1975b; Boldt et al., 1977), probably IgM (Debusscher et al., 1975), and of intracellular immunoglobulin (Leech et al., 1975b; Golde et al., 1977a), probably IgM $\lambda$ (Debusscher et al., 1975); and reactivity with the Merritt B-cell alloantibodies (Naeim et al., 1977). However, surface immunoglobulin was demonstrated occasionally to be polyclonal on hairy cells, and receptors for cytophilic antibodies were identified (Jaffe et al., 1974b), while the search for complement receptors gave predominantly negative results (Burns et al., 1977). The responsiveness to mitogens was found to be impaired but less than it is in CLL (Haak et al., 1974). On the hairy cells surface immunoglobulin redistribution was induced by antibodies; polar cap formation occurs as with other B cells and was found to be very active and resistant to various agents, such as low temperature and sodium azide (Salsano et al., 1978). No evidence for a T-cell origin has been found so far.

Ultrastructural investigations also confirm that in lymph nodes the neoplastic cell proliferation begins in the outer cortex. The tumour population consists of one cell type only: the hairy cell shows the same features in all sites and is characterised by the abundant hairy-like cytoplasmic projections interdigitating in a complex way and giving to the cellular clusters a syncytial appearance. Two types of cytoplasmic projections are present on the cell surface (Katayama and Schneider, 1977): thin finger-like microvilli (Fig. 10) and large pseudopods (Fig. 11). Both projection types are present on the same cell, but the numerical ratio between microvilli and pseudopods changes from cell to cell.

The nucleus is polymorphous, either oval or reniform (Fig. 11), with slight indentations, or more often bilobed or multilobed. Nuclear pockets are rarely seen. Chromatin is more dispersed than it is in lymphocytes, and one or rarely two nucleoli are present. The ribosome-lamellar complexes (RLC) already mentioned are present in the cytoplasm of hairy cells in a variable percentage of cases. In different patients the RLC are present in $0.2 \%$ to $90 \%$ of the tumour cells (Katayama and Schneider, 1977). The RLC (Fig. 10) are 8 to $13 \mu$ long and 0.5 $\mu$ wide, open tubular structures with a wall formed by concentric lamellae and ribosomes. RLC are rarely observed in other haematopoietic disorders, such as CLL, multiple myeloma, Waldenström's disease, acute monoblastic leukaemia, centroblastic-centrocytic ML, and also in human adrenal cortex adenoma cells, monkey renal tubular cells, and plant cells (Anday et al., 1973; Katayama et al., 1973; Burke et al., 1976; Reynes and Diebold, 1977). However, since the RLC are much more numerous in hairy cells, they can be considered a useful diagnostic marker for light and electron microscopy.

Other features in the cytoplasm of hairy cells (Figs 10 and 11) are a limited number of mitochondria, a relatively well-developed Golgi apparatus, scattered rough endoplasmic reticulum cisternae, numerous free mono- and polyribosomes, pinocytotic vesicles, azurophilic granules, rare lysosomal inclusions, bundles of microfilaments, microtubules, centrioles, and occasional lipid inclusions. By SEM, hairy cells demonstrate microvilli, which are characteristic to a certain extent of B-cell lymphocytes, and ruffled membranes, which are a peculiar characteristic of monocytes. A surface variation is manifested. Some cells have a villous surface whereas others have ruffled membranes only (Deegan et al., 1976); hybrid cells showing both features are also seen.

In summary, hairy cells show hybrid features that are predominantly typical for B lymphocytes and, in part, for monohistiocytic cells. A partial explanation may be that hairy cell leukaemia is not a completely homogeneous pathological entity. Furthermore, there is as yet no known normal counterpart with which the hairy cell can be compared.

\section{Malignant lymphoma of germinal centre cell origin}

Immunological as well as morphological light and 

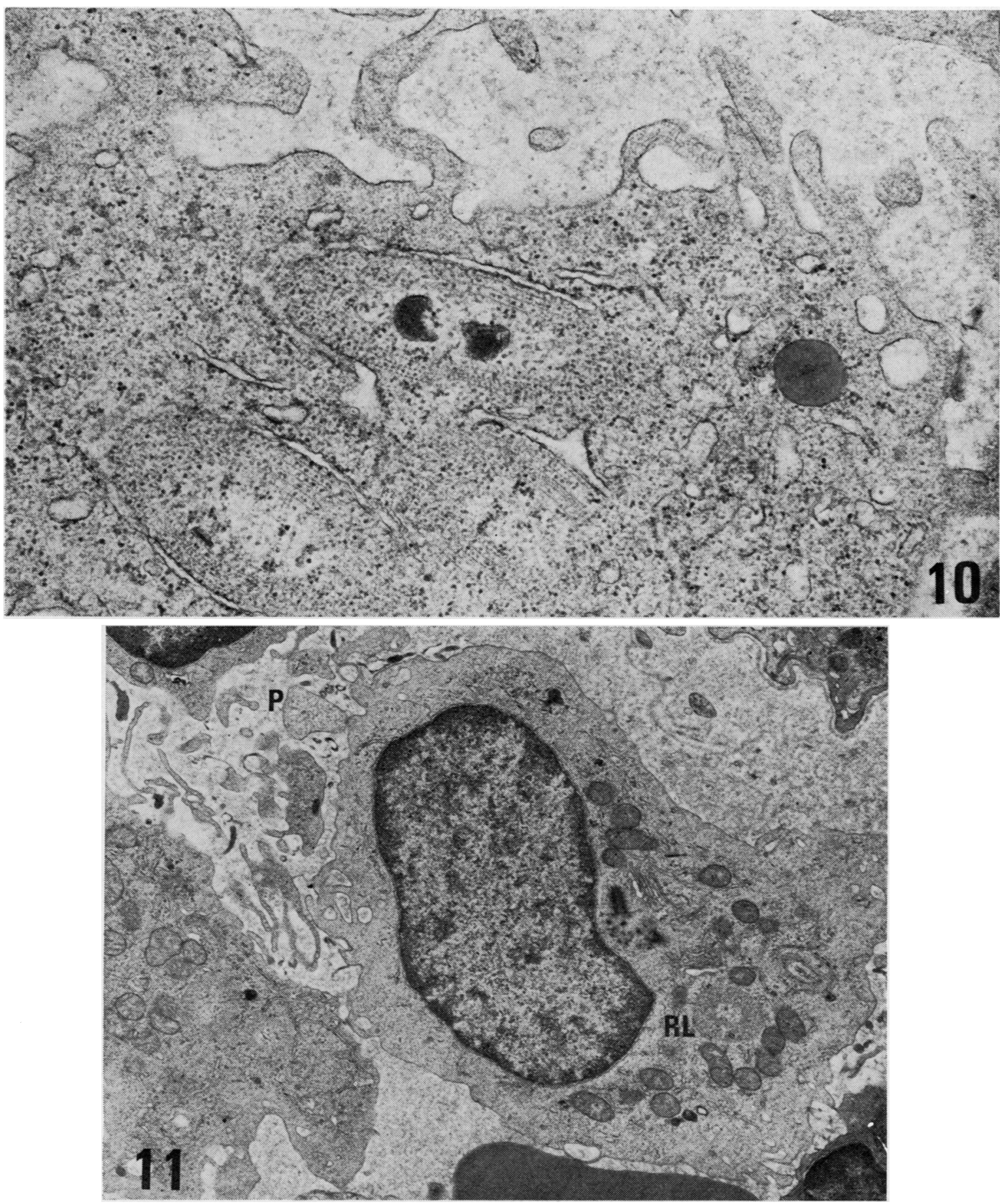

Fig. 10 Hairy cell leukaemia. A portion of hairy cell, which shows finger-like microvilli, three ribosome-lamella complexes, two lysosomal inclusions, and a lipid droplet. $(\times 46000)$

Fig. 11 Hairy cell leukaemia. A hairy cell with a kidney-shaped pale nucleus, a ribosome-lamella complex $(R L)$, a well-developed Golgi apparatus, and a large pseudopod $(P) .(\times 14000)$ 
electron microscopic studies (Sordat et al., 1970) indicate that lymphatic follicles and their germinal centres are, at least in their early phase, the site of multiplication of B-lymphocyte clones, which react specifically to antigenic stimulation. In fact, large deposits of immunoglobulin are accumulated within germinal centres (Nossal et al., 1968). Cytologically, in secondary stimulated follicles, several cell types are identifiable. There are specific large cells named germinoblasts (Lennert, 1957; Lennert and Remmele, 1958), renamed centroblast ${ }^{1}$ (Gerard-Marchant et al., 1974), and small cells named germinocytes (Lennert, 1964) renamed centrocytes ${ }^{1}$, and, in addition, dendritic reticulum cells (Milanesi, 1965a, 1965b), 'tingible body' macrophages (histiocytic reticulum cells), a few plasma cells and precursors, and occasional immunoblasts (ie, large basophilic transformed lymphocytes). In germinal centres mitotic activity is always very intense.

Normal centroblasts are round cells measuring between 12 and $15 \mu$ with basophilic cytoplasm and a rather clear nucleus in which two to three nucleoli are located against the nuclear membrane. Normal centrocytes are small cells with little cytoplasm, an indented nucleus, and very small nucleoli. These cells are easily identified in thin and well-stained sections of properly fixed material. They are also readily identified in imprints. The relationship between centroblasts and centrocytes is interpreted as the transformation of the former into the latter on the basis of cytophotometric and autoradiographic investigations which showed that the cellular proliferation in germinal centres is primarily a function of centroblasts (Lennert et al., 1969). Opposing views have been expressed by Lukes and Collins (1974). It appears, however, that non-stimulated primary follicles do not contain centroblasts and are made up predominantly of centrocytes, some of which carry natural antibody on the cell surface. It has been stressed that centroblasts and centrocytes are specific transformed lymphoid cells of the germinal centres which have unique distinctive properties. It has also been emphasised that it seems inadvisable to use for their identification inappropriate names, such as histiocytes or poorly differentiated lymphocytes (Lennert, 1973). It also seems unrealistic to define the cells of germinal centres by use of the recommended terms, such as large lymphoid cells and medium-sized lymphocytes (Cottier et al., 1973), since the same are also applied to other cell types seen in histological sections of lymph nodes that have different staining properties of the cytoplasm, structure of the nucleus, and size and number of nucleoli.

${ }^{1}$ Greek: $\chi \chi^{\prime} v \tau \rho o \nu=$ point, centre; $\beta \lambda \alpha \sigma \tau o ́ \nu=$ offspring, germ; $\chi \chi^{\prime} \tau \sigma \sigma=$ cavity, container.
The derivation of ML from the cells of the germinal centres has been the subject of a long-standing debate. Morphological light microscopic and ultrastructural data (Lennert et al., 1966; Mori and Lennert, 1969; Kojima et al., 1973; Lennert, 1973; Kaiserling, 1977a), immunological findings (Shevach et al., 1973; Jaffe et al., 1974a), and cytochemical data (Lennert, 1964, 1968) were accumulated essentially in favour of a derivation of ML from the cells that are the constituents of the primary and secondary lymphatic follicles (Lennert et al., 1975c).

\section{CENTROCYTIC MALIGNANT LYMPHOMA}

(GERMINOCYTOMA)

Lymphomas made up of cells that correspond to the normal centrocyte have also been defined as poorly differentiated, lymphocytic ML. In lymph nodes, these tumours always reveal a diffuse growth pattern, even though they may also display a vaguely nodular aspect (Fig. 12). In such cases there are ill-defined, small, compact nodules, which closely resemble primary follicles, but a definite follicular architecture with compression of the periphery of the reticulin fibre network and of the vessels is never seen. The centrocytes reveal a rather wide range of sizes. In general, they are small or medium-sized (Kaiserling, 1977a), have cleaved and indented nuclei, usually with one or rarely two very small nucleoli that are distant from the nuclear membrane, and a small amount of slightly basophilic PAS-negative cytoplasm. The main differences from lymphocytes of B-CLL in sections consist of the slightly larger size, the nuclear indentations, and the chromatin structure; however, the nuclear irregularities are less impressive in imprints. In those cases in which the cells are predominantly small and not heavily indented, the diagnosis of lymphocytic intermediate type ML has been applied (Dick et al., 1974). However, even small indented cells are different from the small lymphocytes of CLL, as has also been shown in viable cells (Schrek and Donnelly, 1961).

There are cases in which the centrocytes are quite large, with a size that is double that of the small ones. ML made up of large centrocytes is a separate subgroup termed large, cleaved, follicular centre cell ML of Lukes and Collins' (1974) classification. Large centrocytes have prominent nucleoli and a basophilic cytoplasm, show marked atypia, and reveal a high mitotic index. Cell kinetic studies indicate that large cell centrocytic ML has a higher degree of proliferation than do the small cell types (Silvestrini et al., 1977). For these cases centrocytic sarcoma was the diagnosis proposed by Kaiserling (1977a).

Of the accompanying cells centroblasts are usually recognisable in sections but centroblast-like cells may 

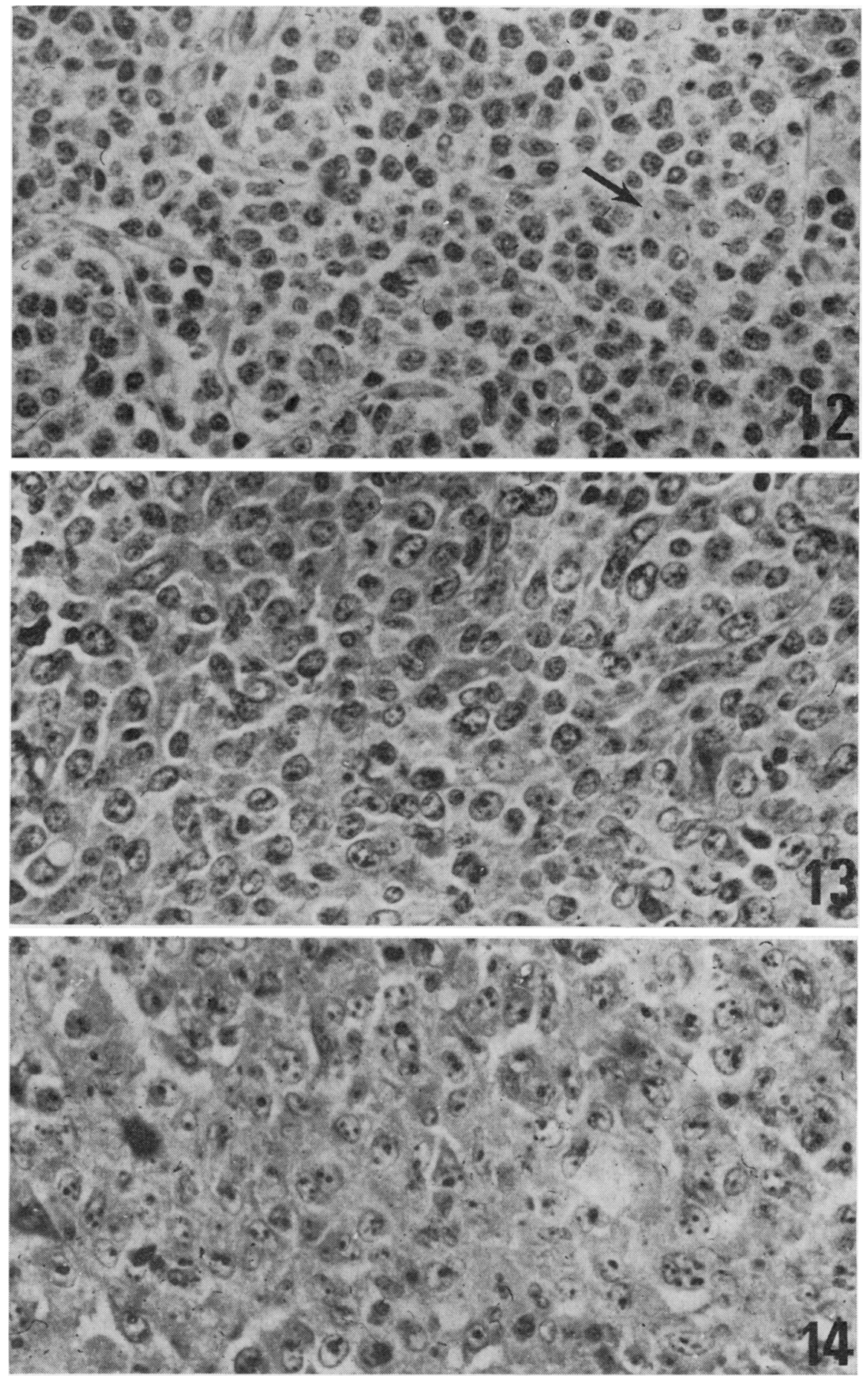

Fig. 12 Malignant lymphoma, centrocytic: axillary lymph node, 59-year-old man. Small-sized centrocytes with indented nuclei and small nucleoli. Possible dendritic cells (arrow). Diffuse type of growth. (Giemsa $\times 400)$ Fig. 13 Malignant lymphoma, centroblastic-centrocytic, diffuse: mesenteric lymph node, 38-year-old man. The two cell types are approximately equally represented. $(P A S \times 400)$

Fig. 14 Malignant lymphoma, centroblastic: mesenteric lymph node, 27-year-old man. Monomorphic diffuse growth of centroblasts. (Giemsa $\times 400)$ 
occasionally be identified in imprint preparations of affected lymph nodes. Furthermore, a small number of plasma cells and precursors may be found. In some cases there is a variable amount of sclerosis. Interspersed dendritic reticulum cells are a frequent finding even on light microscopy which is confirmed on electron microscopy (Lennert et al., 1975b). In imprints of lymph nodes and smears of extranodal centrocytic ML, centrocytes are quite typical because of their nuclear shape and the lightly basophilic, small cytoplasm (Rilke et al., 1978b). Small cell centrocytic ML seems to be among those tumours the cells of which have been shown to have immunological properties intermediate between CLL and follicular centroblastic-centrocytic ML (Jaffe et al., 1977) and frequently to show a strong alkaline phosphatase activity on their cellular membranes, thus reflecting similarities to the cells of primary follicles (Nanba et al., 1977a). In imprints, centrocytes reveal a moderate acid phosphatase reaction and a cell membrane-bound ATPase activity (Kaiserling, 1977a).

CENTROBLASTIC-CENTROCYTIC MALIGNANT LYMPHOMA (GERMINOBLASTOMA)

Even if Brill et al. (1925) and Symmers (1927) are commonly given credit for the first description of follicular ML, the first clear documentation of a ML with a germinal centre-like structure was given in 1916 by Ghon and Roman. This entity, which is practically unknown in childhood (Butler, 1969; Lennert, 1973; Hausner et al., 1977), is most commonly, at least in the initial stages, made up of follicular structures of variable size, which are very likely to be the malignant counterpart of the secondary lymphatic follicle, since they contain two proliferating cell types which are present in the normal follicles in various proportions, depending on their functional activity (Lennert and MüllerHemerlink, 1975). De novo diffuse centroblasticcentrocytic ML is uncommon, while in a number of cases follicular and diffuse patterns are present at the same time. Cytologically, the neoplastic population is made up of centrocytes, which are identical with those described previously, and of centroblasts which may also show some variation in size. Their nucleus is round and contains a delicate chromatin network with two or three prominent nucleoli, which are adjacent to the nuclear membrane. The cytoplasm is basophilic and pyroninophilic and does not contain PAS-positive material. In imprints, centrocytes and centroblasts reveal a moderate acid phosphatase activity. 5'-Nucleotidase and adenosinetriphosphatase activities were found at the cellular membrane of centroblasts and centrocytes (Lennert and Rinnerberg, 1961; Müller-Hermelink, 1974;
Kaiserling, 1977a). A variant of this lymphoma with a variable degree of sclerosis was described by Bennett and Millett (1969) and has a better prognosis (Bennett, 1975).

Proteinaceous, eosinophilic, and PAS-positive precipitate is present in some of the neoplastic follicles (Rosas-Uribe et al., 1973). Intercellular accumulation of immunoglobulin and/or antigenantibody complexes in neoplastic follicles is much less evident than it is in benign hyperplastic germinal centres (Braylan and Rappaport, 1973). The presence of dendritic reticulum cells may already be suspected on light microscopy in sections and in smears, but it can be better demonstrated ultrastructurally (Lennert and Niedorf, 1969; Glick et al 1975; Lennert and Müller-Hermelink, 1975; Levine and Dorfman, 1975). When the centrocytes predominate, as is more commonly the case, the histological diagnosis of nodular, poorly differentiated lymphocytic ML is usually applied. When centrocytes and centroblasts are present in a similar proportion, then the diagnosis of nodular mixed lymphocytic and histiocytic ML is usually made, whereas when the large cells predominate, the diagnosis of nodular histiocytic ML is applied. The most common combinations are the first and the second. The mitotic index is usually low, but it is increased when the centroblasts predominate. Follicular lymphomas may maintain their follicular pattern for a long time, even until the death of the patient (Warnke et al., 1977); however, they may also tend to transform into the diffuse form (Fig. 13), while the reverse has never been observed (Rappaport et al., 1956). The morphological steps of the transformation from the follicular to the diffuse type of growth pattern have already been illustrated (Rappaport et al., 1956; Rappaport, 1966; Lukes and Collins, 1975). The evolution to the diffuse growth may either not produce changes in the cellular population or accompany an abrupt increase either of centroblasts or, rarely, of anaplastic centrocytes. The increase of the centroblastic component is paralleled by the increase of the cellular proliferation rate, as has been shown by cell kinetic studies (Silvestrini et al., 1977). Centroblasticcentrocytic ML may eventually undergo an anaplastic transformation, and in that case identification of the histological type becomes difficult. Differential diagnosis between centrocytic and centroblasticcentrocytic, diffuse ML has been discussed in detail (Kaiserling, 1977a).

Malignant lymphomas made up exclusively or almost exclusively of cells identifiable as malignant centroblasts, that is, large, round cells with basophilic cytoplasm and a vesicular nucleus with two to three nucleoli adjacent or adeherent to the nuclear membrane (Fig. 14), are usually diagnosed as histio- 

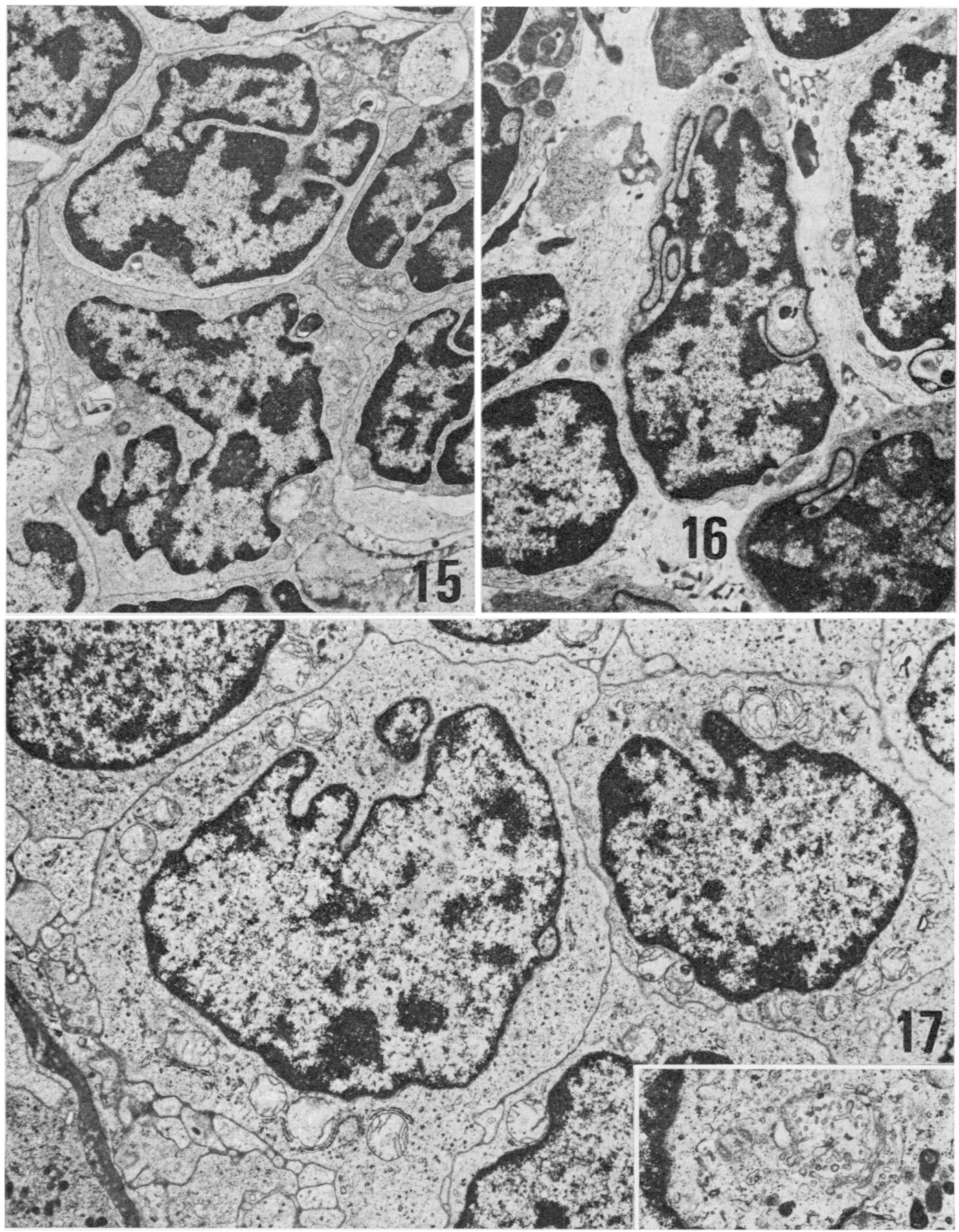

Fig. 15 Malignant lymphoma, centrocytic. Two centrocytes showing deeply indented nuclei with condensed chromatin and small nucleoli. $(\times 10000)$

Fig. 16 Malignant lymphoma, centroblastic-centrocytic, diffuse. A centrocyte with nuclear blebs. $(\times 11000)$

Fig. 17 Malignant lymphoma, centrocytic, large cell subtype. The large centrocytes have an indented nucleus with diffuse chromatin. $(\times 10000)$ Inset: the Golgi apparatus is more developed than in the usual centrocytes. $(\times 22000)$ 
cytic ML. In sequential biopsies of centroblasticcentrocytic ML and at necropsy (Lennert, 1976) of former centroblastic-centrocytic $M L$, the transformation into a pure centroblastic ML (germinoblastic sarcoma) may become evident and should be considered as the transition to a high-grade $\mathrm{ML}$ with a poor prognosis. Although infrequently, primary centroblastic malignant lymphomas do exist as de novo malignancies and may occasionally be follicular (Kaiserling, 1977a), even if more often they appear with a diffuse growth pattern. The most prominent feature of centroblastic ML is the uniform proliferation of highly malignant-looking cells, which retain the morphological and immunological characteristics of the centroblast. Cytologically, these cells are larger and different from those of Burkitt type ML, in which the nucleoli are more variable in number and size and commonly not adherent to the nuclear membrane and the cytoplasm is more deeply basophilic and contains lipidic droplets. Quite often the proliferating cell population is also made up, in addition to the malignant centroblasts, of some immunoblasts and centrocytes. Immunological studies on six cases of large cell ML, which developed in patients with a previous diagnosis of 'nodular' lymphoma, revealed the persistence of B-lymphocyte markers (Jaffe et al., 1977).

Ultrastructurally, the centrocytes have a diameter $(5-10 \mu)$ and cytoplasmic characteristics that approach those of the small circulating lymphocytes, from which they differ mainly in the morphology of their nuclei. Centrocytes (Fig. 15) have a deeply cleaved nuclear membrane, which confers on the nucleus a characteristic lobed appearance with lobes connected by narrow bridges. Heterochromatin is less dense than it is in normal small lymphocytes, and nucleoli are inconspicuous or absent. Nucleolar pockets (blebs) are sometimes found (Fig. 16). The cytoplasmic areas surrounded by the nuclear pockets occasionally contain strictly interlaced tubules of smooth endoplasmic reticulum (Fig. 16). Their scanty cytoplasm contains a few small mitochondria and rough endoplasmic reticulum cisternae, a small Golgi apparatus, and numerous monoribosomes. Centrioles, lipid droplets, small microfilament bundles, and lysosome-like dense granules are observed in some cells. Neoplastic centrocytes are similar to normal cells but their nuclei are more wrinkled and show a larger number of blebs than do those of normal cells.

Large centrocytes (Fig. 17) have similar twisted nuclei but are larger (7-14 $\mu$ in diameter) and show more signs of morphological activation than do the small centrocytes. The chromatin is more dispersed, the nucleoli, the Golgi apparatus (Fig. 17, inset), and the rough endoplasmic reticulum are more promi- nent, and polyribosomes and mitochondria are more abundant than they are in small centrocytes.

The centroblasts (Fig. 18) measure 7 to $30 \mu$ in diameter, have large oval or oblong nuclei, dispersed chromatin, and one or more prominent nucleoli with a well-developed nucleolonema. Nucleoli are either central or placed against the nuclear membrane. Although the nuclei of centroblasts may show some irregularities, these are not as conspicuous as they are in centrocytes. Nuclear blebs are seldom observed. Polyribosomes are much more abundant and larger than they are in centrocytes, while monoribosomes are rarely present in the cytoplasm. Several electron-lucent mitochondria, a welldeveloped Golgi apparatus, a small amount of granular and agranular endoplasmic reticulum, and a few lysosomes are also found in the cytoplasm. Nuclei of neoplastic centroblasts occasionally disdisplay more indentations and irregularities than do those of normal cells.

In a few cases of centroblastic-centrocytic ML, both tumour cell types (Figs 19, 20), and especially the centrocytes, have a well-developed rough endoplasmic reticulum (Kaiserling, 1977a). The long and flat cisternae either assume a circular arrangement around the nucleus (Fig. 20) or form whirl-like structures. The cells with a well-developed endoplasmic reticulum also present more numerous mitochondria and lysosome-like dense bodies (Fig. 20 , inset) and a better developed Golgi apparatus than do the usual centroblasts and centrocytes.

Dendritic cells are easily observed among tumour cells in follicular centroblastic-centrocytic ML. Such cells are less common in the diffuse variant (Levine and Dorfman, 1975). The dendritic cell plasma membrane forms long, branch-like processes, which sometimes interdigitate with those of other dendritic cells. Junctional apparatuses of the macula aderens type are observed at the sites of membrane contact (Fig. 21). Numerous fine cytoplasmic filaments condense, especially in connection with desmosomes. Phagocytosis is absent. The dendritic cell nucleus has a characteristic wavy shape. Chromatin is diffusely dispersed and only slightly condensed along the nuclear membrane. Nucleoli have a welldeveloped nucleolonema. An inconspicuous Golgi apparatus, scattered mono- and polyribosomes, a few mitochondria and rough endoplasmic reticulum cisternae, and rare ribosomes are present in the cytoplasm.

The concept that the ML described above are actually neoplasms of germinal centre cells has been strongly supported by immunological studies. Complement receptors were reported to be characteristic of B cells within lymphoid follicles (Braylan et al., 1975; Jaffe et al., 1974a, 1975), while surface 

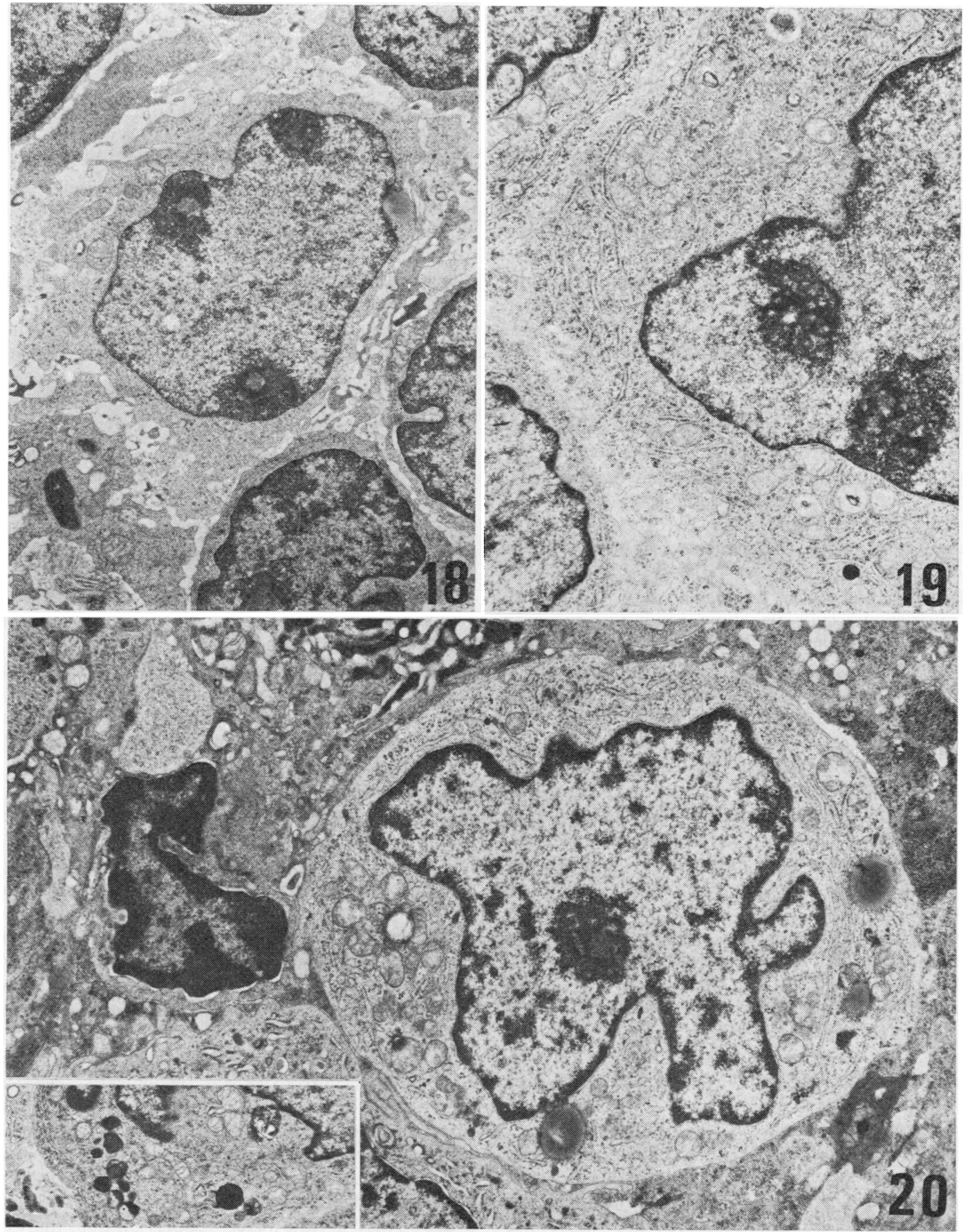

Fig. 18 Malignant lymphoma, centroblastic-centrocytic. A centroblast presenting a roughly oval nucleus with dispersed chromatin and three well-developed nucleoli adjacent to the nuclear membrane. $(\times 9000)$

Fig. 19 Malignant lymphoma, centroblastic-centrocytic, diffuse. A centroblast with well-developed rough endoplasmic reticulum. $(\times 12000)$

Fig. 20 Malignant lymphoma, centroblastic-centrocytic, diffuse. A centrocyte with abundant flat endoplasmic reticulum cisternae and some lipid droplets. $(\times 12000)$ Inset: numerous lysosome-like dense bodies in a centrocyte with abundant rough endoplasmic reticulum. $(\times 9000)$ 
immunoglobulin-bearing $\mathbf{B}$ cells are distributed in both follicles and the medullary cords. It was shown that follicular lymphomas are of B-cell type origin and that all their cells have complement receptors and the majority bear surface immunoglobulin (GajlPeczalska et al., 1973; Shevach et al., 1973; Jaffe et al., 1974a; Aisenberg and Long, 1975; Leech et al., 1975a; Bloomfield et al., 1976). The same applies to centrocytic ML (Stein, 1975). The cells of follicular lymphomas have neither receptors for cytophilic antibody nor do they form spontaneous $E$ rosettes. The presence of the complement receptor is unrelated to the cytological subtype of follicular lymphoma, although a loss of these receptors was reported during the transition from the nodular to the diffuse pattern (Crossman et al., 1977). Except for a few IgG-containing cells, none of the tumour cells contains cytoplasmic immunoglobulin (Johansson et al., 1976). In contrast to B-CLL lymphocytes, the small follicular centre cells of cases with leukaemic manifestations and either a nodular or diffuse structure show a lesser tendency to form rosettes with mouse erythrocytes (Koziner et al., 1977). Quite conceivably, the cells of diffuse centroblasticcentrocytic ML with anaplasia may behave as 'receptor-silent' cells or show immature receptor profiles, as has been reported (Habeshaw et al., 1977) for some diffuse, mixed, and histiocytic ML, which correspond to large cleaved and non-cleaved follicular centre cell ML described by Lukes and Collins (1974).

It has been postulated that for the characterisation of centroblastic-centrocytic ML, further investigation of the tissue between the neoplastic follicles may yield significant additional information. In fact, morphologically on light and electron microscopy, the interfollicular tissue contains many structures (postcapillary venules with recirculating lymphocytes, T-associated plasma cells, interdigitating reticulum cells) that are characteristic of the paracortical area of lymph nodes (Kaiserling, 1977a). In addition, immunologically, at the periphery of the neoplastic follicles, an unforeseen accumulation of $T$ lymphocytes has been detected (Jaffe et al., 1977). Whether this finding should be interpreted as a host defence or as a process relevant to the follicular tumorigenesis remains a challenging question.

In a number of cases, ML of germinal centre cell origin presents with leukaemic spread, the first description of which may be identified in the report of Isaacs (1937). He reported a type of lymphocytic leukaemia associated with lymphosarcoma in the lymph nodes, which he believed to be different from other types of lymphocytic leukaemia. Lymphosarcoma cell leukaemia may occur either as an early phenomenon (early leukaemic lymphosarcoma) or may appear as a late manifestation (late leukaemic lymphosarcoma) (Mathé et al., 1976). In all cases of blood involvement the marrow is invariably infiltrated, but whether or not marrow infiltration without blood involvement should be considered leukaemic conversion is debatable (Wintrobe et al., 1974).

Owing to the use of the Rappaport classification, in which nodular, poorly differentiated lymphocytic ML comprise pseudonodular centrocytic as well as follicular centroblastic-centrocytic ML, and diffuse, poorly differentiated lymphocytic ML comprise centrocytic and centroblastic-centrocytic diffuse ML, it is difficult to reinterpret previous reports, since quite often nodular and diffuse ML cases are reported together. The impression that one gains, however, is that in both instances centrocytes are the most frequently circulating cell type (Figs 22 and 23). In any case, centrocytes in blood smears and in marrow smears bear striking similarities to the 'notchednucleus' cells described by Anday and Schmitz (1952) in follicular lymphomas, to the "haematogones' described by Rosenthal et al. (1952) also in follicular lymphomas, and to the cells observed in some of the cases described by Schwartz et al.(1965). The same cell type corresponds to the third type of leukaemic lymphosarcomas described by Mathé et al. (1975b) and to the notched-nucleus lymphocytes described by Spiro et al. (1975). The cytoplasm may contain vacuoles, azurophilic granules, and basophilic granules, which appear structureless on electron microscopy (Wintrobe et al., 1974). In a series of 16 cases with lymphosarcoma cell leukaemia (Schnitzer et al., 1970) lymph node biopsy revealed a poorly differentiated lymphocytic ML, which was diffuse in six and nodular in 10 cases. In the majority of diffuse ML leukaemia was present at diagnosis but was a later manifestation in the nodular cases. The changes in the course of the disease were also demonstrated by the fact that, at the time of necropsy, one case only had maintained the nodular structure of the lymphoma, while the others had changed towards a diffuse pattern.

In the blood of centroblastic-centrocytic follicular ML, mostly centrocytes are recognisable, whereas centroblasts may be found only occasionally (Lennert, 1969). The circulating centrocytes reveal the same previously described immunological surface markers as do the cells in the solid tumour, thus confirming their B-type nature and germinal centre origin. There are, however, reports on dual markers for B and T cells detected in cases of lymphosarcoma cell leukaemia (Hsu et al., 1975; Lin and Hsu, 1976).

In a survey of 75 cases of follicular lymphoma, among which all cytological subtypes (small and large cells) were represented, 25 cases were found to 
have abnormal cells in the blood (Spiro et al., 1975). In 17 the blood lymphocyte count ranged between 5 and $30 \times 10^{9} / 1$, and in another eight cases it was below $5 \times 10^{9} / 1$; in all these cases, however, the marrow aspirate films showed neoplastic lymphocytic infiltration made up of abnormal notched-nucleus cells. These were also found in blood films of cases of nodular lymphoma with large cell type predominance (histiocytic). The most important defining characteristic of the circulating cells, in addition to the nuclear clefts of varying depth, was the chromatin pattern, which was more homogeneous than was that of the small lymphocytes and did not reveal any structure made up of coarse blocks of densely stained chromocentres. In addition to the cells with the indented nuclei, other circulating cells with scanty basoplilic cytoplasm and barely perceptible nuclear notches were identified in the blood.

Examination of marrow trephine biopsy sections at the time of initial diagnosis of follicular lymphomas reveals a high percentage with involvement (Dick et al., 1974; McKenna et al., 1975; Castellani et al., 1977), although the degree of infiltration and the pattern of distribution is variable (Jones et al., 1972, 1973; Dick et al., 1974). Marrow films are somewhat less reliable. For diffuse, poorly differentiated lymphocytic ML, marrow invasion was found by trephine in about $30 \%$ of cases. Marrow involvement by nodular lymphomas with predominantly small cells (nodular lymphocytic, poorly differentiated) was much more frequently encountered than in those with large cells (nodular histiocytic) (Jones et al., 1972, 1973).

With regard to the cell types encountered in marrow invasion, the morphological description of a small cell (7-10 $\mu$ in diameter) with an irregularly cleaved nucleus, small inconspicuous nucleoli, and scanty, lightly basophilic cytoplasm corresponds to that of a centrocyte, small cleaved follicular centre cell (Lukes and Collins, 1974), small nodular lymphoma cell (McKenna et al., 1975), 'haematogone' (Rosenthal et al., 1952), and the lymphocytic cell of poorly differentiated lymphocytic ML (Dick et al., 1974). If this is the cell most commonly found in these instances, it is also not uncommon to identify both large cells (which measure up to $20 \mu$ in diameter with a round nucleus, multiple nucleoli, and basophilic cytoplasm) that correspond to centroblasts and cells with features intermediate between the centrocytes and the centroblasts (Dick et al., 1974; McKenna et al., 1975). The rare circulating large cells are cytologically different from immunoblasts inasmuch as their cytoplasm is less basophilic and their large nuclei contain multiple nucleoli rather than a single huge central nucleolus.
The morphological differences between haematogones found in the marrow of children and adults in health and in various pathological conditions and the neoplastic haematogones (Rosenthal et al.,1952) have been noted by McKenna et al. (1975). On the other hand, the occasional finding of cells similar to small centrocytes in marrow films in various non-neoplastic haematological conditions has also been reported (McKenna et al., 1975). It seems, therefore, that this cell type is sufficiently distinct to be differentiated on cytological grounds alone from the small lymphocyte.

In summary, almost all the reports on the leukaemic manifestations of poorly differentiated lymphocytic ML, both nodular and diffuse, and of nodular ML of other cell types clearly indicate that the haematological, morphological, and immunological features observed are different from those of CLL. It appears that in these cases the circulating cells are exclusively or predominantly centrocytes, which may reveal more or less accentuated features of atypia, whereas the presence of centroblasts is much less common. The need for a better correlation in the future between histological and haematological cell morphology of leukaemic, poorly differentiated lymphocytic ML is justified, since immunological differences between diffuse and nodular types of ML have been reported (Aisenberg and Long, 1975; Aisenberg and Wilkes, 1976). In fact, clinical and haematological differences between the purely centrocytic diffuse and the follicular centroblastic-centrocytic ML do exist. The greater tendency towards generalised dissemination and marrow invasion (Castellani et al., 1977), and leukaemic change in some cases with a high WBC and a fulminant course, in addition to the existence of the large cell variant (Silvestrini et al., 1977), are some of the distinguishing features of centrocytic ML versus follicular centroblastic-centrocytic ML, which in turn are more frequently associated with a chronic leukaemic manifestation. At the same time it is fair to add that the importance of these distinctions has been doubted (Dorfman, 1977).

\section{BURKITT LYMPHOMA}

In spite of clinical (Levine et al., 1975), epidemiological, immunological (Epstein et al., 1976), and virological (Zur Hausen, 1975; Andersson et al., 1976; Ziegler et al., 1976) differences between endemic African (Burkitt, 1958) and sporadic African and non-African (O'Conor et al., 1965; Burkitt, 1967) Burkitt lymphomas, their morphological-cytological expressions are very similar (Berard et al., 1969). This tumour has been considered as the most classic example of an undifferentiated ML because of its uniform and 
monomorphic cellular population without evidence of maturation. In section, the cells measure 7 to $12 \mu$ and have roundish or oval nuclei, which contain two to five prominent basophilic nucleoli, usually not adherent to the nuclear membrane. Abnormalities of the nuclear membrane, such as indentations, are commonly absent. The chromatin is usually made up of large, coarse chromocentres, and the mitotic index is high. The cytoplasm is amphophilic and pyroninophilic and contains small vacuoles.

In imprints of tumour tissue, the cells measure 10 to $25 \mu$ in diameter and have a deeply basophilic cytoplasm. The cytoplasm is usually not abundant and contains droplets of neutral Oil Red O-positive lipids, which correspond to well-defined clear vacuoles in alcohol-fixed preparations.

Furthermore, the cytoplasm usually does not contain PAS-positive material, except for rare coarse granules, and does not reveal any non-specific esterase of peroxidase activity. Small amounts of acid phosphatase may be present. Alkaline phosphatase activity could be demonstrated in some cells (Nanba et al., 1977a). Macrophages reveal a high content of acid phosphatase and non-specific esterase.

A common but not constant phenomenon is the large number of 'tingible body' macrophages similar to those of the secondary follicle among the tumour cells. These are the cells whose relative pallor contrasts in sections with the dark, nuclear-dense masses of lymphoma cells to produce the well-known but non-specific 'starry-sky' appearance. The macrophages contain cellular debris and ingested tumour cells. Dendritic reticulum cells, however, are absent (Kaiserling, 1977a).

Electron microscopically, the picture is also dominated by large lymphoid blast cells mixed with a varying number of non-malignant histiocytes (Epstein and Barr, 1965). In the blast cells the nuclear:cytoplasmic ratio is high (Epstein and Achong, 1965; Flandrin et al., 1975). The pale nuclei are round or oval and occasionally slightly indented. Heterochromatin is scarce and placed along the nuclear membrane. Nuclear blebs are frequently observed. Nucleoli are prominent. The cytoplasm contains a few endoplasmic reticulum cisternae and a characteristically large number of free ribosomes and polyribosomes. Well-developed polarised mitochondria, lipid droplets, probably made up of hydrophobic unsaturated lipids (Feremans et al., 1976), and clear vesicles are also found. The Golgi apparatus is usually inconspicuous but occasionally is relatively well developed. Annulate lamellae are observed in some cases (Epstein and Achong, 1965). The plasma membrane is generally smooth.

The cells of Burkitt lymphoma have been con- sidered to derive from germinal centre cells (small centroblasts) because of their similarities to the normal counterpart within the lymphatic germinal follicle (Lukes and Collins, 1974). Immunologically, in many cases of both African endemic and nonAfrican sporadic Burkitt lymphoma, monoclonal surface-bound immunoglobulin was identified on the malignant cells (Klein, 1971). Tumour cells have been shown to synthesise immunoglobulin also in tissue cultures (van Furth et al., 1972). The same finding, that is, the presence of surface IgM (and occasionally of IgG) with $\lambda$ light chains, was demonstrated in neoplastic leukaemic cells of non-endemic American Burkitt lymphomas (Flandrin et al., 1975; Mann et al., 1976). In addition, complement receptors (Nussenzweig et al., 1971; Shevach et al., 1972; Stein, 1975) and receptors for aggregated IgG (Flandrin et al., 1975) were identified on a number of cells. Burkitt cells do not form spontaneous $E$ rosettes (Flandrin et al., 1975). Differences in surface marker patterns were reported for endemic Epstein-Barr virus (EBV) genome-containing and for sporadic EBV-negative Burkitt ML (Epstein et al., 1976).

The most relevant recent morphological finding in biopsies and necropsies is the involvement of germinal centres of lymph nodes and Peyer's patches (Mann et al., 1976). In particular, the confinement of foci of Burkitt ML to single germinal centres further supports the suggestion that this lymphoma should be considered a tumour of germinal centre origin. Some remaining uncertainties on the nature of the proliferating tumour cells, their 'lymphoblastic' (that is, immature lymphoid) appearance, the prevalence of the tumour in childhood, and its occasional acute leukaemic manifestation suggested its inclusion among high-grade lymphoblastic ML of the Kiel classification.

Marrow invasion (Wright, 1968) is quite variable; it develops in about 10 to $20 \%$ of cases in Africa and is even more common outside Africa (Levine et al., 1975; Brearley et al., 1977). No correlation between the percentage of lymphoma cells in marrow or blood was found in non-African cases (Brunning et al., 1977). The leukaemic manifestation may be present at onset (Bluming et al., 1972) or may develop terminally. The terminal leukaemic pattern is quite rare in Africa (Clift et al., 1963), and its morphology is that of an ALL of B-cell type (Chessells et al., 1977). Outside Africa, Burkitt type ALL has been reported to represent $2 \%$ of all ALL (Flandrin et al., 1975). In African (Manolov and Manolova, 1972) and non-African (Hübner and Littlefield, 1975; Philip et al., 1977) Burkitt ML, structural chromosomal abnormalities were found. 

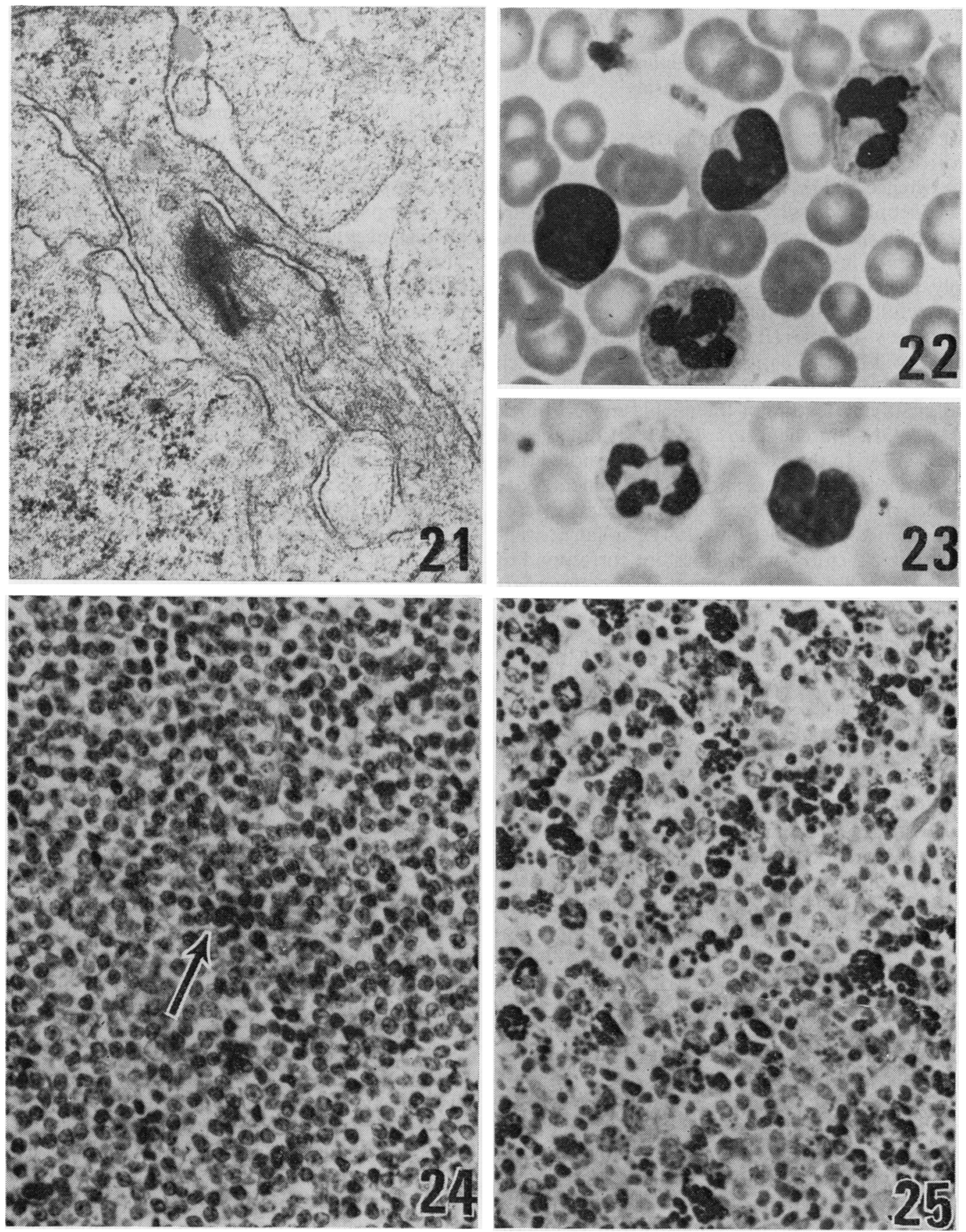

Fig. 21 Malignant lymphoma, centroblastic-centrocytic, follicular, and diffuse. A junctional apparatus between the process of two dendritic reticulum cells. $(\times 51000)$

Fig. 22 Malignant lymphoma, centrocytic. Leukaemic blood smear:WBC $26.5 \times 10^{9} / l$. Circulating centrocytes $26 \%$. Two atypical centrocytes. (May Grünwald-Giemsa $\times 1000$ )

Fig. 23 Malignant lymphoma, centroblastic-centrocytic. Leukaemic blood smear: WBC $21 \cdot 7 \times 10^{9} /$ l. Circulating centrocytes $95 \%$. An atypical centrocyte. (May Grünwald-Giemsa $\times 1000$ )

Fig. 24 Malignant lymphoma, lymphoplasmacytoid: axillary lymph node, 60-year-old woman. Diffuse growth of small round cells with scattered PAS-positive Russell bodies (arrow). $(P A S \times 400)$

Fig. 25 Malignant lymphoma, lymphoplasmacytoid polymorphous: cervical lymph node, 47-year-old man. Numerous variably sized Russell bodies. (PAS × 400) (Courtesy of Professor L. Tropeano, Rho). 
Malignant lymphoma of immunoglobulin-secreting cells and lymphoplasmacytic dyscrasias

\section{LYMPHOPLASMACYTOID MALIGNANT \\ LYMPHOMA}

The existence of ML in which a variable proportion of the neoplastic cells show mature or immature plasmacytic or plasmacytoid features is fully recognised. While in some classifications of ML it has simply been stated that some subtypes may show plasmacytoid 'differentiation' without therefore creating new subtypes (Bennett et al., 1974), in other schemes well-defined entities are recognised in which the mature and/or immature plasma cell component is the qualifying feature of the neoplasm (Dorfman, 1974; Gerard-Marchant et al., 1974; Lukes and Collins, 1974). In this context it should be noted that discrepancies between morphology and function are not uncommon; one example is primary macroglobulinaemia (Waldenström, 1944), a fairly welldefined clinical entity, which does not correspond to a similarly well-defined morphological counterpart (Stein et al., 1972).

Primary macroglobulinaemia is a progressive and systemic lymphoproliferative disease, which is associated with monoclonal IgM production. In the proliferating cells $\mu \kappa$ and/or $\mu \lambda$ immunoglobulin was identified, even in paraffin sections, by the immunoperoxidase technique (Pinkus and Said, 1977). The morphological heterogeneity of primary macroglobulinaemia is visualised by the fact that in many cases the predominant proliferating cell type is either the small lymphocyte (Pangalis et al., 1977) or the plasmacytoid lymphocyte (Lennert et al., 1975b; Lukes and Collins, 1975), while in other cases more pleomorphic histological pictures were reported. In addition, some of the patients with this disease later develop large cell lymphoid tumours. On the other hand, Lennert et al. (1975c) and Stein et al. (1974b) reported cases of ML that corresponded to the morphological patterns described above in which macroglobulinaemia could be detected only in a minority of the cases but in which accumulated monoclonal and occasionally polyclonal immunoglobulin could be detected within the tumour tissue. Finally, the identification of ML, still with the same morphology but with production of $\operatorname{IgG}$ or $\operatorname{IgA}$, made the existence of Waldenström's macroglobulinaemia as a pathological entity questionable. From a diagnostic point of view it seems more important to realise that the existence of ML made up of lymphocytes with plasmacytoid features or of mixtures of lymphocytes and plasma cells with increased tissue immunoglobulin should be recognised, regardless of whether or not there is a monoclonal increase of IgM or of other immunoglobulin in the serum.

A number of cases of lymphoplasmacytoid ML have probably been diagnosed in the past as diffuse well-differentiated lymphocytic ML, as was recently pointed out by Pangalis et al. (1977), who found that $90 \%$ of patients with this lymphoma associated with monoclonal gammopathy revealed plasma cells and/ or plasmacytoid lymphocytes in their neoplasms. The same type of tumour is considered a distinct entity among B-cell type ML that derive from the plasmacytoid lymphocyte (Lukes and Collins, 1974).

The morphological normal counterpart of one of the proliferating cells has been identified by Lennert (Lennert and Müller-Hermelink, 1975) as the lymphatic plasma cell originally described by Moeschlin. This cell is smaller than the classic reticulum or Marschalko (1895) plasma cell, has a smaller Golgi body, and a scanty cytoplasm, and the nucleus is not eccentric. However, the structure of the cytoplasm does not differ qualitatively on electron microscopy from that of the reticulum plasma cell, but on the surface of circulating lymphatic plasma cells IgM could be detected (Lennert and Müller-Hermelink, 1975). It has been postulated that lymphatic plasma cells may originate rapidly from B lymphocytes, bypassing the stage in the follicular centres, and become responsible for IgM synthesis. Reticulum plasma cells after maturation within the germinal centres (Nieuwenhuis and Keuning, 1974) are responsible foro the production of IgG and IgA. Therefore, lympho-: plasmacytoid ML were defined also as immunocytomas (Stein et al., 1974b; Lennert et al., 1975c) with reference to the functional nomenclature proposed by Dameshek (1967).

Three main histological variants of lymphoplasmacytoid ML can be recognised (Lennert et al., 1975c; Schwarze et al., 1976) in sections of lymph nodes or in other common extranodal sites, such as the subcutaneous tissue, the orbit, the leptomeninges, and the gastrointestinal tract (Rilke et al., 1978b). The first variant is the lymphoplasmacytic subtype, which is made up of a mixture of small lymphocytes, identical with those of CLL, and of immature as well as mature Marschalko-type plasma cells. The second variant is the lymphoplasmacytoid ML in which, in addition to some lymphocytes, there is a uniform proliferation of lymphatic plasma cells, which are slightly larger than the lymphocytes and have a scanty, homogeneous basophilic cytoplasm. The nucleus is central or slightly eccentric and contains moderately coarse or delicate chromatin and a barely visible central nucleolus. Mast cells are more numerous than they are in CLL, and their number helps in the differential diagnosis in equivocal cases (Satodate et al., 1977). The reticulin fibre network is fairly abundant. 
The third variant is the pleomorphic lymphoplasmacytoid ML in which a mixture of lymphocytes, lymphatic plasma cells, centroblasts, centrocytes, and immunoblasts dominates the picture. It has been shown that the degree of pleomorphism of this ML parallels the proliferation rate (Silvestrini et al., 1977). Pleomorphic malignant lymphomatous proliferations with plasmacytic differentiation, polyclonal hyperimmunoglobulinaemia, and autoimmune haemolytic anaemias were reported (Flandrin et al., 1972).

The cytoplasm of the proliferating cells often shows a diastase-resistant, granular PAS positivity, which is related to the glycoprotein content. In addition, in a very variable number of cells there are round globular inclusions both in the cytoplasm (Figs 24 and 25) and in the nuclei that are PAS positive (Kaiserling et al., 1973); they represent accumulated immunoglobulin, mostly IgM but occasionally also IgG or IgA (Stein et al., 1972). In about $30 \%$ of these cases, immunoglobulin of the same class in the serum may be increased. The cytoplasmic inclusions have been referred to as Russell's bodies (Russell, 1890) and the intranuclear inclusions as Dutcher's bodies (Dutcher and Fahey, 1959). Intranuclear material seems to derive from extranuclear accumulation of immunoglobulin in the perinuclear cisternae, with subsequent invagination into the nuclear structure (Brunning and Parkin, 1976).

All lymphoplasmacytoid ML show a diffuse proliferation pattern with occasional pseudonodular configuration. Remnants of secondary follicles may persist. Evolution to basophilic large cell immunoblastic ML can occur (Lennert et al., 1975b). Leukaemic manifestation develops in about onethird of the cases and is associated with a moderately high WBC count, which seldom exceeds $30 \times 10^{9} / 1$. The clinical picture of CLL may predominate, particularly in cases that may be considered borderline, such as those reported in a retrospective study on a series of cases of CLL among which a certain percentage was actually characterised by a leukaemic proliferation of lymphoplasmacytoid cells (Rudders, 1976). In marrow and blood smears the same cells can be identified and differentiated from CLL lymphocytes by virtue of their cytoplasmic basophilia and the slightly larger area of the cytoplasm. The leukaemic manifestation of immunocytomas occasionally shows the cytological pattern of plasma cell leukaemia.

The description of a method for the demonstration of specific immunoglobulin in plasma cells and lymphoplasmacytoid cells in formalin-fixed and paraffinembedded material using a peroxidase-conjugated antibody and an indirect sandwich technique
(Taylor and Burns, 1974) has greatly facilitated the identification of the function of these cells in benign and neoplastic conditions. The electron microscopic investigation of a series of lymphoplasmacytoid ML shows a wide spectrum of morphological variations, ranging from a pattern that consists of a large number of lymphocytes and a much smaller number of plasma cells, lymphoplasmacytoid cells, and immunoblasts, to an almost typical plasmacytoma. In some cases centroblasts and centrocytes are also found. Quite often the neoplastic cells are indistinguishable from normal cells.

Lymphoplasmacytoid cells (Fig. 26) have a nucleus with abundant heterochromatin and an inconspicuous nucleolus, similar to the nucleus of the small circulating lymphocytes. In the cytoplasm, more or less abundant long and flat rough endoplasmic reticulum cisternae, placed around the nucleus, are observed (Lennert and MüllerHermelink, 1975). Plasma cells with the mature appearance of the Marschalko type have a very abundant rough endoplasmic reticulum, a large Golgi apparatus, and nuclear chromatin, which forms clumps lying against the nuclear membrane; they may also have a nucleus with diffuse chromatin and less abundant rough endoplasmic reticulum, indicating a lesser degree of maturation (Fig. 27). It is frequently possible to follow a spectrum of morphological variants from the plasmacytoid cells to the plasma cells. Deeply indented lobed nuclei are frequently observed in plasma cells of some cases of immunocytoma (Fig. 28) and plasma cell leukaemia (Klein et al., 1977).

Immunoblasts have a cytoplasm that contains a scanty endoplasmic reticulum, very numerous polyribosomes, and a well-developed Golgi apparatus. The nucleus is round with dispersed chromatin and large nucleoli (Florentin, 1975).

Intranuclear inclusions, which are bound by a single membrane and which usually contain a granular or fibrillar material (Kuhn, 1967; Mori and Lennert, 1969; Cawley and Hayhoe, 1973), are observed in both plasma cells and lymphoplasmacytoid cells. These inclusions correspond to the PASpositive Dutcher bodies (Dutcher and Fahey, 1959; Napoli et al., 1977). Russell bodies (Fig. 28) and crystalline inclusions of the rough endoplasmic reticulum are also occasionally observed (Bessis, 1961; Argani and Kipkie, 1965).

As for the possible derivation of lymphoplasmacytoid ML, their relationship to both germinal centre cells and cells that develop outside germinal centres has been considered (Kaiserling, 1977a): in one-half of the cases complement receptors as well as surface immunoglobulin may be detected on the cells, whereas in the other half no complement receptors are 

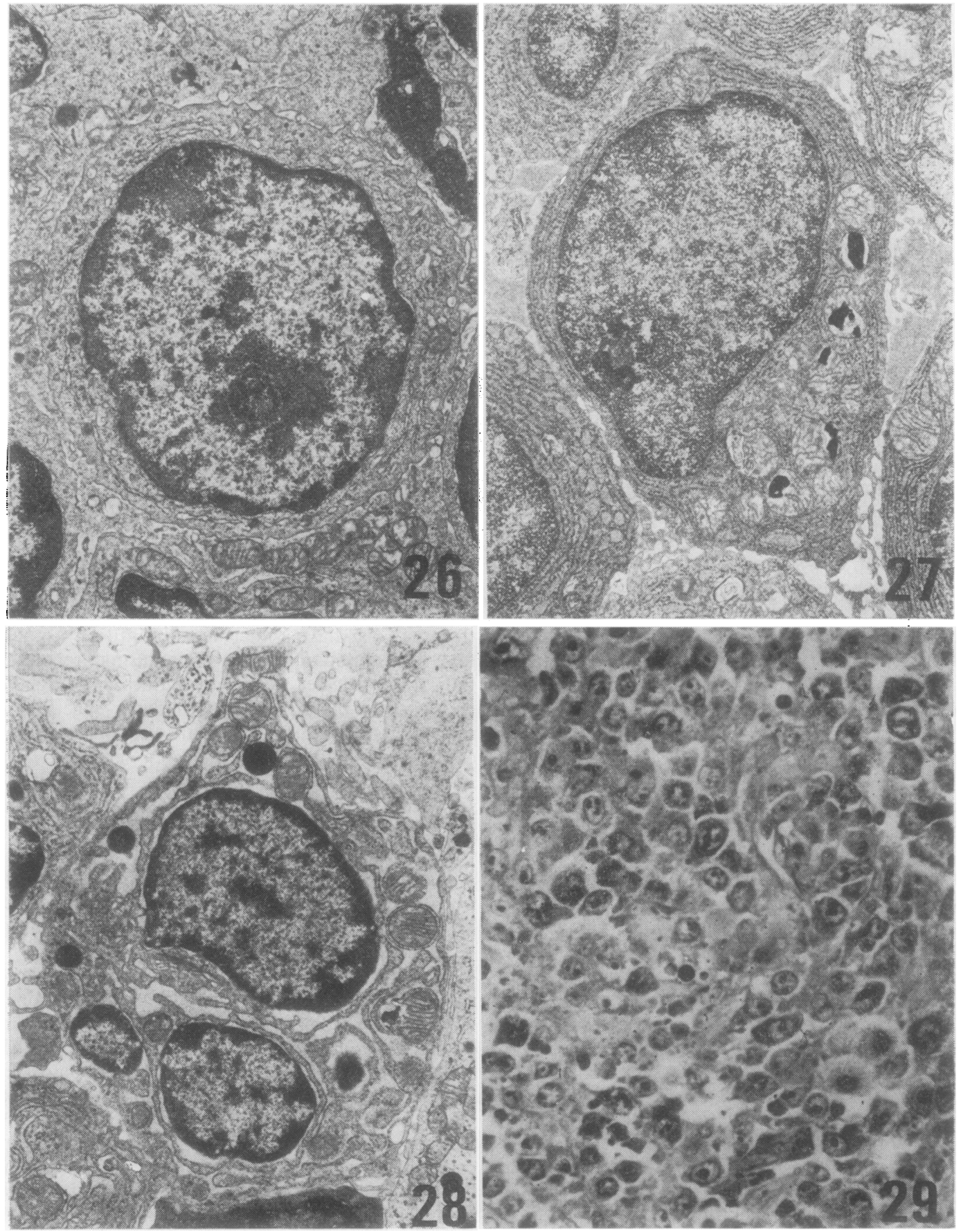

Fig. 26 Malignant lymphoma, lymphoplasmacytoid polymorphous. A lymphoplasmacytoid cell with abundant heterochromatin, an inconspicuous nucleolus, and flat endoplasmic reticulum cisternae placed around the nucleus. $(\times 12000)$

Fig. 27 Malignant lymphoma, lymphoplasmacytic. An immature plasma cell that shows a nucleus with diffuse chromatin and a small nucleolus. Dense inclusions are observed in the mitochondria. $(\times 12000)$

Fig. 28 Malignant lymphoma, lymphoplasmacytoid polymorphous. A plasma cell with a lobed nucleus and Russell bodies within the rough endoplasmic reticulum cisternae. $(\times 11000)$

Fig. 29 Malignant lymphoma, immunoblastic: axillary lymph node, 66-year-old man. Diffuse proliferation of large cells with basophilic cytoplasm and large central nucleolus. A few cells reveal plasmacytoid features. (Giemsa $\times 400$ ) 
found (Stein, 1975). Lymphoplasmacytoid ML have therefore been considered neoplasms of B cells, the range of which goes from cells that are halfway between the non-secreting and the secreting stage to those that are capable of secretory activity but in a majority of the cases are unable to discharge the product into the blood (Stein, 1975). In fact, less than one-third of the cases of lymphoplasmacytoid ML are diagnosed clinically as Waldenström's disease. Owing to the variable morphological pattern, Waldenström's disease has also been defined as a lymphoplasmacytic dyscrasia with abnormal secretion of monoclonal immunoglobulin. The same definition may also be applied to heavy chain diseases, which are characterised by the secretion of subunits of immunoglobulin.

\section{HEAVY CHAIN DISEASES}

Heavy chain diseases comprise a group of conditions in which populations of lymphoid cells synthesise and secrete immunoglobulin heavy chains that are structurally defective (Buxbaum, 1976). They have also been defined as immunoproliferative disorders which are characterised by the presence in the serum of a monoclonal population of molecules composed of incomplete heavy polypeptide chains which belong to a given class or subclass of immunoglobulin and are devoid of light chains (Warner et al., 1974). Three types have been recognised so far: alpha chain disease (Seligmann et al., 1968), gamma chain disease (Franklin et al., 1964), and mu chain disease (Ballard et al., 1970; Forte et al., 1970).

The diagnosis is based exclusively on non-morphological investigations; the clinical pattern is different from that of multiple myeloma and appears to be extremely variable. Even though in some cases no morphological evidence of abnormal cellular proliferation is found, in most cases mixed patterns similar to those found in macroglobulinaemia are seen in marrow smears and in lymph nodes.

Except for a few cases with a respiratory form of the disease (Florin-Christensen et al., 1974), alpha chain disease affects predominantly the digestive tract, producing malabsorption (Rambaud et al., 1968). Even though alpha chain disease may occasionally be associated with immunoblastic ML of the intestine, in the majority of cases it is associated with what has been defined as Mediterranean lymphoma or immunoproliferative small intestinal disease of Mediterranean type (Rambaud and Matuchansky, 1973). There is a diffuse and massive infiltration of the lamina propria of the intestine by plasma cells and/or lymphocytes (Rappaport et al., 1972; Seligmann, 1975) without evidence of cellular atypia. The proliferation may also be present in mesenteric nodes, but it never spreads to either the marrow or to extra-abdominal sites; it usually begins in the upper small intestine and subsequently involves it completely. The cellular composition varies from completely mature plasma cells to a mixture of plasma cells and lymphocytes or to intermediate lymphoplasmacytoid cells. The mature cell proliferation may occasionally be moderately invasive with atrophy of the intestinal villi. In other cases the proliferating plasma cells are more obviously malignant, and they invade the muscular layer of the intestine. Finally, there are cases in which there is a highly malignant proliferation of immunoblasts, which may or may not be associated with a still evident benign lymphoplasmacytoid proliferation (Ala et al., 1976). A word of caution is needed concerning the neoplastic nature of the most benign types, since the condition is rarely reversible either spontaneously or after antibiotic treatment with disappearance of the plasmacyte excess and of the abnormal alpha chain (Ala et al., 1976). It has been proved that the lymphomas arising late in the course of the intestinal form of alpha chain disease derive from the same B-cell clone as does the initial plasma cell proliferation (Brouet et al., 1975b, 1977; Pangalis and Rappaport, 1977; Ramot et al., 1977). By contrast, 'Western type' ML of the small bowel have clinical and morphological differences and seem to be made up of a different cell type (Lewin et al., 1976).

Gamma chain disease often shows intermediate features between multiple myeloma and ML. It has in common with the former anaemia, frequency of infections, and a variable clinical course, often with severe renal disease. However, there are no lytic bone lesions. In common with ML there is often enlargement of lymph nodes, splenomegaly, and hepatomegaly. It may be associated with a lymphoplasmacytic ML, either leukaemic or non-leukaemic, or with pleomorphic cells in transition to immunoblastic ML. It may occasionally be associated with extra-osseous plasmacytoma and may show plasma cell leukaemia in the terminal phase.

Mu chain disease is rare and has been sometimes. found in association with an immunocytoma (Lennert, personal communication, 1978). In marrow samples, in addition to lymphocytosis, a certain degree of plasmacytosis is found. The plasma cells have been reported to be vacuolated. In both gamma and mu chain disease, cases without evidence of abnormal cell proliferation have also been reported (Seligmann, 1972; Danon et al., 1975).

\section{PLASMACYTIC MALIGNANT LYMPHOMA}

Pure plasmacytic ML of extra-osseous sites was. added later to the low-grade ML of the Kiel classification (Gerard-Marchant et al., 1974). It is equiva-- 
lent to the extramedullary plasmacytoma (Wiltshaw, 1976), which may arise in lymph nodes, in the upper and lower air passages and the lung, in the spleen, in the skin and subcutaneous tissues, in the gastrointestinal tract (stomach, small intestine, large intestine), and less frequently in other sites. It has been shown that extramedullary plasmacytoma is composed of an autonomous and irreversible proliferation of plasma cells of varying degrees of differentiation and has characteristic features, which distinguish it from myelomatosis and from solitary myeloma of the bone (Wiltshaw, 1976). The tumour masses are made up of mature plasma cells of the Marschalko reticular type with an eccentric nucleus and typical arrangement of the chromatin; the nucleus is surrounded by a clear halo, and the cytoplasm is intensely eosinophilic and pyroninophilic and shows diastase-resistant PAS positivity. In addition, less well-differentiated and poorly differentiated plasma cells may be present to a variable extent, and in some cases the tumour is made up of very pleomorphic plasma cells. In these the nuclei are more centrally located and may be multiple, the nucleolus is more prominent, and the cytoplasm is more scarce; however, the perinuclear halo is often still present.

In lymph nodes the plasmacytic ML may be either the primary or the metastasis of an extramedullary plasmacytoma (Fishkin and Spiegelberg, 1976). Extranodal extramedullary plasmacytomas show a high incidence of metastatic spread to soft tissues (Wiltshaw, 1976). It has been pointed out that in spite of the anatomical distribution of plasma cells, which is similar to that of lymphocytes, plasmacytic tumours are rare in lymph nodes and much more common in the bone marrow. An unsuspected proportion of plasma cell tumours among the ML arising in the gastrointestinal tract has been reported recently (Henry and Farrer-Brown, 1977). At their presentation, extramedullary plasmacytic ML are rarely associated with serum protein abnormalities, whereas at a later stage paraproteinaemia may appear (Wiltshaw, 1976).

\section{Immunoblastic malignant lymphoma}

The identification of this entity among the heterogenous group of more or less differentiated reticulum cell sarcomas (Oberling, 1928; Roulet, 1930; RobbSmith, 1938; Rössle, 1939) depends upon electron microscopy and immunological methods (Kaiserling et al., 1973; Stein et al., 1972, 1974a). Immunoblastic ML is characterised by a monomorphic proliferation of large cells (15-30 $\mu$ in diameter) with pale eosinophilic but deeply pyroninophilic cytoplasm, a moderate or large amount of endoplasmic reticulum, round or oval clear nuclei, one or two large, centrally located eosinophilic nucleoli, and, in some cases, the presence of condensed IgM in the cytoplasm. Mitotic figures are common. The similarities of the neoplastic cells to transformed lymphocytes led to the introduction of the term immunoblastic ML derived from the original terminology of Dameshek (1963).

These neoplasms have previously been classified either as undifferentiated non-Burkitt ML or as $\overrightarrow{0}$ diffuse poorly differentiated histiocytic ML. Im- $\overrightarrow{\vec{\omega}}$ munoblastic ML are high-grade malignancies and $\omega$ have a very poor prognosis, allowing only a short survival of the patient. Although in many instances the neoplasm appears rapidly de novo, in a number of cases it represents the late transformation of $\vec{\neg}$ lymphoplasmacytoid ML, of immunoblastic lymphadenopathy (Lukes and Tindle, 1975), of plasma cell proliferations of various types, and even of $\mathrm{O}$ follicular lymphomas (Dick et al., 1977). In these latter cases the B-cell type origin of the tumour is $z$ very likely, since the common clonal origin of the lymphoplasmacytic proliferation in alpha chain disease and of immunoblasts in the supervening ML could be ascertained.

The cytoplasm contains diastase-resistant PAS $\overrightarrow{0}$ positive granules but no naphthyl esterase activit (Stein et al., 1972; Glick et al., 1975), or acid phosephatase (except for a few granules), whereas these enzymatic activities are highly evident in phagocytosing reticulum cells (Carr, 1973). Membranebound ATPase activity is strong, while 5'-nucleotidase is absent (Kaiserling, 1977a).

The identification of these cells in imprints of lymph nodes, as well as in smears of blood and marrow, is based upon the above-mentioned features, and differential diagnosis has to take into consideration Burkitt type ML, centroblastic ML, true histiocytic neoplastic proliferations, and myeloid sarcoma. In particular, in haematoxylin-eosinstained sections, the cells of the latter may be difficult to identify as myeloid in nature unless there are myelocytes and eosinophilic cells among the myeloblasts. When the degree of differentiation is low (Brugo et al., 1975; Carmichael and Lee, 1977), additional stains, such as Giemsa for eosinophilic No granules, PAS for neutrophilic intracytoplasmic granules, and naphthol AS-D chloracetate esterase, may be very helpful (Leder and Stutte, 1975). Reactions for peroxidase and the use of Sudan black $B$ are also recommended. Cytoplasmic basophilia, 0 ascertained with methyl green-pyronine and Giemsa, is lower in immature myeloid cells than it is in immunoblasts.

Immunoblastic ML is not always cytologically monomorphic but may show two main types of 
admixture. More commonly, immunoblasts are mixed with a component of plasmablasts and mature plasma cells (Fig. 29). The presence of the latter has been considered a prerequisite for the recognition of a true immunoblastic sarcoma (Lukes and Collins, 1974). On the other hand, this finding may indicate either some trend to a plasmacytic differentiation of the tumour or suggest the origin from a preceding plasmacytic benign or malignant proliferation or from a lymphoplasmacytoid ML. In other instances, immunoblasts are intermingled with malignant centroblasts or even centrocytes, even though a follicular structure is never observed. Macrophages and occasionally epithelioid cells are also found (Kaiserling, 1977a), and plentiful reticulin fibre production may be seen. Histiocyte proliferation and fibre production by fibroblastic reticulum cells may possibly be stimulated by the immunoglobulinproducing and immunoglobulin-secreting tumour cells.

Marrow invasion is not uncommon, and immunoblastic leukaemia is characterised by the presence in the blood of large macronucleolated and basophilic immunoblasts (Fig. 30, inset A). This leukaemia has been described (Mathé et al., 1975a) as type 1 of leukaemic lymphosarcomas. Similarly, previously reported cases of a transformation of 'reticulum cell sarcomas' into acute leukaemias might have been immunoblastic ML (Lowenbraun et al., 1971).

Even though a large proportion of 'histiocytic' and 'undifferentiated pleomorphic' ML retain with marked variability B-lymphocyte markers (Jaffe et al., 1977), it seems understandable that in a number of cases of morphologically characteristic malignant immunoblastic proliferations, immunological markers cannot be visualised and that the cells remain unidentified to a great extent (Brouet et al., 1975b, 1976; Habeshaw and Stuart, 1975; Jaffe et al., 1977; Kaiserling, 1977a). In these cases the term immunoblastic ML is not strictly appropriate, and the noncommittal term large lymphoid cell tumour should be applied. It seems, however, that those immunoblastic ML that supervene in patients with previously ascertained B-cell-derived ML may be considered B-cell-derived high-grade malignancies.

Large cell T-type ML (Jaffe et al,., 1975, 1977) and specifically $\mathrm{T}$-immunoblastic $\mathrm{ML}$, that is, ML made up of T-cell type transformed lymphocytes (Habeshaw and Stuart, 1975), cannot at present be distinguished with certainty on light microscopy.

Ultrastructurally, neoplastic B-derived immunoblasts (Fig. 30) have a large, round or oval nucleus with dispersed chromatin and one or two prominent nucleoli usually located centrally or occasionally against the nuclear membrane. Rough endoplasmic reticulum is generally scanty, but the cytoplasm is crowded with monoribosomes and many polyribosomes (Fig. 30, inset B). However, some plasmablast-like cells with many rough endoplasmic reticulum cisternae are also present. A well-developed Golgi apparatus and a few mitochondria are found. The diffuse or globular PAS positivity, which is sometimes seen within the cytoplasm on light microscopy, corresponds to immunoglobulin produced by the cells and accumulated in the perinuclear spaces and the cisternae of the rough endoplasmic reticulum.

\section{Malignant lymphoma, lymphoblastic and acute lymphoblastic leukaemia}

MALIGNANT LYMPHOMA, LYMPHOBLASTIC CONVOLUTED CELL TYPE

This entity is characterised by the peculiar morphology especially in sections of a variable proportion of the nuclei of the proliferating atypical cells, which under low power appear round, whereas under high power they disclose a 'cerebriform' appearance due to deep indentations and lobulations almost without intervening cytoplasm (Fig. 31, inset) (Lukes and Collins, 1974; Barcos and Lukes, 1975). The percentage of cells of convoluted nuclei varies considerably from case to case and decreases in patients beyond adolescence. In the absence of nuclear convolution the cells are highly immature in appearance and indistinguishable from the lymphoblasts of ALL (Nathwani et al., 1976). This ML used to be classified among the diffuse lymphocytic, poorly differentiated lymphomas, and since it is more frequent in, but not exclusive to, childhood and adolescence (Rilke $e t$ al., 1975) it was also called childhood lymphosarcoma (Sternberg, 1915).

In sections of lymph nodes, there is infiltration by a population of cells with a considerable variation in size (10-20 $\mu$ in diameter); one of the distinctive features of this ML is the non-cohesiveness of its cells. The nuclear chromatin is delicate, primitive, and 'dusty', and the nucleoli are small and inconspicuous (Fig. 32). The mitotic index is very high, and, in addition, numerous pyknotic nuclei simulate mitotic figures. The cytoplasm is scarce and ill defined. A starry-sky pattern due to actively phagocytosing macrophages may be present. Residual secondary follicles may be found; reticulin fibres are scanty.

In less than half of the cases PAS-positive material is irregularly present in the cytoplasm, usually in the form of circumscribed paranuclear foci or of granules (Smith et al., 1973; Catovsky et al., 1974b). In the majority of cases there is a strong positive acid phosphatase reaction in the cells (Catovsky et al., 1974a; Lennert et al., 1975b, 1975c; Ritter et al., 1975), which is restricted to one site (Fig. 31) 

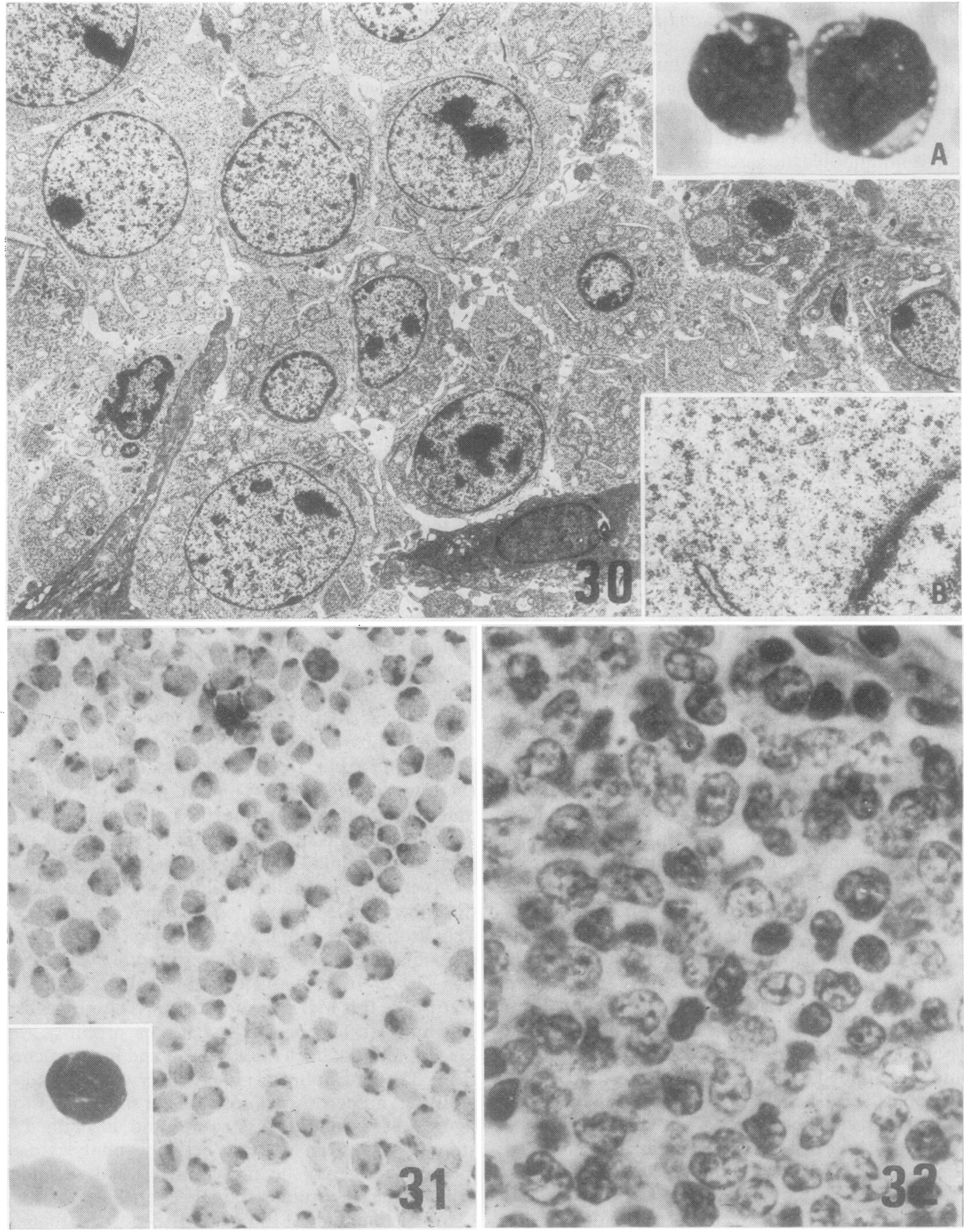

Fig. 30 Malignant lymphoma, immunoblastic. Immunoblasts with oval or round pale nuclei, prominent nucleoli, and scanty rough endoplasmic reticulum. (× 4000) Inset A: ML, immunoblastic; 66-year-old man. Blood smear: WBC $56 \times 10^{9} / \mathrm{l}$. Circulating immunoblasts $40 \%$. Two immunoblasts. (May Grünwald-Giemsa $\times 1000)$. Inset B: Abundant polyribosomes. $(\times 30000)$

Fig. 31 Malignant lymphoma, lymphoblastic, convoluted cell type, Imprint of cervical lymph node, 30-year-old man. Spot-like acid phosphatase activity (Leder and Stutte, 1975). ( $\times 1000)$. Inset: circulating 'convoluted' lymphoblast in blood smear. (May Grünwald-Giemsa $\times 1000$ )

Fig. 32 Malignant lymphoma, lymphoblastic, convoluted cell type: axillary lymph node, 5-year-old boy. Immature non-cohesive cells with irregularly shaped nuclei, small nucleoli, and scanty cytoplasm. (Giemsa $\times 1000)$ 
corresponding to the Golgi area and to some adjacent lysosomal granules (Catovsky et al., 1975b). Nonspecific esterase, peroxidase, Sudan black $B$, and alkaline phosphatase are negative.

On electron microscopy the tumour population is formed by cells of different size and nuclear features (Fig. 33). The largest cells have been described (Barcos and Lukes, 1975) as having a nucleus that is more deeply infolded than it is in the smaller ones; however, small cells with convoluted nuclei and large cells with roughly oval non-indented nuclei are found. In some areas cells with kidney-shaped nuclei are the most frequent. Larger cells generally have more dispersed nuclear chromatin than do the smaller ones. Nucleoli are not prominent. The cytoplasm contains some round mitochondria and a few rough endoplasmic reticulum cisternae. Polyribosomes are abundant, especially in large cells. A well-developed Golgi apparatus (Fig. 33, inset), frequently localised within a nuclear indentation, is observed in a large number of cells. Lysosome-like dense bodies are found, especially in the Golgi region (Fig. 33, inset). Lysosomes and the Golgi apparatus probably correspond to the focal accumulation of acid phosphatase activity observed by light microscopy (Lennert et al., 1975b). The plasma membrane does not present any projection or infolding.

The cell type described, which is characteristic for this ML, is almost identical with that found in cases in which the clinical picture at onset is that of ALL with or without a tumour mass. The latter is quite often represented by a mediastinal tumour in the thymic region, with the same anatomical features described by Sternberg in 1915. Quite often, however, the leukaemic manifestation develops after the appearance of the ML, usually within six months from onset, with high WBC count, a high incidence of early CNS involvement (Greenberg et al., 1976), and a poor prognosis (Catovsky et al., 1974b; Sen and Borella, 1975; Belpomme et al., 1977), particularly in males (Hann et al., 1977). The distinction between leukaemia and lymphoma, based on the presence of marrow involvement at diagnosis, was not of prognostic significance in one reported series (Coccia et al., 1976).

The cells, whether in the marrow or elsewhere, are of lymphoblasts with $\mathrm{E}$ receptors (Borella and Sen, 1973; Smith et al., 1973; Catovsky et al., 1974a; Kaplan et al., 1974; Ritter et al., 1975; Stein et al., 1976) and/or human T-lymphocyte antigen (Kersey et al., 1975; Greaves, 1977). The finding in some cases of complement receptors in addition to the $\mathrm{E}$ receptor has been interpreted as an indication that the cells derive from immature T-precursor cells (Stein et al., 1976). The cells do not respond to mitogens.
In one case of T-cell ALL, the suppressor activity was retained by the neoplastic cells (Broder et al., 1978).

The availability of various enzymatic markers (Lancet, 1977), such as terminal deoxynucleotidyl transferase (McCaffrey et al., 1975), combined with immunological differences, are already giving some indication as to the possible heterogeneity of T-cell lymphoblastic leukaemias (Gelfand and Chechik, 1976). On the other hand, it should be pointed out that the clinical evidence of a mediastinal mass and the cytological evidence of a positive acid phosphatase reaction are not specific for a ML and/or leukaemia of the convoluted cell type of thymic origin but may also be observed, although less frequently, in cases of ALL in which the cells do not display immunological markers (Chessells et al., 1977; Seligmann et al., 1977b; Catovsky et al., 1978).

\section{ACUTE LYMPHOBLASTIC LEUKAEMIA}

The difficulties and contradictions in classifying ALL have been discussed (Flandrin and Bernard, 1975) with special reference to the significance of the cellular size (Binet et al., 1975; Mathé et al., 1976). In general, the lymphoblasts of ALL are immature lymphoid cells with a high nuclear:cytoplasmic ratio and basophilic cytoplasm without granules. They have been subdivided into two main groups according to their size (Lennert and Mohri, 1971). The small cell type consists of cells that measure about $10 \mu$ in diameter, have slightly irregular nuclei with finely granular chromatin, usually one small nucleolus, and scanty and basophilic cytoplasm. The cells of the large cell type measure about $15 \mu$ in diameter and contain a nucleus with a more regular contour and a prominent nucleolus. Intracytoplasmic coarse diastase-resistant, as well as fine diastase-sensitive PASpositive granules, were described, and their presence was related to prognosis in some series (Laurie, 1968; Humphrey et al., 1974).

Under the electron microscope there is also a variable morphology (Cawley and Hayhoe, 1973). The nuclear:cytoplasmic ratio is high. The nucleus is seldom kidney-shaped, but mostly it is deeply indented (Fig. 34) and presents nuclear pockets (Fig. 35). Nuclear chromatin is generally dispersed, but there are some chromatin condensations (Fig. 34). However, dense nuclei such as those of small circulating lymphocytes are never observed. Nucleoli are variably developed and occasionally have a prominent nucleolonema. A few peroxidase-negative pleomorphic granules of a lysosomal nature (Fig. 34) are sometimes seen in the cytoplasm. The mitochondria are variable in size, shape, and total number; in some cells they may be abundant. A large accumulation of glycogen (Fig. 34, inset) is 

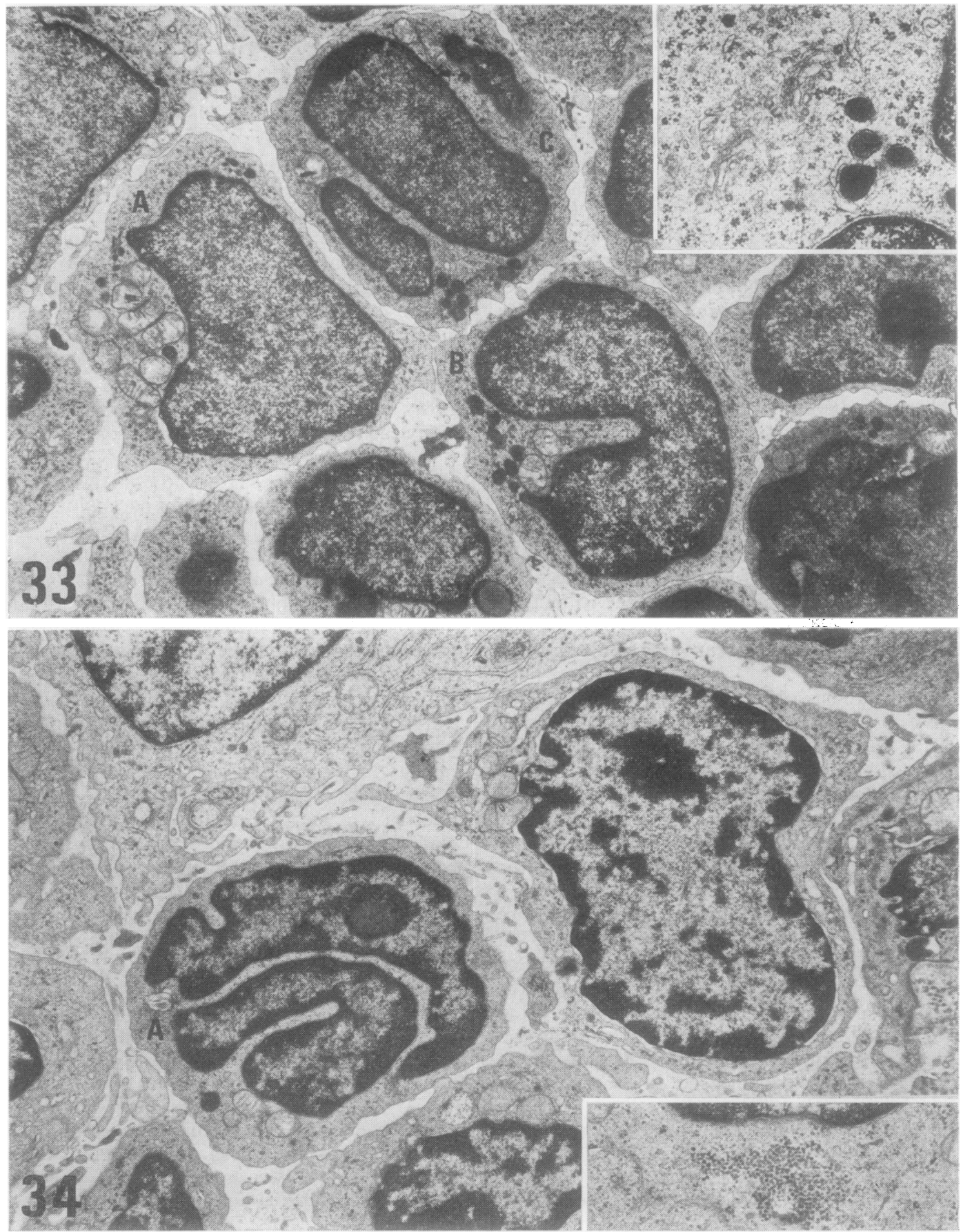

Fig. 33 Malignant lymphoma, lymphoblastic, convoluted cell type. Lymphoblasts with non-idented pale nucleus $(A)$, kidney-shaped nucleus $(B)$, and lobed convoluted nucleus $(C) .(\times 10000)$ Inset: Golgi apparatus and lysosome-like dense bodies. $(\times 30000)$

Fig. 34 Acute lymphoblastic leukaemia. Lymphoblasts with more or less deeply indented nuclei. One cell $(A)$ shows condensed nuclear chromatin, an inconspicuous nucleolus, and a lysosome-like dense granule. $(\times 12000)$ Inset: large accumulation of glycogen. ( $\times 27000)$ 
characteristic of the leukaemic lymphoblasts (Lennert, 1975), and bundles of microfilaments are sometimes noted. The cytoplasm contains little rough endoplasmic reticulum and is crowded with monoribosomes and some polyribosomes. Differences in ribosomal cytoplasmic content between large and small cell type ALL were reported as the most relevant distinguishing feature; large cells are rich in polyribosomes, whereas in small cells monoribosomes predominate (Kaiserling, 1977a). Membrane-bound dense inclusions of an uncertain nature and autophagic vacuoles are not infrequently observed. A poorly developed Golgi apparatus is present (Fig. 35). Transmission and SEM do not show differences between T and non-T ALL; however, electron microscope cytochemistry may be able to distinguish between null- and T-lymphoblasts. Whereas the strong acid phosphatase reaction of T-ALL blasts is localised within the Golgi apparatus and within the lysosomal granules near the Golgi areas in 30 to $70 \%$ of the cells and whereas granules localised in other cytoplasmic areas are generally unreactive, in patients with non-T ALL the reaction is present in one or two granules of less than $10 \%$ of the cells, but not within the vesicles of the Golgi apparatus (Catovsky et al., 1975b).

In ALL, the lymph nodes may show a variable degree of distortion of the architecture. While in some cases the enlargement of the lymph node is due to a massive accumulation of cells without marked destruction of the architecture of the lymph node, in other cases the lymph node tissue is entirely replaced by the proliferating cells, as in other diffuse ML (Lennert and Mohri, 1971). The marrow is usually massively infiltrated by tumour cells.

The contribution of morphology, both at the light microscopic cytological and histopathological level as well as at the ultrastructural one, is certainly not satisfactory but immunological and clinical studies seem to be more fruitful. In summary, these investigations have revealed the existence of several types of ALL.

The least common is the monoclonal B-cell leukaemic proliferation of Burkitt lymphoma blasts (less than $3 \%$ of all ALL). The report of rare cases of B-cell ALL with the cytological features of poorly differentiated lymphocytic ML (Brouet et al., 1975c) indicates that the patients with ML of germinal centre cell origin (centrocytic?) should be considered at risk for leukaemia and accordingly monitored clinically. Cases of ALL of apparent B-cell origin have been described in adults (Gajl-Peczalska et al., 1974), and rarely, as already mentioned, acute blastic transformation of B-CLL can occur.

The previously described T-ALL seems to be closely linked to the lymphoblastic T-type convo- luted cell $\mathrm{ML}$ and represents about 25 to $30 \%$ of all ALL (Borella and Sen, 1973; Chin et al., 1973; Kersey et al., 1973; Greaves, 1977). For diagnostic purposes E-rosette formation by these lymphoblasts appears to be the most reliable diagnostic marker, while acid phosphatase is somewhat less specific (Chessells et al., 1977), and may be less reliable than the reaction for the intracellular acid $a$-naphthyl-acetate esterase activity (Müller et al., 1975). It was found that T-cell ALL lymphoblasts present a positivity that is comparable with that of human thymocytes but different from that of $T$ lymphocytes (Kulenkampff et al., 1977). The considerable difference in prognosis between T-cell ALL and the majority of the other ALL (null-cell) was pointed out by Reid et al. (1977).

The demonstration of the heterogeneity of the group of ALL whose cells do not express any surface characteristics has been given by the identification of a subgroup that reacts with a specific anti-ALL serum (Greaves et al., 1975; Greaves, 1977) and of another that does not (null-cell type). The former is the most frequent type of ALL (65\%), and its most important prognostic feature is the level of the initial WBC count (Chessells et al., 1977). Null-cell type ALL still seems to be an inhomogeneous group of diseases.

\section{Histiocytic disorders}

A large portion of ML made up of large cells and formerly called reticulum cell sarcomas and termed histiocytic ML in the original Rappaport classification has been shown to derive from various modulation stages of the lymphatic cell. Immunological studies revealed that the majority of large cell ML that originate from a progression of low-grade ML with identifiable markers retain those markers, whereas de novo high-grade ML may have a variety of membrane markers or none at all (Jaffe et al., 1975; Brouet et al., 1976). It was estimated that about 50 to $60 \%$ of large cell ML are made up of Bcell, about $10 \%$ of T-cell, and more than $30 \%$ of null-cell populations (Seligmann et al., 1977a). Thus although the term histiocytic $M L$ is therefore inappropriate in most instances, it could also be that in some cases there is a proliferation of malignant histiocytes (Payne et al., 1977). This could be proved by the demonstration of the functional features of this cell type, such as phagocytosis, enzymatic properties, synthesis of muramidase, and the presence of receptor sites for immunoglobulin and complement on its cell surface (Jaffe et al., 1977; Seligmann et al., 1977a).

Owing to the common feature of having cytoplasmic processes, histiocytes are classified among 


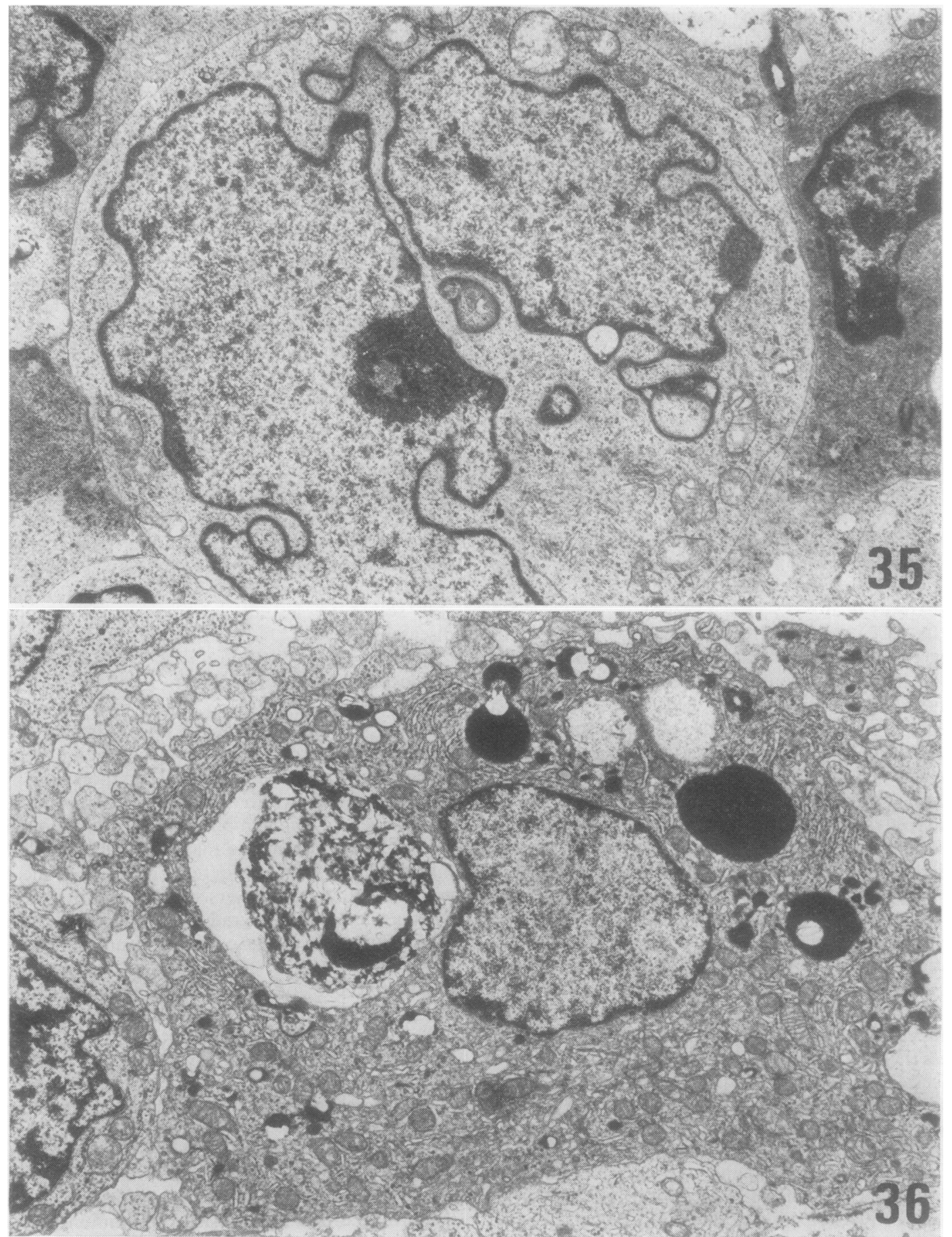

Fig. 35 Malignant lymphoma, lymphoblastic. A lymphoblast showing an irregularly lobed nucleus with dispersed chromatin and relatively well-developed nucleolus and Golgi apparatus. $(\times 13000)$

Fig. 36 Malignant histiocytosis. An actively phagocytosing histiocyte with large digestive vacuoles.

$(\times 10000)$ 
reticulum cells. Whereas the histiocytes of germinal centres ('tingible body macrophages') and subsinus phagocytes are phagocytosing reticulum cells, the dendritic, interdigitating, fibroblastic, and dark reticulum cells are not (Kaiserling, 1977a; Stuart, 1975). Further differences between these cell types become evident on electron microscopy and with enzyme histochemistry.

In spite of the anatomical, cytological, functional, and immunological differences between the peripheral lymphatic tissue and the mononuclear phagocyte system and their different derivation (van Furth et al., 1972), it seems appropriate to mention in this context also the neoplastic malignant disorders of the latter, essentially because their true nature can be established, in most instances with reasonable certainty, by morphology alone using light and electron miscroscopy (Henry, 1975) on lymph node biopsies. A classification of proliferative histiocytic disorders has been proposed on the basis of the unitary concept that all histiocytes or tissue macrophages arise from the BM-derived monocytic series (Cline, 1975). Monoblast-derived monocytes give rise in the tissue to immature ' $A$ ' macrophages that are capable of cell division and to mature ' $B$ ' nonreplicating macrophages. Neoplastic transformation can affect the normal monocyte-histiocyte line at several levels and produce a spectrum of malignant lesions, which are more or less aggressive according to the degree of differentiation of the proliferating cells. The range of the diseases extends from acute monoblastic leukaemia to malignant histiocytosis, which is considered to represent the proliferation of moderately differentiated cells, and to circumscribed histiocytic proliferations of the most differentiated cells. It has been stressed that the clinical manifestations of the various diseases result from a combined effect of the proliferation of the cells and of their functional manifestations (Cline, 1978). The position among histiocytic proliferative disorders of HandSchüller-Christian disease and of eosinophilic granuloma seems debatable, and for them a different derivation has been suggested (Nezelof et al., 1973).

\section{MALIGNANT HISTIOCYTOSIS}

This disease is a clinicopathological entity (Byrne and Rappaport, 1973; Berard and Dorfman, 1974; Warnke et al., 1975; Mathé et al., 1976; Rilke et al., 1978a) that is characterised by the malignant progressive and systemic proliferation of histiocytes and of their precursors (Rappaport, 1966). Malignant histiocytosis has been considered the only proved example of a neoplastic disease of 'true' histiocytic origin, since it may represent the neoplastic transformation of the histiocytes lining the sinuses of the lymphoreticular system (Berard et al., 1976). It was originally described by Scott and Robb-Smith (1939) as histiocytic medullary reticulosis. The anatomical areas predominantly involved by the disease are the lymph nodes, spleen, liver, marrow, and skin (Byrne and Rappaport, 1973; Warnke et al., 1975). The diagnosis is made by histology on biopsy material but may sometimes be apparent in bone marrow smears.

The most important histological criteria for the diagnosis on lymph nodes, which are the elective site for the identification of the disease, are represented $(a)$ by the presence of a neoplastic proliferation within the peripheral and medullary sinuses and/or within the parenchyma of cells that can be identified as histiocytes because of their cytological features, including phagocytosis, and $(b)$ by the distribution of malignant cells that are predominantly isolated and do not usually form either cords or solid nests. The fibrous capsule of the lymph nodes is not usually infiltrated. The neoplastic histiocytes are not monomorphic because of the mixture in variable proportions of deceptively benign-looking cells with highly atypical ones. The latter have thick nuclear membranes, irregular heterochromatin, and prominent but not very large nucleoli. Phagocytosis is a constant finding, even though quantitatively variable; within the cytoplasm of the histiocytes, erythrocytes, leucocytes, platelets, fat droplets, cellular debris, and PASpositive granules may be found. Erythrophagocytosis in particular may be massive and as such is diagnostic. The number of mitotic figures is variable. Plasma cells and eosinophilic granulocytes are often but not constantly found in a variable amount.

In the spleen, neoplastic proliferation occurs predominantly within the red pulp, while the follicles may persist for a long time and are partially or totally obliterated in the advanced phase of the disease. In the liver, cellular growth is recognisable as an infiltration of the portal spaces and/or of the liver parenchyma with the presence of histiocytes within the liver cords. The finding of histiocytes in marrow is not constant, and invasion may be made up only of small foci of atypical cells. In the skin the atypical histiocytes are more often grouped in the dermis around the skin appendages and the vessels and may also infiltrate the papillary dermis and the subcutaneous tissue.

In addition to the light microscopic findings mentioned, the histiocytic nature of the neoplastic cells is confirmed by enzyme histochemistry, immunology, and electron microscopy. The high cytoplasmic content of acid phosphatase activity (Leder and Stutte, 1975) and of fluoride-resistant non-specific esterase ( $\mathrm{Li}$ et al., 1972) is easily demonstrated. Immunological markers for monocytes (receptors for 


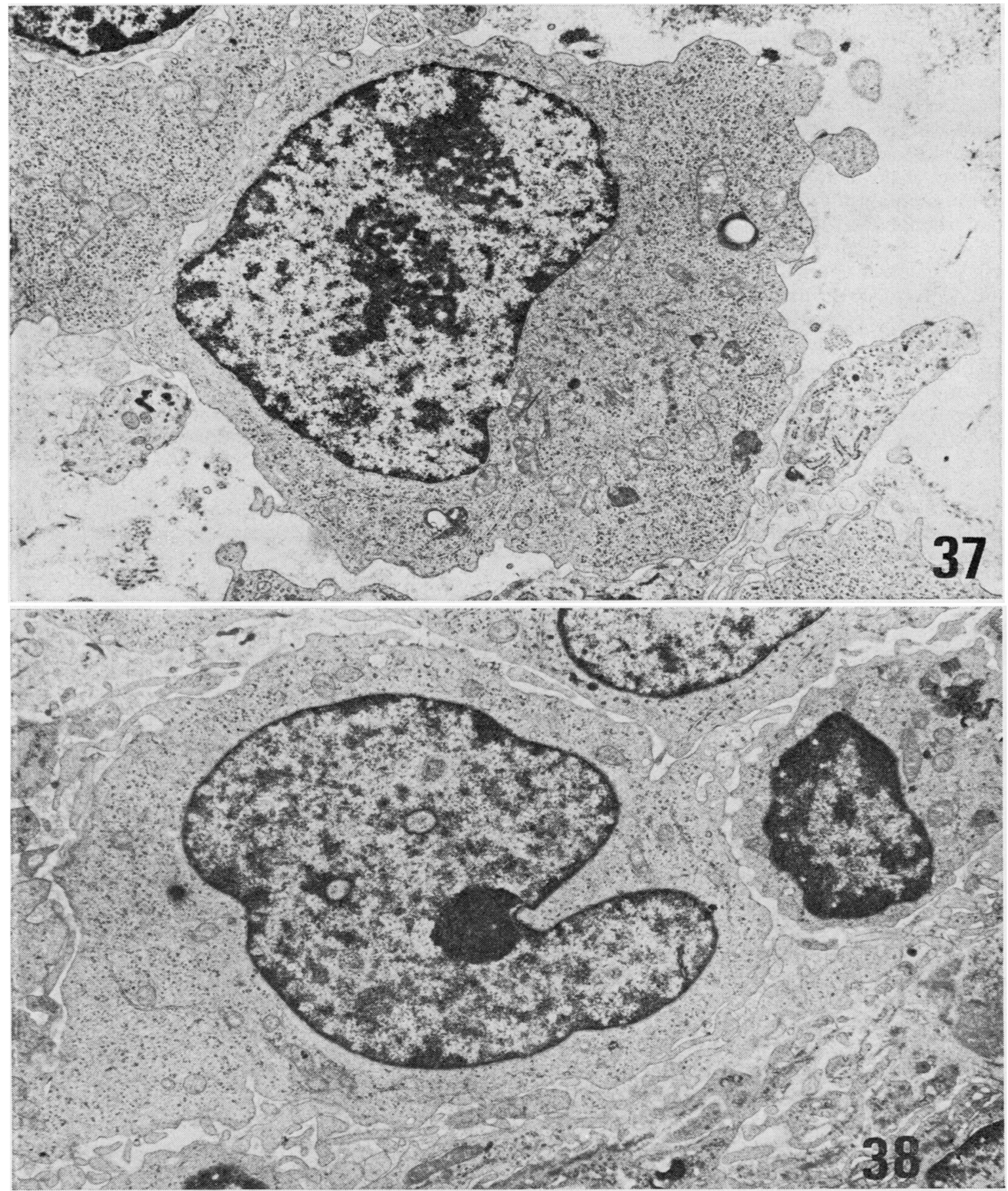

Fig. 37 Malignant histiocytosis. A non-phagocytosing histiocyte with two prominent nucleoli, a large Golgi apparatus, and some primary lysosomes. $(\times 10000)$

Fig. 38 Malignant histiocytosis. An undifferentiated cell with a horseshoe-shaped nucleus and an inconspicuous nucleolus. Lysosome-like dense bodies are absent. $(\times 10000)$ 
the Fc portion of IgG and for complement) have been identified on the cells of malignant histiocytosis (Jaffe et al., 1975).

In our ultrastructural study of six cases of malignant histiocytosis (Lombardi et al., 1978), we observed three types of proliferating cells: actively phagocytosing histiocytes (Fig. 36) with large digestive vacuoles and numerous primary lysosomes; non-phagocytosing histiocytes (Fig. 37) with primary lysosomes only; and undifferentiated cells (Fig. 38) with a few small primary lysosomes. Non-phagocytosing and phagocytosing histiocytes (Figs 36, 37), which show ultrastructural features similar to those of the A and B macrophages described by Cline (1975), have an oval or deeply indented lobed nucleus with well-developed nucleoli and scarce and marginated heterochromatin. Undifferentiated cells (Fig. 38) have a horseshoeshaped or occasionally a lobed pale nucleus with an inconspicuous nucleolus. All these cell types generally have a scarce, smooth, and rough endoplasmic reticulum and abundant free ribosomes. Some phagocytosing and non-phagocytosing histiocytes with a well-developed rough and smooth endoplasmic reticulum were observed in two cases only. Some multinucleated phagocytosing histiocytes and some cells with features intermediate either between undifferentiated and non-phagocytosing histiocytes or between non-phagocytosing and phagocytosing histiocytes are also observed.

In some cases of circumscribed histiocytic cutaneous and/or nodal neoplasm, similar proliferating cells were observed. Histologically at high magnification the tumour cells could not be distinguished from those found in the sinuses of clearcut cases of malignant histiocytosis. At low power, however, the higher degree of cohesiveness and the lower degree of atypia represented the main, although qualitatively not well-defined, differences between localised histiocytic tumours and malignant histiocytosis.

Histological differential diagnosis takes into consideration familial haemaphagocytic reticulosis (Farquhar et al., 1958), immunoblastic hyperplasia, sinus histiocytosis with massive lymphadenopathy (Rosai and Dorfman, 1969), other histiocytic disorders, high-grade non-Hodgkin's ML, and Hodgkin's disease (Byrne and Rappaport, 1973; Warnke et al., 1975; Rilke et al., 1978a).

This study was supported in part by grants no. 76.01081 and no. 77.01849 from the Consiglio Nazionale delle Ricerche, Rome. We thank Ms. B. Johnston for editing and preparing the manuscript.
References

Aisenberg, A. C., and Bloch, K. J. (1972). Immunoglobulins on the surface of neoplastic lymphocytes. New England Journal of Medicine, 287, 272-276.

Aisenberg, A. C., Bloch, K. J., and Long, J. C. (1973a). Cell-surface immunoglobulins in chronic lymphocytic leukemia and allied disorders. American Journal of Medicine, 55, 184-191.

Aisenberg, A. C., Bloch, K. J., Long, J. C., and Colvin, R. B. (1973b). Reaction of normal human lymphocytes and chronic lymphocytic leukaemia cells with an antithymocyte antiserum. Blood, 41, 417-423.

Aisenberg, A. C., Long, J. C. (1975). Lymphocyte surface characteristics in malignant lymphoma. American Journal of Medicine, 58, 300-306.

Aisenberg, A. C., and Wilkes, B. (1976). Lymphosarcoma cell leukemia: the contribution of cell surface study to diagnosis. Blood, 48, 707-715.

Ala, F., et al. (1976). Alpha-chain disease and related small-intestinal lymphoma: a memorandum. Bulletin of the World Health Organization, 54, 615-624.

Alexander, E., Sanders, S., and Braylan, R. (1976). Purported difference between human T- and B-cell surface morphology is an artefact. Nature, 261, 239. 241.

Anday, G. J., Goodman, J. R., and Tishkoff, G. H. (1973). An unusual cytoplasmic ribosomal structure in pathologic lymphocytes. Blood, 41, 439-449.

Anday, G. J., and Schmitz, H. L. (1952). Follicular lymphoma with transient leukemic phase: brief review of literature and report of a case. Archives of Internal Medicine, 89, 621-634.

Andersson, M., Klein, G., Ziegler, J. L., and Henle, W. (1976). Association of Epstein-Barr viral genomes with American Burkitt lymphoma. Nature, 260, 357-359.

Argani, I., and Kipkie, G. F. (1965). The cellular origin of macroglobulins. A study of the protein secreting cells in Waldenström's disease. Laboratory Investigation, 14, 720-728.

Astaldi, G., and Verga, L. (1957). The glycogen content of the cells of lymphatic leukaemia. Acta Haematologica, 17, 129-135.

Ballard, H. S., Hamilton, L. M., Marcus, A. J., and Illes, C. H. (1970). A new variant of heavy-chain disease ( $\mu$ chain disease). New England Journal of Medicine, 282, 1060-1062.

Barcos, M. P., and Lukes, R. J. (1975). Malignant lymphoma of convoluted lymphocytes: a new entity of possible T-cell type. In Conflicts in Childhood Cancer: An Evaluation of Current Management, volume 4, edited by L. F. Sinks and J. O. Godden, pp. 147-178. A. Liss, New York.

Belpomme, D., Mathé, G., and Davies, A. J. S. (1977). Clinical significance and prognostic value of the T-B immunological classification of human primary acute lymphoid leukaemias. Lancet, 1, 555-558.

Bennett, M. H. (1975). Sclerosis in non-Hodgkin's lymphomata. British Journal of Cancer, 31, Supplement 2, 44-52.

Bennett, M. H., Farrer-Brown, G., Henry, K., and Jelliffe, A. M. (1974). Classification of non-Hodgkin's lym- 
phomas (Letter). Lancet, 2, 405-406.

Bennett, M. H., and Millett, Y. L. (1969). Nodular sclerotic lymphosarcoma. A possible new clinicopathological entity. Clinical Radiology, 20, 339-343.

Bentwich, Z., and Kunkel, H. G. (1973). Specific properties of human $B$ and $T$ lymphocytes and alterations in disease. Transplantation Reviews, 16, 29-50.

Berard, C. W. (1975). Reticuloendothelial system: an overview of neoplasia. In The Reticuloendothelial System, Chapter 15, edited by J. W. Rebuck, C. W. Berard, and M. R. Abell, pp. 301-317. Williams \& Wilkins, Baltimore.

Berard, C. W., and Dorfman, R. F. (1974). Histopathology of malignant lymphomas. Clinics in Haematology, 3, 39-76.

Berard, C. W., Gallo, R. C., Jaffe, E. S., Green, I., and De Vita, V. T., Jr. (1976). Current concepts of leukemia and lymphoma: etiology, pathogenesis and therapy. Annals of Internal Medicine, 85, 351-366.

Berard, C. W., O'Conor, G. T., Thomas, L. B., and Torloni, H. (Eds.) (1969). Histopathological definition of Burkitt's tumour. Bulletin of the World Health Organization, 40, 601-607.

Bessis, M. C. (1961). Ultrastructure of lymphoid and plasma cells in relation to globulin and antibody formation. Laboratory Investigation, 10, 1040-1067.

Bianco, C., Patrick, R., and Nussenzweig, V. (1970). A population of lymphocytes bearing a membrane receptor for antigen-antibody-complement complexes. I. Separation and characterization. Journal of Experimental Medicine, 132, 702-720.

Binet, J. L., Dighiero, G., D’Athis, P., Feinermann, M., de Montaut, F., and Seroude, J. (1975). Volumetric determinations of blood cells in acute lymphoblastic leukemia. In Unclassifiable Leukemias, edited by $\mathrm{M}$. Bessis and G. Brecher, pp. 95-97. Springer, Berlin.

Binet, J. L., Leporrier, M., Dighiero, G., Charron, D., D'Athis, P., Vaugier, G., Beral, H. M., Natali, J. C., Raphael, M., Nizet, B., and Follezou, J. Y. (1977a). A clinical staging system for chronic lymphocytic leukemia. Cancer, 40, 855-864.

Binet, J. L., Vaugier, G., Dighiero, G., d'Athis, P., and Charron, D. (1977b). Investigation of a new parameter in chronic lymphosytic leukemia: the percentage of large peripheral lymphocytes determined by the Hemalog D. Prognostic significance. American Journal of Medicine, 63, 683-688.

Bloomfield, C. D., Kersey, J. H., Brunning, R. D., and Gajl-Peczalska, K. J. (1976). Prognostic significance of lymphocyte markers in adult non-Hodgkin's malignant lymphoma. Lancet, 2, 1330-1333.

Bluming, A. Z., Ziegler, J. L., and Carbone, P. P. (1972). Bone marrow involvement in Burkitt's lymphoma. Results of a prospective study. British Journal of Haematology, 22, 369-376.

Boldt, D. H. Speckart, S. F., MacDermott, R. P., Nash, G. S., and Valeski, J. E. (1977). Leukemic reticuloendotheliosis: 'hairy cell leukemia,' functional and structural features of the abnormal cell in a patient with profound leukocystosis. Blood, 49, 745-757.

Borella, L., and Sen, L. (1973). T cell surface markers on lymphoblasts from acute lymphocytic leukemia.
Journal of Immunology, 111, 1257-1260.

Bouroncle, B. A., Wiseman, B. K., and Doan, C. A. (1958). Leukemic reticuloendotheliosis. Blood, 13, 609-630.

Braylan, R. C., Jaffe, E. S., and Berard, C. W. (1975). Malignant lymphomas: current classification and new observations. Pathology Annual, 10, 213-270.

Braylan, R. C., Jaffe, E. S., Burbach, J. W., Frank, M. M., Johnson, R. E., and Berard, C. W. (1976). Similarities of surface characteristics of neoplastic well-differentiated lymphocytes from solid iissues and from peripheral blood. Cancer Research, 36, 1619-1625.

Braylan, R. C., and Rappaport, H. (1973). Tissue immunoglobulins in nodular lymphomas as compared with reactive follicular hyperplasias. Blood, 42, 579. 589.

Brearley, R. L., Lister, T. A., Whitehouse, J. M. A., and Stansfeld, A. G. (1977). Burkitt's lymphoma in British adults: clinical features and response to chemotherapy. British Journal of Cancer, 35, 484-487.

Brill, N. E., Baehr, G., and Rosenthal, N. (1925). Generalized giant lymph follicle hyperplasia of lymph nodes and spleen; a hitherto undescribed type. Journal of the American Medical Association, 84, 668-671.

Broder, S., Edelson, R. L., Lutzner, M. A., Nelson, D. L., MacDermott, R. P., Durm, M. E., Goldman, C. K., Meade, B. D., and Waldmann, T. A. (1976). The Sézary syndrome. A malignant proliferation of helper T cells. Journal of Clinical Investigation, 58, 1297-1306

Broder, S., Poplack, D., Whang-Peng, J., Durm, M. Goldman, C., Muul, L., and Waldmann, T. A. (1978) Characterization of a suppressor-cell leukemia Evidence for the requirement of an interaction of two $T$ cells in the development of human suppressor effector cells. New England Journal of Medicine, 298, 66-72.

Broome, J. D., Zucker-Franklin, D., Weiner, M. S., Bianco, C., and Nussenzweig, V. (1973). Leukemic cells with membrane properties of thymus-derived (T) lymphocytes in a case of Sézary's syndrome: morphologic and immunologic studies. Clinical Immunology and Immunopathology, 1, 319-329.

Brouet, J. C., Flandrin, G., Sasportes, M., Preud'homme, J. L., and Seligmann, M. (1975a). Chronic lymphocytic leukaemia of $\mathrm{T}$-cell origin. Immunological and clinical evaluation in eleven patients. Lancet, 2, 890-893.

Brouet, J. C., Flandrin, G., and Seligmann, M. (1973a). Indications of the thymus-derived nature of the proliferating cells in six patients with Sézary's syndrome. New England Journal of Medicine, 289, 341-344.

Brouet, J. C., Labaume, S., and Seligmann, M. (1975b). Evaluation of $\mathbf{T}$ and $\mathrm{B}$ lymphocyte membrane markers in human non-Hodgkin malignant lymphomata. British Journal of Cancer, 31, Supplement 2, 121-127.

Brouet, J. C., Mason, D. Y., Danon, F., Preud'homme, J. L., Seligmann, M., Reyes, F., Navab, F., Galian, A., Rene, E., and Rambaud, J. C. (1977). Alpha-chain disease: evidence for common clonal origin of intestinal immunoblastic lymphoma and plasmacytic proliferation (Letter). Lancet, 1, 861.

Brouet, J. C., Preud'homme, J. L., Flandrin, G., Chelloul, N., and Seligmann, M., (1976). Membrane markers in 'histiocytic' lymphomas (reticulum cell sarcomas). 
Journal of the National Cancer Institute, 56, 631-633.

Brouet, J. C., Preud'homme, J. L., and Seligmann, M. $(1975 \mathrm{c})$. The use of B and T membrane markers in the classification of human leukemias, with special reference to acute lymphoblastic leukemia. In Unclassifiable Leukemias, edited by M. Bessis and G. Brecher, pp. 81-90. Springer, Berlin.

Brouet, J. C., Preud'homme, J. L., Seligmann, M., and Bernard, J. (1973b). Blast cells with monoclonal surface immunoglobulin in two cases of acute blast crisis supervening on chronic lymphocytic leukaemia. British Medical Journal, 4, 23-24.

Brown, G., Greaves, M. F., Lister, T. A., Rapson, N., and Papamichael, M. (1974). Expression of human T and B lymphocyte cell-surface markers on leukaemic cells. Lancet, 2, 753-755.

Brugo, E. A., Larkin, E., Molina-Escobar, J., and Costanzi, J. (1975). Primary granulocytic sarcoma of the small bowel, Cancer, 35, 1333-1340.

Brunning, R. D., McKenna, R. W., Bloomfield, C. D., Coccia, P., and Gajl-Peczalska, K. J. (1977). Bone marrow involvement in Burkitt's lymphoma. Cancer, 40, 1771-1779.

Brunning, R. D., and Parkin, J. (1976). Intranuclear inclusions in plasma cells and lymphocytes from patients with monoclonal gammopathies. American Journal of Clinical Pathology, 66, 10-21.

Burke, J. S., Byrne, G. E., Jr., and Rappaport, H. (1974). Hairy cell leukemia (leukemic reticuloendotheliosis). I. A clinical pathologic study of 21 patients. Cancer, 33, 1399-1410.

Burke, J. S., Mackay, B., and Rappaport, H. (1976). Hairy cell leukemia (leukemic reticuloendotheliosis). II. Ulstrastructure of the spleen. Cancer, 37, 2267-2274.

Burkitt, D. (1958). A sarcoma involving the jaws in African children. British Journal of Surgery, 46, 218223.

Burkitt, D. (1967). Burkitt's lymphoma outside the known endemic areas of Africa and New Guinea. International Journal of Cancer, 2, 562-565.

Burns, G. F., Cawley, J. C., Barker, C. R., and Hayhoe, F. G. J. (1977). Absence of a receptor for fixed C3 on the hairy cells of leukaemic reticuloendotheliosis. Clinical and Experimental Immunology, 29, 442-446.

Butler, J. J., (1969). Non-neoplastic lesions of lymph nodes of man to be differentiated from lymphomas. National Cancer Institute Monographs, 32, 233-255.

Buxbaum, J. N. (1976). Heavy chain diseases in man. Ricerca in Clinica e in Laboratorio, 6, 301-317.

Byrne, G. E., Jr., and Rapport, H. (1973). Malignant histiocytosis. GANN Monographs on Cancer Research, 15, 145-162.

Carbone, A., Santoro, A., Pilotti, S., and Rilke, F. (1978). Bone-marrow patterns and clinical staging in chronic lymphocytic leukaemia (Letter). Lancet, 1, 606.

Carmichael, G. P., Jr., and Lee, Y. T. (1977). Granulocytic sarcoma simulating 'nonsecretory' multiple myeloma. Human Pathology, 8, 697-700.

Carr, I. (1973). The Macrophage: A Review of Ultrastructure and Function. Academic Press, London and New York.

Castellani, R., Bonadonna, G., Spinelli, P., Bajetta, E.,
Galante, E., and Rilke, F. (1977). Sequential pathologic staging of untreated non-Hodgkin's lymphomas by laparoscopy and laparotomy combined with marrow biopsy. Cancer, 40, 2322-2328.

Catovsky, D. (1975). T-cell origin of acid-phosphatasepositive lymphoblasts (Letter). Lancet, 2, 327-328.

Catovsky, D., Cherchi, M., Greaves, M. F., Janossy, G., Pain, C., and Kay, H. E. M. (1978). Acid phosphatase reaction in acute lymphoblastic leukaemia. Lancet, 1, 749-751.

Catovsky, D., Cherchi, M., Okos, A., Hegde, U., and Galton, D. A. G. (1976). Mouse red-cell rosettes in Blymphoproliferative disorders. British Journal of Haematology, 33, 173-177.

Catovsky, D., Frisch, B., Okos, A., and van Noorden, S. (1975a). Scanning electron microscopy and the nature of the hairy cell (Letter). Lancet, 1, 462-463.

Catovsky, D., Frisch, B., and van Noorden, S. (1975b). $\mathrm{B}, \mathrm{T}$, and 'null' cell leukaemias. Electron cytochemistry and surface morphology. In Unclassifiable Leukemias, edited by M. Bessis and G. Brecher, pp. 115-124. Springer, Berlin.

Catovsky, D., Galetto, J., Okos, A., Galton, D. A. G., Wiltshaw, E., and Stathopoulos, G. (1973). Prolymphocytic leukaemia of B and T cell type. Lancet, 2, 232-234.

Catovsky, D., Galetto, J., Okos, A., Miliani, E., and Galton, D. A. G. (1974a). Cytochemical profile of B and $\mathrm{T}$ leukaemic lymphocytes with special reference to acute lymphoblastic leukaemia. Journal of Clinical Pathology, 27, 767-771.

Catovsky, D., Goldman, J. M., Okos, A., Frisch, B., and Galton, D. A. G. (1974b). T-lymphoblastic leukaemia: a distinct variant of acute leukaemia. British Medical Journal, 2, 643-646.

Catovsky, D., Pettit, J. E., Galetto, J., Okos, A., and Galton, D. A. G. (1974c). The B-lymphocyte nature of the hairy cell of leukaemic reticuloendotheliosis. British Journal of Haematology, 26, 29-37.

Cawley, J. C., Barker, C. R., Britchford, R. D., and Smith, J. L. (1973). Intracellular IgA immunoglobulin crystals in chronic lymphocytic leukaemia. Clinical and Experimental Immunology, 13, 407-416.

Cawley, J. C., and Hayhoe, F. G. J. (1973). Ultrastructure of Haemic Cells: A Cytological Atlas of Normal and Leukaemic Blood and Bone Marrow. W. B. Saunders Co., Ltd., Philadelphia and London.

Chessells, J. M., Hardisty, R. M., Rapson, N. T., and Greaves, M. F. (1977). Acute lymphoblastic leukaemia in children: classification and prognosis. Lancet, 2 , 1307-1309.

Chin, A. H., Saiki, J. H., Trujillo, J. M., and Williams, R. C., Jr. (1973). Peripheral blood T- and B-lymphocytes in patients with lymphoma and acute leukemia. Clinical Immunology and Immunopathology, 1, 499-510.

Clark, C., Rydell, R. E., and Kaplan, M. E. (1973). Frequent association of IgM with crystalline inclusions in chronic lymphatic leukemic lymphocytes. New England Journal of Medicine, 289, 113-117.

Clift, R. A., Wright, D. H., and Clifford, P. (1963). Leukemia in Burkitt's lymphoma. Blood, 22, 243-251. Cline, M. J. (1975). The White Cell. Harvard University 
Press, Cambridge, Massachusetts.

Cline, M. J. (1978). Malignant diseases of the mononuclear phagocyte system, pp. 85-86. In Cline, M. J. (moderator), Monocytes and macrophages: function and diseases. Annals of Internal Medicine, 88, 78-88.

Coccia, P. F., Kersey, J. H., Gajl-Peczalska, K. J., Krivit, W., and Nesbit, M. E. (1976). Prognostic significance of surface marker analysis in childhood non-Hodgkin's lymphoproliferative malignancies. American Journal of Haematology, 1, 405-417.

Cossman, J., Schnitzer, B., and Deegan, M. J. (1977). Immunologic surface markers in non-Hodgkin's lymphomas. American Journal of Pathology, 87, 19-32.

Cottier, H., Turk, J., and Sobin, L. (1973). A proposal for a standardized system of reporting human lymph node morphology in relation to immunological function. Journal of Clinical Pathology, 26, 317-331.

Crossen, P. E., Mellor, J. E. L., Finley, A. G., Ravich, R. B. M., Vincent, P. C., and Gunz, F. W. (1971). The Sézary syndrome. Cytogenetic studies and identification of the Sézary cell as an abnormal lymphocyte. American Journal of Medicine, 50, 24-34.

Dameshek, W. (1963). 'Immunoblasts' and 'immunocytes.' An attempt at functional nomenclature. Blood, 21, 243-245.

Dameshek, W. (1967). Chronic lymphocytic leukemia. An accumulative disease of immunologically incompetent lymphocytes. Blood, 29, 566-584.

Danon, F., Mihaesco, C., Bouvry, M., Clerc, M., and Seligmann, M. (1975). A new case of heavy $\mu$-chain disease. Scandinavian Journal of Haematology, 15, 5-9.

Debusscher, L., Bernheim, J. L., Collard-Rongé, E., Govaerts, A., Hooghe, R., Lejeune, F. J., Zeicher, M., and Stryckmans, P. A. (1975). Hairy cell leukemia: functional, immunologic, kinetic, and ultrastructural characterization. Blood, 46, 495-507.

Deegan, M. J., Cossman, J., Chosney, B. T., and Schnitzer, B. (1976). Hairy cell leukemia. An immunologic and ultrastructural study. Cancer, 38, 1952-1961.

Dick, F., Bloomfield, C. D., and Brunning, R. D. (1974). Incidence, cytology, and histopathology of nonHodgkin's lymphomas in the bone marrow. Cancer, 33, 1382-1398.

Dick, F. R., Parks, W., and O'Connor, M. (1977). Transformation of nodular lymphoma to an immunoblastic IgM-producing tumor. American Journal of Clinical Pathology, 68, 611-615.

Dickler, H. B., Siegal, F. P., Bentwich, Z. H., and Kunkel, H. G. (1973). Lymphocyte binding of aggregated IgG and surface Ig staining in chronic lymphocytic leukaemia. Clinical and Experimental Immunology, 14, 97-106.

Dorfman, R. F. (1974). Classification of non-Hodgkin's lymphomas (Letter). Lancet, 1, 1295-1296.

Dorfman, R. F. (1977). Pathology of the non-Hodgkin's lymphomas: new classifications. Cancer Treatment Reports, 61, 945-951.

Dorfman, R. F., Rice, D. F., Mitchell, A. D., Kempson, R. L., and Levine, G. (1973). Ultrastructural studies of Hodgkin's disease. National Cancer Institute Monographs, 36, 221-238.

Douglas, S. D., Cohnen, G., König, E., and Brittinger, G. (1973). Lymphocyte lysosomes and lysosomal enzymes in chronic lymphocytic leukaemia. Blood, 41, 511-518.

Duhamel, G. (1974). Histopathologie Clinique de la Moëlle Osseuse, pp. 71-77. Masson, Paris.

Dutcher, T. F., and Fahey, J. L. (1959). The histopathology of the macroglobulinemia of Waldenström. Journal of the National Cancer Institute, 22, 887-917.

Edelson, R. L., Kirkpatrick, C. H., Shevach, E. M., Schein, P. S., Smith, R. W., Green, I., and Lutzner, M. (1974). Preferential cutaneous infiltration by neoplastic thymus-derived lymphocytes. Annals of Internal Medicine, 80, 685-692.

Epstein, A. L., Henle, W., Henle, G. Hewetson, J. F., and Kaplan, H. S. (1976). Surface marker characteristics and Epstein-Barr virus studies of two established North American Burkitt's lymphoma cell lines. Proceedings of the National Academy of Sciences of the United States of America, 73, 228-232.

Epstein, M. A., and Achong, B. G. (1965). Fine structural organization of human lymphoblasts of a tissue culture strain (EBI) from Burkitt's lymphoma. Journal of the National Cancer Institute, 34, 241-253.

Epstein, M. A., and Barr, Y. M. (1965). Characteristics and mode of growth of a tissue culture strain (EBI) of human lymphoblasts from Burkitt's lymphoma. Journal of the National Cancer Institute, 34, 231-240.

Ewald, O. (1923). Die leukämische Reticuloendotheliose. Deutsches Archiv für klinische Medizin, 142, 222-228.

Farquhar, J. W., MacGregor, A. R., and Richmond, J. (1958). Familial haemophagocytic reticulosis. British Medical Journal, 2, 1561-1564.

Feremans, W. W., Demaertelaere, E., Delalieux, G., and Neve, P. (1976). Clinical and ultrastructural study of Burkitt-like leukaemia. Pathologia Europaea, 11, 137146.

Fishkin, B. G., and Spiegelberg, H. L. (1976). Cervical lymph node metastasis as the first manifestation of localized extramedullary plasmacytoma. Cancer, 38, 1641-1644.

Flandrin, G., and Bernard, J. (1975). Cytological classification of acute leukemias. A survey of 1400 cases. In Unclassifiable Leukemias, edited by M. Bessis and G. Brecher, pp. 7-16. Springer, Berlin.

Flandrin, G., Brouet, J. C., Daniel, M. T., and Preud'homme, J. L. (1975). Acute leukemia with Burkitt's tumor cells: a study of six cases with special reference to lymphocyte surface markers. Blood, 45, 183-188.

Flandrin, G., Daniel, M. T., El Yafi, G., and Chelloul, N. (1972). Sarcomatoses ganglionnaires diffuses a différenciation plasmocytaire avec anémie hémolytique autoimmune. Actualités Hématologiques, 6, 24-41.

Flandrin, G., Daniel, M. T., Fourcade, M., and Chelloul, N. (1973). Leucémie a 'tricholeucocyte' (hairy cell leukemia), étude clinique et cytologique de 55 observations. Nouvelle Revue Française d'Hématologie, 13, 609-640.

Florentin, I. (1975). The immunoblast. Biomedicine, 22, 457-460.

Florin-Christensen, A., Doniach, D., and Newcomb, P. B. (1974). Alpha-chain disease with pulmonary manifestations. British Medical Journal, 2, 413-415. 
Forte, F. A., Prelli, F., Yount, W. J., Jerry, L. M., Kochwa, S., Franklin, E. C., and Kunkel, H. G. (1970). Heavy chain disease of the $\mu(\gamma \mathrm{M})$ type: report of the first case. Blood, 36, 137-144.

Franklin, E. C., Lowenstein, J., Bigelow, B., and Meltzer, M. (1964). Heavy chain disease-a new disorder of serum $\gamma$-globulins. Report of the first case. American Journal of Medicine, 37, 332-350.

Frøland, S. S., Natvig, J. B., and Stavem, P. (1972). Immunological characterization of lymphocytes in lymphoproliferative diseases. Restriction of classes, subclasses and $\mathrm{Gm}$ allotypes of membrane-bound Ig. Scandinavian Journal of Immunology, 1, 351-360.

Fu, S. M., Winchester, R. J., and Kunkel, H. G. (1974). Occurrence of surface IgM, IgD, and free light chains on human lymphocytes. Journal of Experimental Medicine, 139, 451-456.

van Furth, R., Cohn, Z. A., Hirsch, J. G., Humphrey, J. H., Spector, W. G., and Langevoort, H. L. (1972). The mononuclear phagocyte system: a new classification of macrophages, monocytes, and their precursor cells. Bulletin of the World Health Organization, 46, 845-852.

Gajl-Peczalska, K. J., Bloomfield, C. D., Nesbit, M. E., and Kersey, J. H. (1974). B-cell markers on lymphoblasts in acute lymphoblastic leukemia. Clinical and Experimental Immunology, 17, 561-569.

Gajl-Peczalska, K. J., Hansen, J. A., Bloomfield, C. D., and Good, R. A. (1973). B lymphocytes in untreated patients with malignant lymphoma and Hodgkin's disease. Journal of Clinical Investigation, 52, 30643073.

Galton, D. A. G. (1966). The pathogenesis of chronic lymphocytic leukemia. Canadian Medical Association Journal, 94, 1005-1010.

Galton, D. A. G., Goldman, J. M., Wiltshaw, E., Catovsky, D., Henry, K., and Goldenberg, G. J. (1974). Prolymphocytic leukaemia. British Journal of Haematology, 27, 7-23.

Garrett, J. V., Newton, R. K., Scarffe, J. H. (1977). Abnormal blood lymphocytes in non-Hodgkin's lymphoma (Letter). Lancet, 1, 542.

Gelfand, E. W., and Chechik, B. E. (1976). Unmasking the heterogeneity of acute lymphoblastic leukemia. New England Journal of Medicine, 294, 275-276.

Gerard-Marchant, R., Hamlin, I., Lennert, K., Rilke, F., Stansfeld, A. G., and van Unnik, J. A. M. (1974). Classification of non-Hodgkin's lymphomas (Letter). Lancet, 2, 406-408.

Ghon, A., and Roman, B. (1916). Über das Lymphosarkom. Frankfurter Zeitschrift für Pathologie, 19, 1138.

Glick, A. D., Leech, J. H., Flexner, J. M., and Collins, R. D. (1976). Ultrastructural study of Reed-Sternberg cells. Comparison with transformed lymphocytes and histiocytes. American Journal of Pathology, 85, 195-208.

Glick, A. D., Leech, J. H., Waldron, J. A., Flexner, J. M., Horn, R. G., and Collins, R. D. (1975). Malignant lymphomas of follicular center cell origin in man. II. Ultrastructural and cytochemical studies. Journal of the National Cancer Institute, 54, 23-36.

Goldberg, G. M., and Emanuel, B. (1964). A study of malignant lymphomas and leukemias. VII. Lymphogenous leukemia and lymphosarcoma involvement of the lymphatic and hemic bed, with reference to differentiating criteria. Cancer, 17, 277-287.

Golde, D. W., Saxon, A., and Stevens, R. H. (1977a). Macroglobulinemia and hairy-cell leukemia. New England Journal of Medicine, 296, 92-93.

Golde, D. W., Saxon, A., and Stevens, R. H. (1977b). Letter to the Editor (on hairy-cell leukemia). New England Journal of Medicine, 296, 882.

Goldstone, A. H., Cawley, J. C., Roberts, S. O., Leventine, A., and Barker, C. R. (1976). A case of small-cell Sézary's syndrome with null-cell features. Journal of Clinical Pathology, 29, 848-851.

Gray, J. L., Jacobs, A., and Block, M. (1974). Bone marrow and peripheral blood lymphocytosis in the prognosis of chronic lymphocytic leukemia. Cancer, 33, 1169-1178.

Greaves, M. F. (1977). Immunodiagnosis of leukaemia. In Immunodiagnosis of Cancer, edited by R. Herberman and K. McIntyre. Marcel Dekker Inc, New York.

Greaves, M. F., Brown, G., Rapson, N. T., and Lister, T. A. (1975). Antisera to acute lymphoblastic leukemia cells. Clinical Immunology and Immunopathology, 4, 67-84.

Greenberg, B. R., Peter, C. R., Glassy, F., and MacKenzie, M. R. (1976). A case of T-cell lymphoma with convoluted lymphocytes. Cancer, 38, 1602-1607.

Grey, H. M., Rabellino, E., and Pirofsky, B. (1971). Immunoglobulins on the surface of lymphocytes. IV. Distribution in hypogammaglobulinemia, cellular immune deficiency, and chronic lymphatic leukemia. Journal of Clinical Investigation, 50, 2368-2375.

Haak, H. L., De Man, J. C. H., Hijmans, W., Knapp, W., and Speck, B. (1974). Further evidence for the lymphocytic nature of leukaemic reticuloendotheliosis (hairy cell leukaemia). British Journal of Haematology, 27, 31-38.

Habeshaw, J. A., Macaulay, R. A. A., and Stuart, A. E. (1977). Correlation of surface receptors with histological appearance in 29 cases of non-Hodgkin lymphoma. British Journal of Cancer, 35, 858-867.

Habeshaw, J. A., and Stuart, A. E. (1975). Cell receptor studies on seven cases of diffuse histiocytic malignant lymphoma (reticulum cell sarcoma). Journal of Clinical Pathology, 28, 289-297.

Hann, H. L., London, W. T., and Evans, A. E. (1977). Lymphoblasts with $\mathrm{T}$-cell markers in five girls with acute lymphocytic leukemia. Cancer, 39, 2001-2003.

Harigaya, K. (1977). Enzyme histochemical characteristics of non-Hodgkin's lymphomas. Acta Pathologica Japonica, 27, 345-358.

Hausner, R. J., Rosas-Uribe, A., Wickstrum, D. A., and Smith, P. C. (1977). Non-Hodgkin's lymphoma in the first two decades of life. A pathological study of 30 cases. Cancer, 40, 1533-1547.

Henry, K. (1975). Electron miscroscopy in the nonHodgkin's lymphomata. British Journal of Cancer, 31 (Supplement 2), 73-93.

Henry, K., and Farrer-Brown, G. (1977). Primary lymphomas of the gastrointestinal tract. I. Plasma cell tumors. Histopathology, 1, 53-76. 
Henry, K., and Goldman, J. M. (1975). The lymphocyte. In Recent Advances in Pathology, no. 9, edited by C. V. Harrison and K. Weinbren, pp. 30-72. Churchill Livingstone, Edinburgh and London.

Hsu, C. C. S., Marti, G. E., Schrek, R., and Williams, R. C., Jr. (1975). Lymphocytes bearing B- and T-cell markers in patients with lymphosarcoma cell leukemia. Clinical Immunology and Immunopathology, 3, 385395.

Huber, C., Dworzak, E., Fink, U., Michlmayr, G., Braunsteiner, H., and Huber, H. (1974). Receptor sites for aggregated gammaglobulin (AGG) on lymphocytes in lymphoproliferative diseases. British Journal of Haematology, 27, 643-654.

Hübner, K. F., and Littlefield, L. G. (1975). Burkitt lymphoma in three American children. American Journal of Diseases of Children, 129, 1219-1223.

Humphrey, G. B., Nesbit, M. E., and Brunning, R. D. (1974). Prognostic value of the periodic acid-Schiff (PAS) reaction in acute lymphoblastic leukemia. American Journal of Clinical Pathology, 61, 393-397.

Hurez, D., Flandrin, G., Preud'homme, J. L., and Seligmann, M. (1972). Unreleased intracellular monoclonal macroglobulin in chronic lymphocytic leukaemia. Clinical and Experimental Immunology, 10, 223234.

Isaacs, R. (1973). Lymphosarcoma cell leukemia. Annals of Internal Medicine, 11, 657-662.

Jaffe, E. S., Braylan, R. C., Nanba, K., Frank, M. M., and Berard, C. W. (1977). Functional markers: a new perspective on malignant lymphomas. Cancer Treatment Reports, 61, 953-962.

Jaffe, E. S., Shevach, E. M., Frank, M. M., Berard, C. W., and Green, I. (1974a). Nodular lymphomaevidence for origin from follicular B lymphocytes. New England Journal of Medicine, 290, 813-819.

Jaffe, E. S., Shevach, E. M., Frank, M. M., and Green, I. (1974b). Leukemic reticuloendotheliosis: presence of a receptor for cytophilic antibody. American Journal of Medicine, 57, 108-114.

Jaffe, E. S., Shevach, E. M., Sussman, E. H., Frank, M. M., Green, I., and Berard, C. W. (1975). Membrane receptor sites for the identification of lymphoreticular cells in benign and malignant conditions. British Journal of Cancer, 31 (Supplement 2), 107-120.

Johansson, B., and Klein, E. (1970). Cell surface localized IgM-kappa immunoglobulin reactivity in a case of chronic lymphocytic leukaemia. Clinical and Experimental Immunology, 6, 421-428.

Johansson, B., Klein, E., and Haglund, S. (1976). Correlation between the presence of surface localized immunoglobulin (Ig) and the histological type of human malignant lymphomas. Clinical Immunology and Immunopathology, 5, 119-132.

Jondal, M., Holm, G., and Wigzell, H. (1972). Surface markers on human T and B lymphocytes. I. A large population of lymphocytes forming nonimmune rosettes with sheep red blood cells. Journal of Experimental Medicine, 136, 207-215.

Jones, S. E., Fuks, Z., Bull, M., Kadin, M. E., Dorfman, R. F., Kaplan, H. S., Rosenberg, S. A., and Kim, H. (1973). Non-Hodgkin's lymphomas. IV. Clinicopath- ological correlation in 405 cases. Cancer, 31, 806-823.

Jones, S. E., Rosenberg, S. A., and Kaplan, H. S. (1972). Non-Hodgkin's lymphomas. I. Bone marrow involvement. Cancer, 29, 954-960.

Kaiserling, E. (1977a). Non-Hodgkin-Lymphome: Ultrastruktur und Cytogenese. G. Fischer, Stuttgart.

Kaiserling, E. (1977b). Morphologische Befunde zur Microökologie des T-Zonen-Lymphoms und des centroblastisch/centrocytischen Lymphoms (Abstract). Verhandlungen der Deutschen Gesellschaft für Pathologie, 61, 362.

Kaiserling, E., Stein, H., and Lennert, K. (1973). IgMproducing malignant lymphomas without macroglobulinemia. Morphological and immunochemical findings. Virchow's Archiv, B: Zellpathologie, 14, 1-18.

Kaplan, J., Mastrangelo, R., and Peterson, W. D., Jr. (1974). Childhood lymphoblastic lymphoma, a cancer of thymus-derived lymphocytes. Cancer Research, 34, 521-525.

Katayama, I., Nagy, G. K., and Balogh, K., Jr. (1973). Light microscopic identification of the ribosomelamella complex in 'hairy cells' of leukemic reticuloendotheliosis. Cancer, 32, 843-846.

Katayama, I., and Schneider, G. B. (1977). Further ultrastructural characterization of hairy cells of leukemic reticuloendotheliosis. American Journal of Pathology, 86, 163-182.

Kaung, D. T., and Ott, M. (1975). Are normal lymphocytes small? (Letter). Lancet, 2, 414.

Kay, N. E., Douglas, S. D., and Estren, S. (1974). T-cells in chronic lymphocytic leukaemia (Letter). Lancet, 2 , 1326.

Kersey, J., Nesbit, M., Hallgren, H., Sabad, A., Yunis, E., and Gajl-Peczalska, K. J. (1975). Evidence for origin of certain childhood acute lymphoblastic leukemias and lymphomas in thymus-derived lymphocytes. Cancer, 36, 1348-1352.

Kersey, J. H., Sabad, A., Gajl-Peczalska, K. J., Hallgren, H. M., Yunis, E. J., and Nesbit, M. E. (1973). Acute lymphoblastic leukemic cells with $T$ (thymus-derived) lymphocyte markers. Science, 182, 1355-1356.

Klein, B., Lewinski, U., Shabtai, F., Freidin, N., and Djaldetti, M. (1977). Transmission and scanning electron microscopy study on plasma cell leukemia. Blut, 35, 11-19.

Klein, G. (1971). Immunological aspects of Burkitt's lymphoma. Advances in Immunology, 14, 187-250.

Kojima, M., Imai, Y., and Mori, N. (1973). A concept of follicular lymphoma. A proposal for the existence of a neoplasm originating from the germinal center. $G A N N$ Monographs on Cancer Research, 15, 195-207.

Koziner, B., Filippa, D. A., Mertelsmann, R., Gupta, S., Clarkson, B., Good, R. A., and Siegal, F. P. (1977). Characterization of malignant lymphomas in leukemic phase by multiple differentiation markers of mononuclear cells. Correlation with clinical features and conventional morphology. American Journal of Medicine, 63, 556-567.

Krause, J. R., Srodes, C., and Lee, R. E. (1977). Use of the bone marrow imprint in the diagnosis of leukemic reticuloendotheliosis ('hairy cell leukemia'). American Journal of Clinical Pathology, 68, 368-371. 
Kuhn, C. (1967). Nuclear bodies and intranuclear globulin inclusions in Waldenström's macroglobulinemia. Laboratory Investigation, 17, 404-415.

Kulenkampff, J., Janossy, G., and Greaves, M. F. (1977). Acid esterase in human lymphoid cells and leukaemic blasts: a marker for T lymphocytes. British Journal of Haematology, 36, 231-240.

Lancet (1977). Enzyme markers in leukaemia. (Editorial). Lancet, 2, 539-540.

Laurie, H. C. (1968). Duration of remissions in lymphoblastic leukaemia of childhood. British Medical Journal, 2, 95-97.

Lay, W. H., Mendes, N. F., Bianco, C., and Nussenzweig, V. (1971). Binding of sheep red blood cells to a large population of human lymphocytes. Nature, 230, 531532.

Leder, L. D. (1971). Zytochemische Differenzierung normaler und pathologischer mononuklärer Blut- und Knochenmarkszellen. Acta Histochemica, Supplement 9, 141-151.

Leder, L., D., and Stutte, H. J. (1975). Seminar für hämatologisch-zytochemische Techniken. Verhandlungen der Deutschen Gesellschaft für Pathologie, 59, 503-509.

Leech, J. H., Glick, A. D., Waldron, J. A., Flexner, J. M., Horn, R. G., and Collins, R. D. (1975a). Malignant lymphomas of follicular center cell origin in man. I. Immunologic studies. Journal of the National Cancer Institute, 54, 11-21.

Leech, J., Roy, R. M., Flexner, J. M., Glick, A. D., Waldron, J. A., and Collins, R. D. (1975b). Evidence for synthesis of surface immunoglobulin in leukemic reticuloendotheliosis (Abstract) Blood, 46, 1037.

Lennert, K. (1957). Über die Erkennung von Keimzentrumszellen in Lymphknotenausstrich. Klinische Wochenschrift, 35, 1130-1132.

Lennert K. (1961). Lymphknoten Diagnostik in Schnitt und Ausstrich. A. Cytologie und Lymphadenitis (Handbuch der speziellen pathologischen Anatomie und Histologie, Bd. 1, Th. 3). Springer, Berlin.

Lennert, K. (1964). Pathologie der Halslymphknoten. Springer, Berlin.

Lennert, K. (1968). Classification of the malignant lymphomas (European concept). In Progress in Lymphology: Proceedings of the International Symposium on Lymphology, Zürich, edited by A. Rüttimann, pp. 103-109. Thieme, Stuttgart.

Lennert, K. (1969). Pathologisch-anatomische Klassifikation der malignen Lymphome. Strahlentherapie, Supplement 69, 1-7.

Lennert, K. (1973). Follicular lymphoma. A tumor of the germinal centers. GANN Monograph on Cancer Research, 15, 217-231.

Lennert, K. (1974). Origin of malignant lymphomas (Letter). Lancet, 2, 586.

Lennert, K. (1975). Morphology and classification of malignant lymphomas and so-called reticuloses. Acta Neuropathologica, Supplement 6, 1-16.

Lennert, K. (1976). Klassifikation und Morphologie der Non-Hodgkin-Lymphome. Blut, Supplement, 18, 145-166.

Lennert, K., Caesar, R., and Müller, H. K. (1966).
Electron miscroscopic studies of germinal centers in man. In Germinal Centers in Immune Responses, edited by $\mathbf{H}$. Cottier, N. Odartchenko, R. Schindler and C. C. Congdon, pp. 49-59. Springer, Berlin.

Lennert, K., Kaiserling, E., and Müller-Hermelink, H. K. (1975a). T-associated plasma-cells. Lancet, 1, 10311032.

Lennert, K., Mitrou, P., and Müller-Hermelink, H. K. (1969). Cytophotometric and autoradiographic investigations on germinal center cells in man. In Lymphatic Tissue and Germinal Centers in Immune Response, edited by L. Fiore-Donati and M. G. Hanna, Jr. pp. 65-71. Plenum Press, New York.

Lennert, K., and Mohri, N. (1971). Zur Pathologie der Leukämien und malignen Lymphome im Kindesalter (Referat). Verhandlungen der Deutschen Gesellschaft für Pathologie, 55, 216-269.

Lennert, K., Mohri, N., Stein, H., and Kaiserling, E. (1975b). The histopathology of malignant lymphoma. British Journal of Haematology, Supplement 31, 193203.

Lennert, K., and Müller-Hermelink, H. K. (1975). Lymphocyten und ihre Funktionsformen. Morphologie, Organisation und immunologische Bedeutung. Verhandlungen der Anatomischen Gesellschaft, 69, 19-62.

Lennert, K., and Niedorf, H. R. (1969). Nachweis von desmosomal verknüpften Reticulumzellen im follikukären Lymphom (Brill-Symmers). Virchows Archiv, B: Zellpathologie, 4, 148-150.

Lennert, K., and Remmele, W. (1958). Karyometrische Untersuchungen an Lymphknotenzellen des Menschen. I. Germinoblasten, Lymphoblasten und Lymphozyten. Acta Haematologica, 19, 99-113.

Lennert, K., and Rinneberg, H. (1961). Fermenthistochemische Untersuchungen des Lymphknotens. II. Adenosintriphosphatase und 5-Nucleotidase imLymphknotenschnitt. Klinische Wochenschrift, 39, 923-924.

Lennert, K., Stein, H., and Kaiserling, E. (1975c). Cytological and functional criteria for the classification of malignant lymphomata. British Journal of Cancer, 31, Supplement 2, 29-43.

Levin, W. C., Gehan, E., Griffith, K., Huguley, C. M., Silver, R. T., Steinfeld, J. L., Weiner, L., and Cahn, E. L. (1973). Proposed guidelines for protocol studies. III. Chronic lymphocytic leukemia. Cancer Chemotherapy Reports, 4 (3), 159-165.

Levine, G. D., and Dorfman, R. F. (1975). Nodular lymphoma: an ultrastructural study of its relationship to germinal centers and a correlation of light and electron microscopic findings. Cancer, 35, 148-164.

Levine, P. H., Cho, B. R., Connelly, R. R., Berard, C. W., O'Conor, G. T., Dorfman, R. F., Easton, J. M., and DeVita, V. T. (1975). The American Burkitt lymphoma registry: a progress report. Annals of Internal Medicine, 83, 31-36.

Lewin, K. J., Kahn, L. B., and Novis, B. H. (1976). Primary intestinal lymphoma of 'Western' and 'Mediterranean' type, alpha chain disease and massive plasma cell infiltration. Cancer, 38, 2511-2528.

Li, C. Y., Yam, L. T., and Crosby, W. H. (1972). Histochemical characterization of cellular and structural elements of the human spleen. Journal of Histo- 
chemistry and Cytochemistry, 20, 1049-1058.

Lille, I., Desplaces, A., Meeus, L., Saracino, R. T., and Brouet, J. C. (1973). Thymus-derived proliferating lymphocytes in chronic lymphocytic leukaemia (Letter). Lancet, 2, 263-264.

Lin, P. S., and Hsu, C. C. S. (1976). Human leukaemic T cells with complement receptors. Clinical and Experimental Immunology, 23, 209-213.

Löffler, H. (1972). Cytologische Befunde beim SézarySyndrom. Verhandlungen der Deutschen Gesellschaft für innere Medizin, 78, 285-287.

Lombardi, L., Carbone, A., Pilotti, S., and Rilke, F. (1978). Malignant histiocytosis: a histological and ultrastructural study of lymph nodes in six cases. Histopathology (In press).

Long, J. C., and Aisenberg, A. C. (1975). Richter's syndrome. A terminal complication of chronic lymphocytic leukemia with distinct clinicopathologic features. American Journal of Clinical Pathology, 63, 786-795.

Long, J. C., and Mihm, M. C. (1974). Mycosis fungoides with extra-cutaneous dissemination: a distinct clinicopathologic entity. Cancer, 34, 1745-1755.

Lowenbraun, S., Sutherland, J. C., Feldman, M. J., and Serpick, A. A. (1971). Transformation of reticulum cell sarcoma to acute leukemia. Cancer, 27, 579-585.

Lukes, R. J. (1968). The pathologic picture of the malignant lymphomas. In Proceedings of the International Conference on Leukemia-Lymphoma, edited by C. J. D. Zarafonetis, pp. 331-354. Lea and Febiger, Philadelphia.

Lukes, R. J., Butler, J. J., and Hicks, E. B. (1966). Natural history of Hodgkin's disease as related to its pathological picture. Cancer, 19, 317-344.

Lukes, R. J., and Collins, R. D. (1974). Immunologic characterization of human malignant lymphomas. Cancer, 34, 1488-1503.

Lukes, R. J., and Collins, R. D. (1975). A functional classification of malignant lymphomas. In The Reticuloendothelial System (International Academy of Pathology Monograph), edited by J. W. Rebuck, C. W. Berard and M. R. Abell, pp. 213-242. Williams and Wilkins Co., Baltimore.

Lukes, R. J., and Tindle, B. H. (1975). Immunoblastic lymphadenopathy. A hyperimmune entity resembling Hodgkin's disease. New England Journal of Medicine, 292, 1-8.

Lutzner, M., Edelson, R., Schein, P., Green, I., Kirkpatrick, C., and Ahmed, A. (1975). Cutaneous Tcell lymphomas: the Sézary syndrome, mycosis fungoides, and related disorders. Annals of Internal Medicine, 83, 534-552.

Lutzner, M. A., Emerit, I., Durepaire, R., Flandrin, G., Grupper, C., and Prunieras, M. (1973). Cytogenetic, cytophotometric, and ultrastructural study of large cerebriform cells of the Sézary syndrome and description of a small-cell variant. Journal of the National Cancer Institute, 50, 1145-1162.

Lutzner, M. A., Hobbs, J. W., and Horvath, P. (1971). Ultrastructure of abnormal cells in Sézary syndrome, mycosis fungoides, and parapsoriasis en plaque. Archives of Dermatology, 103, 375-386.

Lutzner, M. A., and Jordan, H. W. (1968). The ultra- structure of an abnormal cell in Sézary's syndrome. Blood, 31, 719-726.

McCaffrey, R., Harrison, T. A., Parkman, R., and Baltimore, D. (1975). Terminal deoxyncleotidyl transferase activity in human leukemic cells and in normal human thymocytes. New England Journal of Medicine, 292, 775-780.

McKenna, R. W., Bloomfield, C. D., and Brunning, R. D. (1975). Nodular lymphoma: bone marrow and blood manifestations. Cancer, 36, 428-440.

Mann, R. B., Jaffe, E. S., Braylan, R. C., Nanba, K., Frank, M. M., Ziegler, J. L., and Berard, C. W. (1976). Non-endemic Burkitt's lymphoma: a B-cell tumor related to germinal centers. New England Journal of Medicine, 295, 685-691.

Manolov, G., and Manolova, Y. (1972). Marker band in one chromosome 14 from Burkitt lymphomas. Nature, 237, 33-34.

Marschalko, T. (1895). Über die sogenannten Plasmazellen; ein Beitrag zur Kenntnis der Herkunft der entzündlichen Infiltrationszellen. Archiv für Dermatologie und Syphilis, 30, 241-282.

Mathé, G., Belpomme, D., Dantchev, D., Khalil, A., Afifi, A. M., Taleb, N., Pouillart, P., Schwarzenberg, L., Hayat, M., De Vassal, F., Jasmin, C., Misset, J. L., and Musset, M. (1975a). Immunoblastic lymphosarcoma, a cytological and clinical entity? Biomedicine, 22 , 473-488.

Mathé, G., Belpomme, D., Dantchev, D., Pouillart, P., Schlumberger, J. R., and Lafleur, M. (1975b). Leukaemic lymphosarcomas: respective prognosis of the three types: prolymphocytic, lymphoblastic (or lymphoblastoid) and immunoblastic. Blood Cells, 1, 25-36.

Mathé, G., Rappaport, H., O'Conor, G. T., and Torloni, H. (1976). Histological and Cytological Typing of Neoplastic Diseases of Haematopoietic and Lymphoid Tissues, p. 28. World Health Organization, Geneva.

Matter, A., Lisowska-Bernstein, B., Ryser, J. E., Lamelin, J. P., and Vassalli, P. (1972). Mouse thymus-independent and thymus-derived lymphoid cells. Journal of Experimental Medicine, 136, 1008-1030.

Mennemeyer, R., Hammar, S. P., and Cathey, W. J. (1974). Malignant lymphoma with intracytoplasmic IgM crystalline inclusions. New England Journal of Medicine, 291, 960-963.

Milanesi, S. (1965a). Sulla ultrastruttura dei follicoli linfatici del linfonodo. Bollettino della Società Italiana di Biologia Sperimentale, 41, 1221-1223.

Milanesi, S. (1965b). Sulla presenza di dispositivi di giunzione tra le cellule dendritiche dei follicoli linfatici del linfonodo. Bollettino della Società Italiana di Biologia Sperimentale, 41, 1223-1225.

Moran, E. M., Walther, J. R., Aronson, I. K., and Variakojis, D. (1977). Clinical significance of circulating Sézary cells in mycosis fungoides (Abstract). Proceedings of the American Society of Clinical Oncology, 18, 276.

Mori, Y., and Lennert, K. (1969). Electron Microscopic Atlas of Lymph Node Cytology and Pathology. Springer, Berlin, Heidelberg.

Müller, J., Brun del Re, G., Bürki, H., Keller, H. U., Hess, M. W., and Cottier, H. (1975). Nonspecific acid 
esterase activity: a criterion for differentiation of $\mathrm{T}$ and B lymphocytes in mouse lymph nodes. European Journal of Immunology, 5, 270-274.

Müller-Hermelink, H. K. (1974). Characterization of the B-cell and T-cell regions of human lymphatic tissue through enzyme histochemical demonstration of ATPase and 5'-nucleotidase activities. Virchows Archiv, B: Zellpathologie, 16, 371-378.

Müller-Hermelink, H. K., and Kaiserling, E. (1975). Seminar für elektronenmikroskopisch-histochemische Techniken. Verhandlungen der Deutschen Gesellschaft für Pathologie, 59, 522-527.

Naeim, F., Gossett, T., and Walford, R. L. (1977). Reactivity of the Merrit B-cell alloantiserums with hairy cells (Letter). New England Journal of Medicine, 296, 882.

Nanba, K., Jaffe, E. S., Braylan, R. C., Soban, E. J., and Berard, C. W. (1977a). Alkaline phosphatase-positive malignant lymphoma. A subtype of B-cell lymphomas. American Journal of Clinical Pathology, 68, 535-542.

Nanba, K., Jaffe, E. S., Soban, E. J., Braylan, R. C., and Berard, C. W. (1977b). Hairy cell leukemia. Enzyme histochemical characterization, with special reference to splenic stromal changes. Cancer, 39, 2323-2336.

Nanba, K., Soban, E. J., Bowling, M. C., and Berard, C. W. (1977c). Splenic pseudosinuses and hepatic angiomatous lesions. Distinctive features of hairy cell leukemia. American Journal of Clinical Pathology, 67, 415-426.

Napoli, V. M., Nichols, C. W., and Wright, R. E. (1977). Malignant lymphoma of the nasopharynx in Waldenström's macroglobulinemia: report of a case with severe epistaxis. Southern Medical Journal, 70, 508-509.

Nathwani, B. N., Kim, H., and Rappaport, H. (1976). Malignant lymphoma, lymphoblastic. Cancer, 38, 964983.

Newell, D. G., Roath, S., and Smith, J. L. (1976). The scanning electron microscopy of normal human peripheral blood lymphocytes. British Journal of Haematology, 32, 309-316.

Nezelof, C., Basset, F., and Rousseau, M. F. (1973). Histiocytosis X. Histogenetic arguments for a Langerhans cell origin. Biomedicine, 18, 365-371.

Nieuwenhuis, P., and Keuning, F. J. (1974). Germinal centres and the origin of the B-cell system. II. Germinal centres in the rabbit spleen and popliteal lymph nodes. Immunology, 26, 509-519.

Nossal, G. J. V., Abbot, A., Mitchell, J., and Lummus, Z. (1968). Antigens in immunity. XV. Ultrastructural features of antigen capture in primary and secondary lymphoid follicles. Journal of Experimental Medicine, 127, 277-289.

Nussenzweig, V., Bianco, C., Dukor, P., and Eden, A. (1971). Receptors for C3 on B lymphocytes. Possible role in the immune response. In Progress in Immunology, edited by B. Amos, pp. 73-82. Academic Press, New York.

Oberling, C. (1928). Les réticulosarcomes et les réticuloendothéliosarcomes de la moelle osseuse (sarcomes d'Ewing). Bulletin de l'Association Française pour Etude du Cancer, 17, 259-296.

O'Conor, G. T., Rappaport, H., and Smith, E. B. (1965).
Childhood lymphoma resembling 'Burkitt tumor' in the United States. Cancer, 18, 411-417.

Pangalis, G. A., Nathwani, B. N., and Rappaport, H. (1977). Malignant lymphoma, well differentiated lymphocytic. Its relationship with chronic lymphocytic leukemia and macroglobulinemia of Waldenström. Cancer, 39, 999-1010.

Pangalis, G. A., and Rappaport, H. (1977). Common clonal origin of lymphoplasmacytic proliferation and immunoblastic lymphoma in intestinal $a$-chain disease (Letter). Lancet, 2, 880.

Payne, S. V., Smith, J. L., Jones, D. B., and Wright, D. H. (1977). Lymphocyte markers in non-Hodgkin's lymphomas. British Journal of Cancer, 36, 57-64.

Pernis, B., Forni, L., and Amante, L. (1970). Immunoglobulin spots on the surface of rabbit lymphocytes. Journal of Experimental Medicine, 132, 1001-1018.

Peter, C. R., MacKenzie, M. R., and Glassy, F. J. (1974). T or B cell origin of some non-Hodgkin's lymphomas. Lancet, 2, 686-689.

Peterson, L. C., Bloomfield, C. D., Sundberg, R. D., Gajl-Peczalska, K. J., and Brunning, R. D. (1975). Morphology of chronic lymphocytic leukemia and its relationship to survival. American Journal of Medicine, 59, 316-324.

Philip, P., Jensen, M. K., and Pallesen, G. (1977). Marker chromosome $14 \mathrm{q}+$ in non-endemic Burkitt's lymphoma. Cancer, 39, 1495-1499.

Piessens, W. F., Schur, P. H., Moloney, W. C., and Churchill, W. H. (1973). Lymphocyte surface immunoglobulins. Distribution and frequency in lymphoproliferative diseases. New England Journal of Medicine, 288, 176-180.

Pinkus, G. S., and Said, J. W. (1977). Specific identification of intracellular immunoglobulin in paraffin sections of multiple myeloma and macroglobulinemia using an immunoperoxidase technique. American Journal of Pathology, 87, 47-58.

Polliack, A. (1977). Surface morphology of leukemic cells: application of scanning electron microscopy to the study of human leukemias. Israel Journal of Medical Sciences, 13, 701-709.

Polliack, A., Djaldetti, M., Reyes, F., Biberfeld, P., Daniel, M. T., and Flandrin, G. (1977). Surface features of Sézary cells: a scanning electron microscopy study of 5 cases. Scandinavian Journal of Haematology, 18, 207-213.

Preud'homme, J. L., Brouet, J. C., and Seligmann, M. (1975). Lymphocyte membrane markers in human lymphoproliferative diseases. In Membrane Receptors of Lymphocytes, edited by M. Seligmann, J. L. Preud'homme, and F. M. Kourilsky, pp. 417-429. North-Holland Publ. Co., Amsterdam.

Preud'homme, J. L., and Seligmann, M. (1972). Surface bound immunoglobulins as a cell marker in human lymphoproliferative diseases. Blood, 40, 777-794.

Quaglino, D., and Cowling, D. C. (1964). Cytochemical studies on cells from chronic lymphocytic leukaemia and lymphosarcoma cultured with phytohaemagglutinin. British Journal of Haematology, 10, 358-364.

Rai, K. R., Sawitsky, A., Cronkite, E. P., Chanana, A. D., Levy, R. N., and Pasternack, B. S. (1975). Clinical 
staging of chronic lymphocytic leukemia. Blood, 46, 219-234.

Rambaud, J. C., Bognel, C., Prost, A., Bernier, J. J., Le Quintrec, Y., Lambling, A., Danon, F., Hurez, D., and Seligmann, M. (1968). Clinico-pathological study of a patient with 'Mediterranean' type of abdominal lymphoma and a new type of IgA abnormality ('alpha chain disease'). Digestion, 1, 321-336.

Rambaud, J. C., and Matuchansky, C. (1973). Alphachain disease: pathogenesis and relation to Mediterranean lymphoma. Lancet, 1, 1430-1432.

Ramot, B., Levanon, M., Hahn, Y., Lahat, N., and Moroz, C. (1977). The mutual clonal origin of the lymphoplasmocytic and lymphoma cell in alpha heavychain disease. Clinical and Experimental Immunology, 27, 440-445.

Rappaport, H. (1966). Tumors of the Hematopoietic System (Atlas of Tumor Pathology, sect. 3, fasc. 8). Armed Forces Institute of Pathology, Washington, D.C.

Rappaport, H., Ramot, B., Hulu, N., and Park, J. K. (1972). The pathology of so-called Mediterranean abdominal lymphoma with malabsorption. Cancer, 29, 1502-1511.

Rappaport, H., and Thomas, L. B. (1974). Mycosis fungoides: the pathology of extracutaneous involvement. Cancer, 34, 1198-1229.

Rappaport, H., Winter, W. J., and Hicks, E. B. (1956). Follicular lymphoma. A re-evaluation of its position in the scheme of malignant lymphoma, based on a survey of 253 cases. Cancer, 9, 792-821.

Reid, M. M., Craft, A. W., and Walker, W. (1977). Poor prognosis of T-cell leukaemia in children. Lancet, 2, 1074-1075.

Reynes, M., and Diebold, J. (1977). Polysome-lamellae complexes in a case of nodular pleomorphic lymphoblastosarcoma. Biomedicine (Express), 27, 55-57.

Richter, M. N. (1928). Generalized reticular cell sarcoma of lymph nodes associated with lymphatic leukemia. American Journal of Pathology, 4, 285-292.

Rilke, F., Carbone, A., Musumeci, R., Pilotti, S., De Lena, M., and Bonadonna, G. (1978a). Malignant histiocytosis. Clinicopathologic study of 18 consecutive cases. Tumori, 64, 211-227.

Rilke, F., Clemente, C., Pilotti, S., and Musumeci, R. (1975). Il linfoma linfoblastico a cellule convolte. Tumori, 61, 377-391.

Rilke, F., Pilotti, S., and Clemente, C. (1978b). Cytology of non-Hodgkin's malignant lymphomas involving the stomach. Acta Cytologica, 22, 71-79.

Ritter, J., Gaedicke, G., Winkler, K., Beckmann, H., and Landbeck, G. (1975). Possible T-cell origin of lymphoblasts in acid phosphatase-positive acute lymphatic leukaemia (Letter). Lancet, 2, 75.

Robb-Smith, A. H. T. (1938). Reticulosis and reticulosarcoma. A histological classification. Journal of Pathology and Bacteriology, 47, 457-480.

Robinowitz, B. N., Noguchi, S., and Roenigk, H. H., Jr. (1976). Tumor cell characterization in mycosis fungoides. Cancer, 37, 1747-1753.

Roitt, I. M., Greaves, M. F., Torrigiani, G., Brostoff, J., and Playfair, J. H. L. (1969). The cellular basis of immunological responses. Lancet, 2, 367-371.

Rosai, J., and Dorfman, R. F. (1969). Sinus histiocytosis with massive lymphadenopathy. A newly recognized benign clinicopathological entity. Archives of Pathology, 87, 63-70.

Rosas-Uribe, A., Variakojis, D., Molnar, Z., and Rappaport, H. (1974). Mycosis fungoides: an ultrastructural study. Cancer, 34, 634-645.

Rosas-Uribe. A., Variakojis, D., and Rappaport, H. (1973). Proteinaceous precipitate in nodular (follicular) lymphomas. Cancer, 31, 534-542.

Rosenthal, N., Dreskin, O. H., Vural, I. L., and Zak, F. G. (1952). The significance of hematogones in blood, bone marrow and lymph node aspiration in giant follicular lymphoblastoma. Acta Haematologica, 8, 368-377.

Ross, G. D., Rabellino, E. M., Polley, M. J., and Grey, H. M. (1973). Combined studies of complement receptor and surface immunoglobulin-bearing cells and sheep erythrocyte rosette-forming cells in normal and leukemic human lymphocytes. Journal of Clinical Investigation, 52, 377-385.

Rössle, R. (1939). Das Retothelsarkom der Lymphdrüsen : seine Formen und Verwandtschaften. Beiträge zur Pathologischen Anatomie, 103, 385-415.

Roulet, F. (1930). Das primäre Retothelsarkom der Lymphknoten. Virchows Archiv für pathologische Anatomie, 277, 15-47.

Rudders, R. A. (1976). B lymphocyte subpopulations in chronic lymphocytic leukemia. Blood, 47, 229-235.

Russell, W. (1890). An address on a characteristic organism of cancer. British Medical Journal, 2, 13561360.

Salmon, S. E., and Seligmann, M. (1974). B-cell neoplasia in man. Lancet, 2, 1230-1233.

Salsano, F., Pisarri-Salsano, S., Ciancarelli, M. P., Piantelli, M., Lauriola, L., and Musiani, P. (1978). Structural and functional characteristics of hairy cells. Acta Haematologica (In press).

Satodate, R., Schwarze, E. W., and Lennert, K. (1977). Gewebsmastzellenzahl bei Immunocytom und chronischer lymphatischer Leukämie. Virchows Archiv, A: Pathological Anatomy and Histology, 373, 303-309.

Schein, P. S., MacDonald, J. S., and Edelson, R. (1976). Cutaneous T-cell lymphoma. Cancer, 38, 1859-1861.

Schnitzer, B., Loesel, L. S., and Reed, R. E. (1970). Lymphosarcoma cell leukemia. A clinicopathologic study. Cancer, 26, 1082-1096.

Schrek, R., and Donnelly, W. J. (1961). Differences between lymphocytes of leukemic and non-leukemic patients with respect to morphologic features, motility, and sensitivity to guinea pig serum. Blood, 18, 561-571.

Schwartz, D. L., Pierre, R. V., Scheerer, P. P., Reed, E. C., Jr., and Linman, J. W. (1965). Lymphosarcoma cell leukemia. American Journal of Medicine, 38, 778786.

Schwarze, E. W. (1975). T-cell origin of acid-phosphatasepositive lymphoblasts (Letter). Lancet, 2, 1264.

Schwarze, E. W., Radaszkiewicz, T., Pülhorn, G., Goos, M., and Lennert, K. (1976). Maligne und benigne Lymphome des Auges, der Lid- und Orbitalregion. Virchows Archiv, A: Pathological Anatomy and Histo- 
$\log y, 370,85-96$.

Scott, R. B., and Robb-Smith, A. H. T. (1939). Histiocytic medullary reticulosis. Lancet, 2, 194-198.

Seligmann, M. (1972). Heavy chain diseases. Revue Européenne d'Études Cliniques et Biologiques, 17, 349355.

Seligmann, M. (1975). Immunochemical, clinical, and pathological features of a-chain disease. Archives of Internal Medicine, 135, 78-82.

Seligmann, M., Brouet, J. C., and Preud'homme, J. L. (1977a). Immunologic classification of non-Hodgkin's lymphomas: current status. Cancer Treatment Reports, 61, 1179-1183.

Seligmann, M., Brouet, J. C., and Preud'homme, J. L. (1977b). L'hétérogénéité des leucémies lymphoïdes humaines révélée par l'étude immunologique des marqueurs de membrane. Nouvelle Revue Française d'Hématologie, Blood Cells, 18, 339-350.

Seligmann, M., Danon, F., Hurez, D., Milhaesco, E., and Preud'homme, J. L. (1968). Alpha chain disease: a new immunoglobulin abnormality. Science, 162, 1396-1397.

Sen, L., and Borella, L. (1975). Clinical importance of lymphoblasts with $\mathrm{T}$ markers in childhood acute leukemia. New England Journal of Medicine, 292, 828832.

Seshadri, R. S., Brown, E. J., and Zipursky, A. (1976). Leukemic reticuloendotheliosis. A failure of monocyte production. New England Journal of Medicine, 295, 181-184.

Sézary, A., and Bouvrain, Y. (1938). Erythrodermie avec présence de cellules monstreuses dans le derme et dans sang circulant. Bulletin de la Société Française de Dermatologie et de Syphiligraphie, 45, 254-260.

Sheehan, W. W. (1971). The relationship between lymphocytic leukemias and lymphomas. Recent Results in Cancer Research, 36, 24-31.

Shevach, E. M., Herberman, R., Frank, M. M., and Green, I. (1972). Receptors of complement and immunoglobulin on human leukemic cells and human lymphoblastoid cell lines. Journal of Clinical Investigation, 51, 1933-1938.

Shevach, E. M., Jaffe, E. S., and Green, I. (1973). Receptors for complement and immunoglobulin on human and animal lymphoid cells. Transplantation Reviews, 16, 3-28.

Shullenberger, C. C. (1970). Natural history patterns in leukemia and lymphoma as related to clinico-pathologic classification. In Leukemia-Lymphoma, (14th Clinical Conference on Cancer, M. D. Anderson Hospital), pp. 143-148. Year Book Medical Publishers, Chicago.

Siegal, F. P., Voss, R., Al-Mondhiry, H., Polliack, A., Hansen, J. A., Siegal, M., and Good, R. A. (1976). Association of a chromosomal abnormality with lymphocytes having both $T$ and $B$ markers in a patient with lymphoproliferative disease. American Journal of Medicine, 60, 157-166.

Silvestrini, R., Piazza, R., Riccardi, A., and Rilke, F. (1977). Correlation of cell kinetic findings with morphology of non-Hodgkin's malignant lymphomas. Journal of the National Cancer Institute, 58, 499-504.

Smith, J. L., Clein, G. P., Barker, C. R., and Collins, R. D. (1973). Characterisation of malignant mediastinal lymphoid neoplasm (Sternberg sarcoma) as thymic in origin. Lancet, 1, 74-77.

Sordat, B., Sordat, M., Hess, M. W., Stoner, R. D., and Cottier, H. (1970). Specific antibody within lymphoid germinal center cells of mice after primary immunization with horseradish peroxidase: a light and electron microscopic study. Journal of Experimental Medicine, 131, 77-91.

Spiro, S., Galton, D. A. G., Wiltshaw, E., and Lohmann, R. C. (1975). Follicular lymphoma: a survey of 75 cases with special reference to the syndrome resembling chronic lymphocytic leukaemia. British Journal of Cancer, 31, Supplement 2, 60-72.

Stathopoulos, G., Papamichail, M., Sheldon, P., Catovsky, D., Davies, A. J. S., Holborow, E. J., and Wiltshaw, E. (1974). Immunological studies in a case of T-cell leukaemia. Journal of Clinical Pathology, 27, 851-859.

Stein, H. (1975). Immunologische und immunochemische Techniken und ihre Bedeutung für die Klassifikation lymphatischer Neoplasien. Verhandlungen der Deutschen Gesellschaft für Pathologie, 59, 510-522.

Stein, H., and Kaiserling, E. (1974). Surface immunoglobulins and lymphocyte-specific surface antigens on leukaemic reticuloendotheliosis cells. Clinical and Experimental Immunology, 18, 63-71.

Stein, H., Kaiserling, E., and Lennert, K. (1974a). Evidence for B cell origin of reticulum cell sarcoma. Virchows Archiv, A: Pathological Anatomy and Histo$\log y, 364,51-68$.

Stein, H., Kaiserling, E., and Lennert, K. (1974b). Lympho-plasmacytoid immunocytoma-a new entity of human non-Hodgkin's lymphoma. Paper presented at the 10th International Congress of the International Academy of Pathology, Hamburg, Abstract book, p. 50 , no. 105.

Stein, H., Kaiserling, E., Lennert, K., and Parwaresch, M. R. (1973). Makroglobulinbildende chronische lymphatische Leukämie ohne Makroglobulinämie. Klinische Wochenschrift, 51, 389-396.

Stein, H., Lennert, K., and Parwaresch, M. R. (1972). Malignant lymphomas of B-cell type. Lancet, 2, 855857.

Stein, H., Petersen, N., Gaedicke, G., Lennert, K., and Landbeck, G. (1976). Lymphoblastic lymphoma of convoluted or acid phosphatase type-a tumor of T precursor cells. International Journal of Cancer, 17, 292295.

Sternberg, C. (1915). Leukosarkomatose und Myeloblastenleukämie. Beiträge zur pathologischen Anatomie, 61, 75-100.

Stuart, A. E. (1975). Prospectives on the reticulum cell and fibre networks. In Mononuclear Phagocytes in Immunity, Infection, and Pathology, edited by R. van Furth, pp. 111-118. Blackwell, Oxford, London, Edinburgh, Melbourne.

Symmers, D. (1927). Follicular lymphadenopathy with splenomegaly: a newly recognized disease of the lymphatic system. Archives of Pathology and Laboratory Medicine, 3, 816-820.

Taylor, C. R., and Burns, J. (1974). The demonstration of plasma cells and other immunoglobulin-containing 
cells in formalin-fixed paraffin-embedded tissues using peroxidase-labelled antibody. Journal of Clinical Pathology, 27, 14-20.

Thomas, L. B., and Rappaport, H. (1975). Mycosis fungoides and its relationship to other malignant lymphomas. In The Reticuloendothelial System, edited by J. W. Rebuck, C. W. Berard, and M. R. Abell, pp. 243-261. Williams and Wilkins, Baltimore.

Uchiyama, T., Yodoi, J., Sagawa, K., Takatsuki, K., and Uchino, H. (1977). Adult T-cell leukemia: clinical and hematological features of 16 cases. Blood, 50, 481-492.

Utsinger, P. D., Young, W. J., Fuller, C. R., Logue, M. J., and Orringer, E. P. (1977). Hairy cell leukemia: B-lymphocyte and phagocytic properties. Blood, 49, 19-27.

Variakojis, D., Rosas-Uribe, A., and Rappaport, H. (1974). Mycosis fungoides: pathologic findings in staging laparotomies. Cancer, 33, 1589-1600.

Veldman, J. E. (1970). Histophysiology and Electron Microscopy of the Immune Response, pp. 42-79. N. V. Boekdrukkerij Dijkstra Niemeyer, Groningen.

Virchow, R. L. C. (1864-65). Die krankhaften Geschwülste: Dreissig Vorlesungen, vol. 2. Hirschwald, Berlin.

Waldenström, J. G. (1944). Incipient myelomatosis or 'essential' hyperglobulinemia with fibrinogenopenia-a new syndrome? Acta Medica Scandinavica, 117, 216247.

Waldron, J. A., Leech, J. H., Glick, A. D., Flexner, J. M., and Collins, R. D. (1977). Malignant lymphoma of peripheral T-lymphocyte origin. Immunologic, pathologic, and clinical features in six patients. Cancer, 40, 1604-1617.

Warner, N. L., Potter, M., and Metcalf, D. (editors) (1974). Multiple Myeloma and Related Immunoglobulin-producing Neoplasms (UICC Technical Report Series, volume 13). International Union Against Cancer, Geneva.

Warnke, R. A., Kim, H., and Dorfman, R. F. (1975). Malignant histiocytosis (histiocytic medullary reticulosis). I. Clinicopathologic study of 29 cases. Cancer, 35, 215-230.

Warnke, R. A., Kim, H., Fuks, Z., and Dorfman, R. F. (1977). The coexistence of nodular and diffuse patterns in nodular non-Hodgkin's lymphomas. Significance and clinicopathologic correlation. Cancer, 40, 12291233.
Wilson, J. D., and Hurdle, A. D. F. (1973). Surface immunoglobulins on lymphocytes in chronic lymphocytic leukaemia and lymphosarcoma. British Journal of Haematology, 24, 563-569.

Wilson, J. D., and Nossal, G. J. V. (1971). Identification of human $\mathrm{T}$ and $\mathrm{B}$ lymphocytes in normal peripheral blood and in chronic lymphocytic leukaemia. Lancet, 2 , 788-791.

Wiltshaw, E. (1976). The natural history of extramedullary plasmacytoma and its relation to solitary myeloma of bone and myelomatosis. Medicine, 55, 217 238.

Wintrobe, M. M., Lee, G. R., Boggs, D. R., Bithell, T. C., Athens, J. W., and Forester, J. (1974). Clinical Hematology, 7th edition, pp. 1520-1534, 1568-1598. Lea and Febiger, Philadelphia.

Wright, D. H. (1968). Bone marrow involvement in Burkitt's tumor. British Journal of Haematology, 15, 409-416.

Yam, L. T., Li, C. Y., and Finkel, H. E. (1972). Leukemic reticuloendotheliosis. The role of tartrate-resistant acid phosphatase in diagnosis and splenectomy in treatment. Archives of Internal Medicine, 130, 248-256.

Zarrabi, M. H., Grünwald, H. W., and Rosner, F. (1977). Chronic lymphocytic leukemia terminating in acute leukemia. Archives of Internal Medicine, 137, 10591064.

Ziegler, J. L., Andersson, M., Klein, G., and Henle, W. (1976). Detection of Epstein-Barr virus DNA in American Burkitt's lymphoma. International Journal of Cancer, 17, 701-706.

Zittoun, R., Cadiou, M., Dao, C., Blanc, J. M., andệ Bousser, J. (1973). Lymphocytic beta-glucuronidase in. the lymphoproliferative syndromes. Biomedicine, 18, 415-420.

Zucker-Franklin, D., Melton, J. W., III, and Quagliata, F. (1974). Ultrastructural, immunologic, and functional studies on Sézary cells: a neoplastic variant of thymusderived (T) lymphocytes. Proceedings of the National Academy of Sciences of the United States of America, 71, $1877-1881$.

Zur Hausen, H. (1975). Oncogenic herpes viruses. Biochimica et Biophysica Acta, 417, 25-53.

Requests for reprints to: Dr F. Rilke, Instituto Nazionale per lo Studio e la Cuva dei Tumori, Via Venezia 1, 20133 Milan, Italy. 